\begin{abstract}
BERKMAN, ELIF. Growth of GaN from Elemental Gallium and Ammonia via a Modified Sandwich Growth Technique (under the supervision of Dr. Zlatko Sitar)
\end{abstract}

Gallium nitride $(\mathrm{GaN})$ thin films were grown on (0001) sapphire substrates at $1050^{\circ} \mathrm{C}$ by controlled evaporation of gallium $(\mathrm{Ga})$ metal and reaction with ammonia $\mathrm{NH}_{3}$. The feasibility of the growth process was demonstrated and discussed. One of the biggest challenges of working in the $\mathrm{Ga}-\mathrm{NH}_{3}$ system was the instability of molten Ga under $\mathrm{NH}_{3}$ atmosphere at elevated temperatures, especially between $1100-1200^{\circ} \mathrm{C}$.

In the first part of the study, transport of Ga species from the source-to-substrate during the GaN growth process and the influence of ammonia-liquid Ga reaction on $\mathrm{Ga}$ transport were investigated. Experimental results under different conditions were studied and compared to theoretical predictions to quantify the mechanism of transport in the vapor growth technique. In presence of $\mathrm{NH}_{3}$, Ga transport far exceeded the predicted upper limit for the vapor phase transport. Visual observations confirmed that a significant amount of Ga left the source in a cluster rather than atomic form.

A novel Ga source design was employed in an effort to obtain a stable and high vapor phase transport of Ga species at moderate temperatures. In this design, pure $\mathrm{N}_{2}$ was flowed directly above the molten Ga source. This flow prevented the direct contact and reaction between the molten $\mathrm{Ga}$ and $\mathrm{NH}_{3}$ and prevented Ga spattering and GaN crust formation on the source surface. At the same time, it significantly enhanced Ga evaporation rate and enabled control of Ga transport and V/III ratio in the system. 
Growth characteristics were described by a mass transport model based on process parameters and experimentally verified. The results showed that the process was mass transport limited and the maximum growth rate was controlled by transport of both $\mathrm{Ga}$ and reactive ammonia species to the substrate surface. A growth rate of $1.4 \mu \mathrm{m} / \mathrm{h}$ was obtained at $1050^{\circ} \mathrm{C}, 800$ Torr, $3 \mathrm{slm}$ of ammonia flow rate, and $1250^{\circ} \mathrm{C}$ Ga source temperature at a $24 \mathrm{~mm}$ source-to-substrate distance. It was found that the process required a more effective supply of active $\mathrm{NH}_{3}$ to the substrate in order to increase the crystal quality and growth rate.

The surface morphology of the deposited layers was examined by optical and scanning electron microscopies. XRD analysis was used to determine the crystallinity of deposited films and revealed a full-width at half-maximum (FWHM) of $0.6 \mathrm{deg}$. for the (0002) GaN peak. EDX analysis was employed for the chemical characterization of the samples and showed that the deposited material contained only $\mathrm{Ga}$ an $\mathrm{N}$ elements. Room temperature PL spectrum demonstrated the optical quality of the grown samples. 


\title{
GROWTH OF GaN FROM ELEMENTAL GALLIUM AND AMMONIA VIA A MODIFIED SANDWICH GROWTH TECHNIQUE
}

by

\section{ELIF BERKMAN}

A dissertation submitted to the Graduate Faculty of North Carolina State University in partial fulfillment of the requirements for the Degree of Doctor of Philosophy

\section{MATERIALS SCIENCE AND ENGINEERING}

\author{
Raleigh
}

2005

\section{APPROVED BY:}

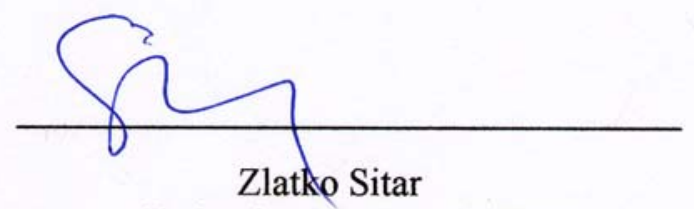

Chair of Advisory Committee
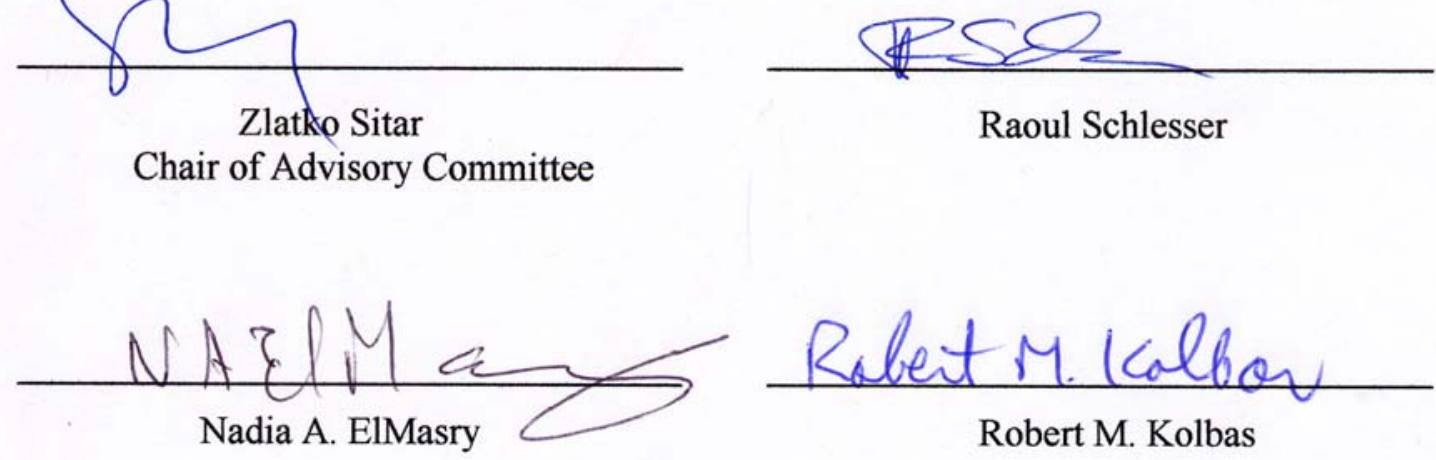
I dedicate this thesis to my family and friends, the coolest girl ever, darling Shiri and my eternal love Acar 


\section{BIOGRAPHY}

Elif Berkman was born on August $7^{\text {th }} 1977$ to Mübeccel and Rıfat Baybörü in Konya, Turkey. After graduating from high school, she studied Metallurgical and Materials Engineering in Middle East Technical University (METU) and received her BS degree in July 1999. She received a MS degree in the same program from the same institution in August 2001. She continued her graduate studies in Materials Science and Engineering Department of North Carolina State University receiving her PhD degree in January 2005. 


\section{ACKNOWLEDGEMENTS}

I would like to express my gratitude to Dr. Zlatko Sitar for his continued support and supervision during my research and education. I would also like to thank Dr. Raoul Schlesser for his patient guidance and assistance during the completion of my thesis. I want to express my appreciation to both of them for their invaluable contribution to this research. Aleks, Ramon and the rest of the lab crew; thank you for a fun yet productive working environment. I am grateful to my committee members; Dr. Nadia El-Masry and Dr. Robert Kolbas. Without the help of Dr. Ramon Collazo this work would not be accomplished, thanks. I am also grateful to Gail Abell and Edna Deas for being so helpful and kind. And Tom, thanks to you for always being a good friend and fixing Acar`s highly modified import street warrior while hiding the tears of jealousy in your eyes for owning much slower and older domestic cars! (guess who wrote this part?). If I get rich, I'll buy you a C6.

Thanks to my family for always supporting me; mom, thanks for caring me all the time and dad, thanks for the scientific talks. P1nar, thanks for being a wonderful sister, listening to me and being a model for me. Acar, thank you for loving me, completing me and always being there for me. Thanks for making me laugh and making me feel great; and thanks for your patience. Can and Zeynep, my best friends ever, thank you. Shiri, gorgeous, I had the most fun whenever you were with us. You were always on the left lane in this journey and managed to compress everything - science, art, sports, love and fun - in 23 years and you did the best in all. Thank you for the great times we had together. 


\section{TABLE OF CONTENTS}

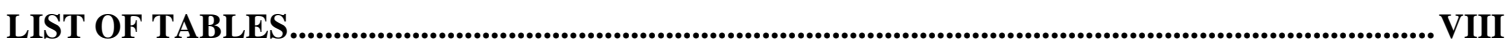

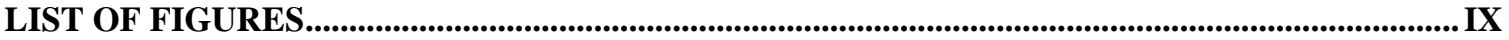

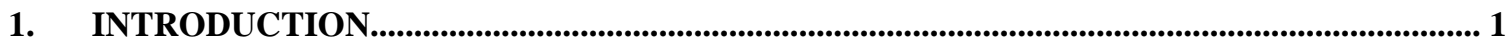

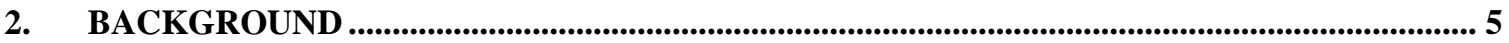

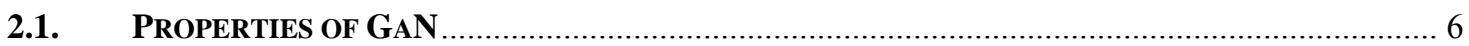

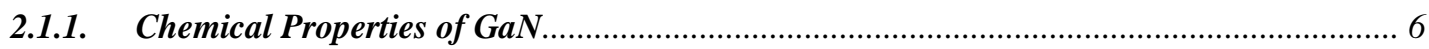

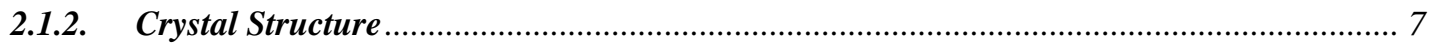

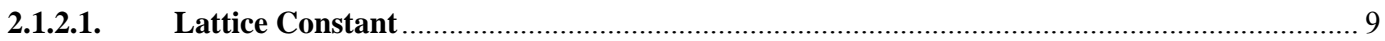

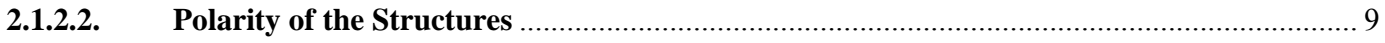

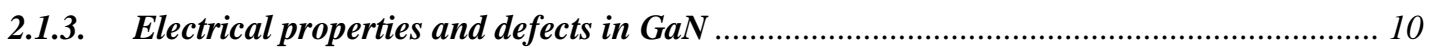

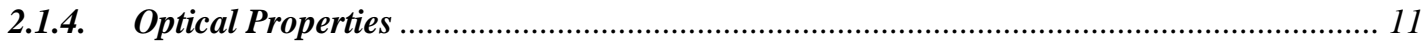

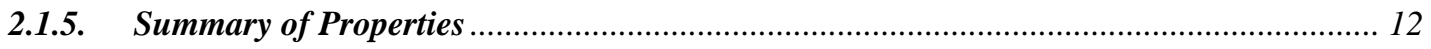

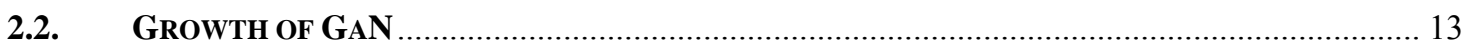

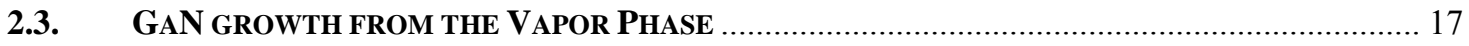

2.3.1. Sublimed GaN vs. Evaporated Ga as Ga Source …….................................................. 17

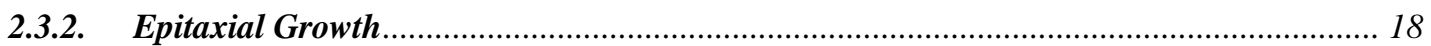

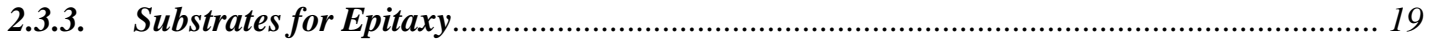

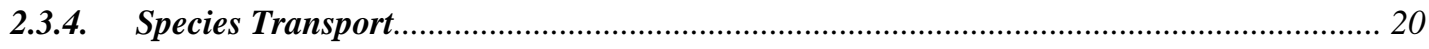

2.3.5. Thermodynamics and Kinetics of GaN Growth ................................................................ 22

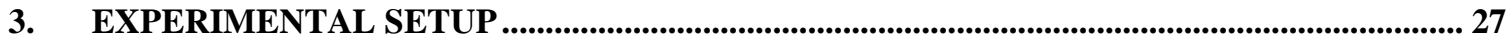

4. GROWTH OF GaN CRYSTALS VIA PHYSICAL EVAPORATION: ON THE TRANSPORT

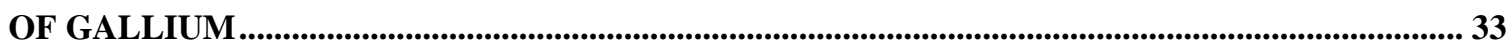

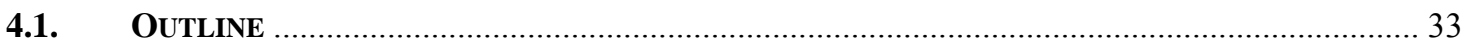

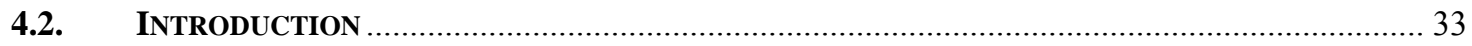

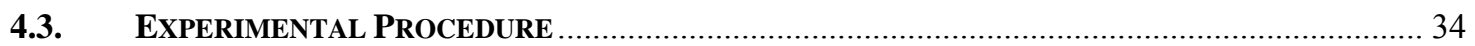




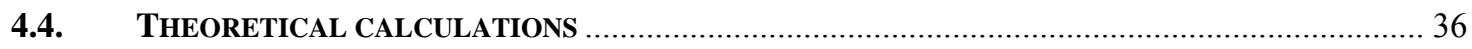

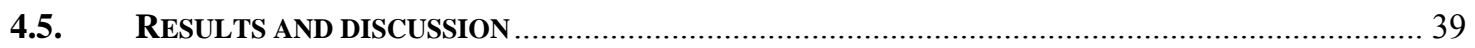

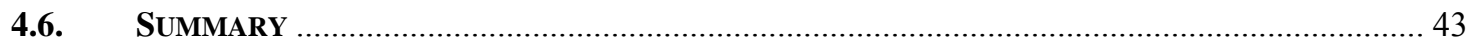

5. GROWTH OF GaN FROM ELEMENTAL GALLIUM AND AMMONIA VIA A MODIFIED

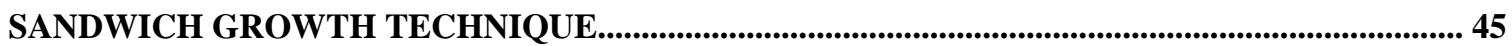

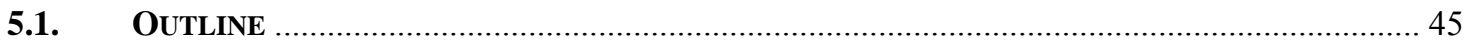

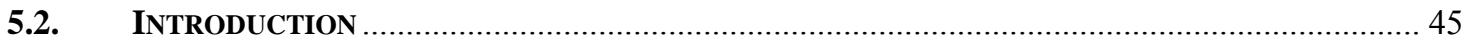

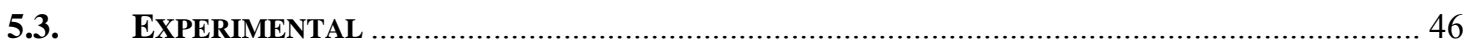

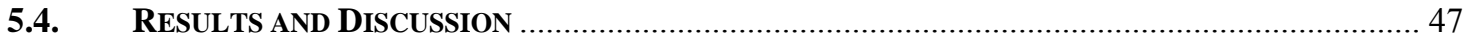

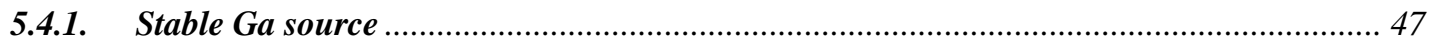

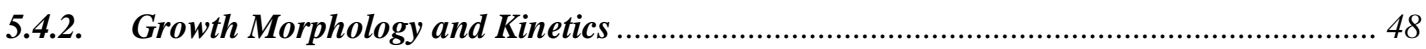

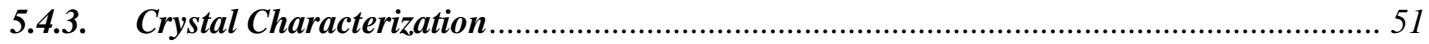

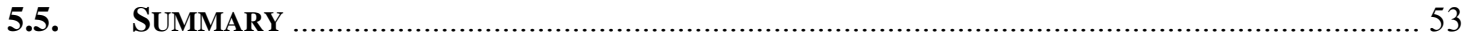

6. MASS TRANSFER IN GaN GROWTH FROM ELEMENTAL GALLIUM AND AMMONIA VIA A MODIFIED SANDWICH GROWTH TECHNIQUE................................................................... 55

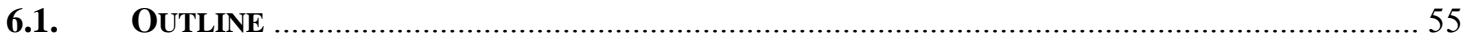

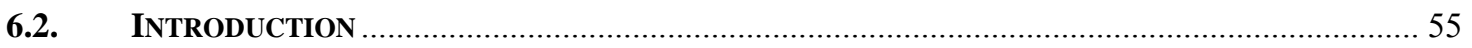

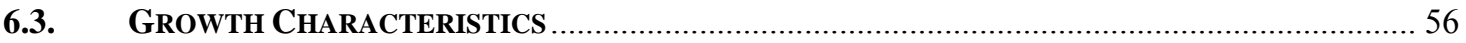

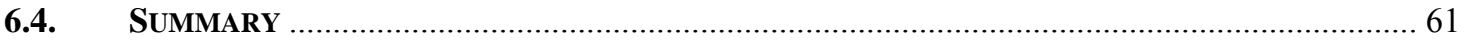

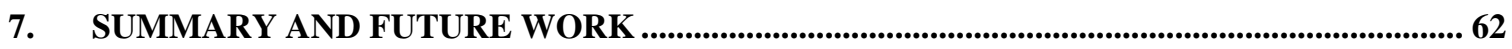

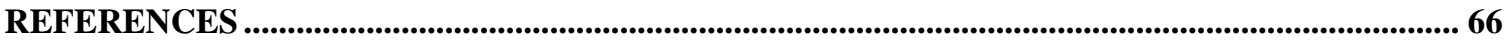

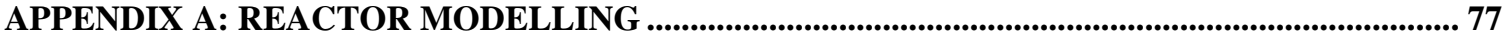

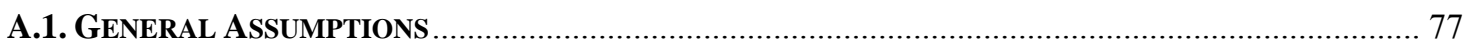

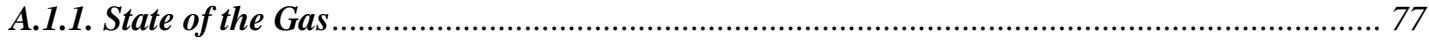

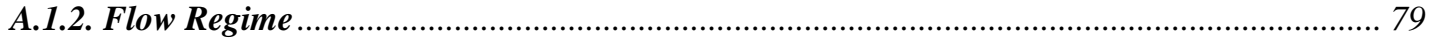

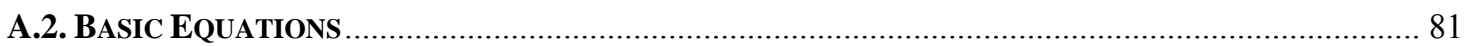




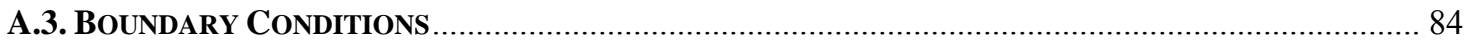

A.4. DISCRETIZATION AND SOLUTION OF THE GOVERNING EQUATIONS .............................................. 85

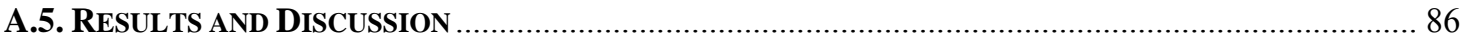

APPENDIX B: REACTION ENERGIES (After Ohring [75]) ........................................................ 91

APPENDIX C: AMMONIA DECOMPOSITION (After Grunze [79])................................................ 95

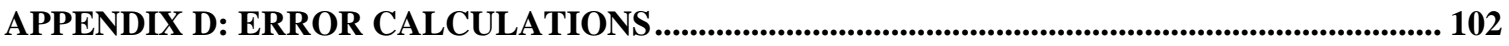

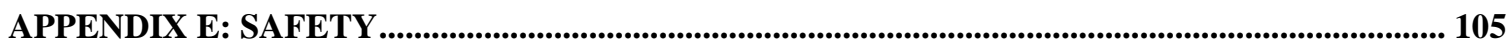

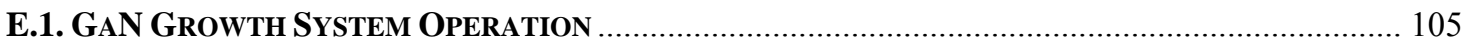

E.1.1. Inserting the substrate into the growth chamber................................................................. 105

E.1.2. Pumping-down the Chamber after loading the source and substrate ............................... 105

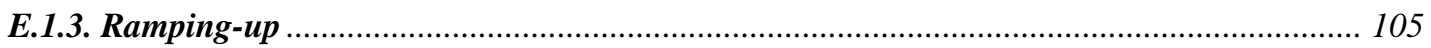

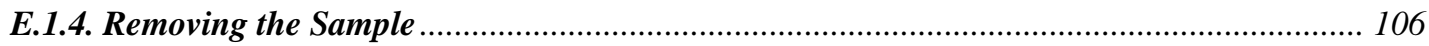

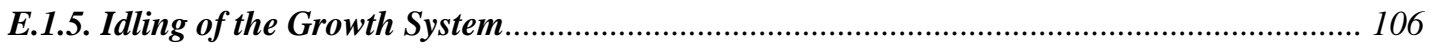

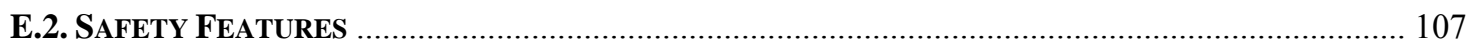




\section{LIST OF TABLES}

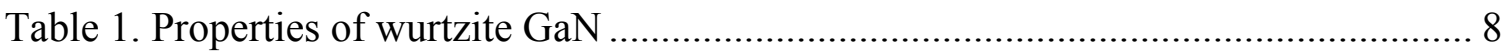

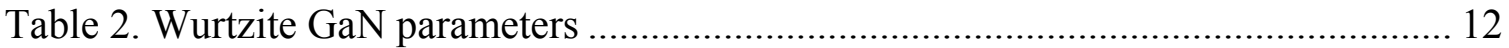

Table 3. Measured Ga mass transport rate under different conditions ........................... 40

Table 4. Summary of experimental conditions for GaN growth ................................. 46

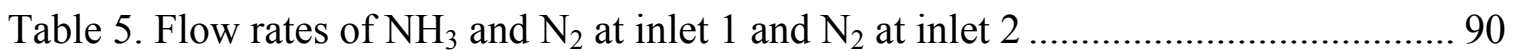

Table 6. Activation energy of ammonia decomposition reaction ................................. 98 


\section{LIST OF FIGURES}

Figure 1. The wurtzite crystal structure: atoms of one specie are black, those of the other specie are white; and the unit cell is marked.

Figure 2 Schematic illustration of GaN formation on a solid surface starting with Ga and

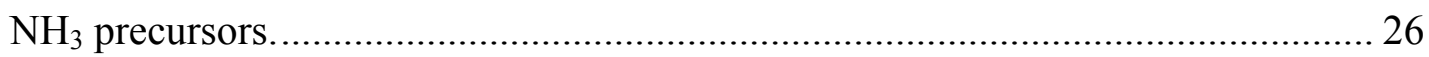

Figure 3. Schematic diagram of the GaN growth system ........................................ 27

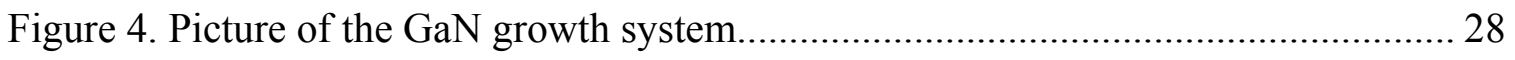

Figure 5. Schematic diagram of the GaN growth chamber. ....................................... 30

Figure 6. Schematic diagram of the growth cell with $\mathrm{N}_{2}$ flow over the molten Ga source.

Figure 7. Schematic diagram of the growth cell. (a) BN cylindrical source holder. (b)

Growth cell with the hot tungsten filament..................................................... 35

Figure 8. Illustration of mass transport by diffusion.............................................. 37

Figure 9. Schematic of diffusivity measurement set up......................................... 38

Figure 10. Ga mass loss rate as a function of total flow rate ..................................... 42

Figure 11. Ga mass loss rate as a function of $\mathrm{NH}_{3}$ flow rate at constant total flow ........ 43

Figure 12. Plot of Ga mass loss rate vs. 1/total pressure, $1 / P_{T} \ldots \ldots \ldots \ldots \ldots \ldots \ldots \ldots \ldots \ldots \ldots . . . . . . . \ldots \ldots$

Figure 13. Surface morphologies of GaN deposited directly on sapphire under different

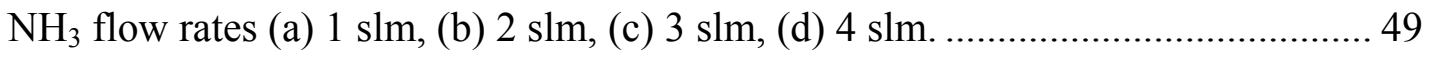

Figure 14. GaN deposition rate versus $\mathrm{NH}_{3}$ flow rate ........................................... 50

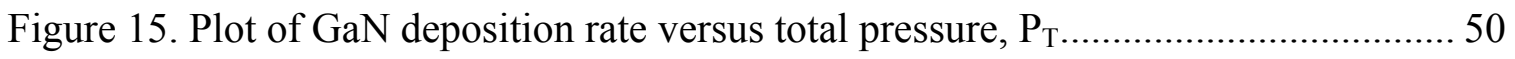

Figure 16 . XRD analysis of a (0002) GaN epilayer deposited at $1050^{\circ} \mathrm{C}$ on $c$-plane

sapphire 
Figure 17. $\chi$-scan X-ray diffraction of (0002) $\mathrm{GaN}$ epilayer deposited at $1050^{\circ} \mathrm{C}$ on c-

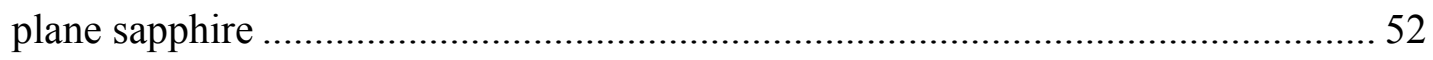

Figure 18. EDX of $\mathrm{GaN}$ epilayer deposited at $1050^{\circ} \mathrm{C}$ on c-plane sapphire................... 52

Figure 19. Photoluminescence spectrum of GaN epilayer deposited at $1050^{\circ} \mathrm{C}$ on c-plane

sapphire 53

Figure 20. Schematic illustration of the modified sandwich configuration

Figure 21. (a) Plot of Ga mass loss rate versus total pressure, $P_{T}$ (b) GaN deposition rate versus total pressure, $P_{T}$

Figure 22. Plot of evaporation normalized growth rate versus total pressure, $P_{T}$

Figure 23. Drawing of the alumina reactor tube 78

Figure 24. (a) Calculation geometry and (b) the grid system of the GaN growth reactor tube

Figure 25. Temperature distribution in the reactor tube 88

Figure 26. (a) Velocity distribution and (b) Streamline distribution in the reactor tube .. 89 Figure 27. Change in Gibbs free energy and equilibrium pressure for the following reactions (1) $\mathrm{Ga}(\mathrm{l})+1 / 2 \mathrm{~N}_{2}(\mathrm{~g})=\mathrm{GaN}(\mathrm{s}),(2) \mathrm{Ga}(\mathrm{g})+1 / 2 \mathrm{~N}_{2}(\mathrm{~g})=\mathrm{GaN}(\mathrm{s})$. 94

Figure 28. Gibbs free energy and enthalpy change versus temperature for ammonia decomposition reaction 96

Figure 29. Energy changes in ammonia decomposition reaction

Figure 30. Ratio of ammonia concentration to the initial concentration versus distance.

Figure 31. Plot of $\Delta P_{G a}(T)$ versus $T$. 


\section{INTRODUCTION}

$\mathrm{GaN}$ and related materials have already demonstrated high-power and low- noise microwave performance. But the most exciting potential is probably in optoelectronic applications. In fact, GaN and its alloys with $\mathrm{AlN}$ and $\mathrm{InN}$ recently became the basic materials for short-wavelength optoelectronics [1]. This was mainly due to their direct energy gaps covering the whole visible spectrum and a large part of the UV range. A blue laser pioneered by Nakamura and efficient blue-, green-, amber-, and white-light-emitting diodes that emerged from initiative work of Pankove hold promise of future solid-state replacements for inefficient and unreliable incandescent bulbs dating to Thomas A. Edison time in terms of their basic design. These materials, besides being a prime object of interest of device engineers, are also an exciting subject of research for a physicist due to their outstanding position in the III-V family of semiconductors. GaN (also $\mathrm{InN}$ and AlN), unlike other III-V materials are hard, partially ionic semiconductor compounds of highly chemical and thermal stability.

Growth of the GaN crystals is a challenge due to its low decomposition temperature relative to its high melting temperature, the low solubility of nitrogen in Ga and the high equilibrium vapor pressure of nitrogen on $\mathrm{GaN}$ at moderate temperatures. But, the major drawback in the development of GaN-based technology is the lack of high quality, large native substrates in large quantities, and most of the epitaxial research and device development rely upon heteroepitaxial growth. Therefore, the growth of bulk $\mathrm{GaN}$ is of great interest. Among the widely studied techniques for GaN bulk or thick film growth techniques, many advantages of growth via vapor phase transport have been reported 
including the use of the simplest source species, and high yield of the growth components. In vapor phase transport technique, evaporated Ga metal or sublimed GaN powder is transported in $\mathrm{NH}_{3}$ atmosphere to the reaction zone in which deposition occurs. High growth rates of up to $0.5 \mathrm{~mm} / \mathrm{h}$ were obtained with this method; however, it was only for short periods until the growth is ceased. In the best case, needle or platelet crystals were obtained but their lateral size was far from desirable. Earlier observations in the growth of $\mathrm{GaN}$ from the vapor phase and the problems encountered with were briefly reviewed in Section 2.3.

The major challenges in the growth of $\mathrm{GaN}$ from elemental $\mathrm{Ga}$ and $\mathrm{NH}_{3}$ have been: 1) limited growth time mainly due to the poor stability of Ga source in $\mathrm{NH}_{3}$ atmosphere, 2) formation of Ga droplets resulting in high but uncontrolled GaN growth rate only for short times of 1-2 hours, 3) formation of thin GaN crust over the Ga source that reduces the outgoing Ga flux from source that changes V/III ratio and eventually causes the interruption of the growth.

The goal of this study is to solve the challenges associated with the growth of bulk/thick single-crystalline GaN and to develop a cost-effective, stable and reproducible process for growing such materials from elemental $\mathrm{Ga}$ and $\mathrm{NH}_{3}$.

In Chapter Two, a literature review covering III-N devices, the motivation for the growth of $\mathrm{GaN}$, the properties and growth of $\mathrm{GaN}$ and the process of growth from the vapor phase are presented. The growth system where the crystal growth experiments were conducted is described in Chapter Three.

Studies on the transport of gallium (Ga) species in a vapor growth system under different conditions are presented in Chapter Four. Comparison between the experiential 
data and the theoretical calculations indicated that Ga species transport involves some additional mechanisms to the vapor transport which was revealed to be caused by ammonia hitting the molten Ga surface. The modification applied to the Ga source in an effort to form reproducible and stable growth conditions and effects of this modification on the Ga transport and the stability of the Ga source are also discussed in this chapter.

Chapter Five presents the growth of GaN on sapphire with a modified sandwich growth method which is a variation of vapor phase transport process. Optimum growth conditions and the quality of the grown crystals are discussed. Necessary process improvements are pointed out which would increase the crystal quality and the growth rate.

A one-dimensional model is developed to describe and understand the observed experimental dependencies in the growth of $\mathrm{GaN}$ from elemental $\mathrm{Ga}$ and $\mathrm{NH}_{3}$ in the modified sandwich growth technique. Results regarding the growth conditions and the validity of the model are discussed in Chapter Six. It was observed that the maximum growth rate is controlled by the transport of both Ga species and reactive ammonia to the substrate surface. Gallium nitride films were grown on (0001) sapphire substrates at $1050^{\circ} \mathrm{C}$ by controlled evaporation of $\mathrm{Ga}$ and reaction with $\mathrm{NH}_{3}$. It was found that the process required an effective supply of $\mathrm{NH}_{3}$ to the substrate in order to increase both the quality and the growth rate of the crystals.

A summary of this study and a description of possible future work are presented in Chapter Seven. The main drawback of the system was found to be the supply of sufficient amount of active nitrogen species to the substrate. Calculations of the catalytic $\mathrm{NH}_{3}$ decomposition rate revealed that the extent of decomposition strongly dependent on the 
growth conditions and the equipment. It was concluded that the process needs further improvement that allows the supply of sufficiently cold, in other words, not decomposed $\mathrm{NH}_{3}$ to the substrate region in order to achieve the growth of high quality thick GaN layers at high growth rates.

Numerical simulations of the temperature distribution and velocity streamlines within the reaction tube based on total reactor pressure, gas flow rates and heater temperatures are presented in Appendix A. These results assisted in understanding the GaN growth characteristics in the system.

In Appendix B, energy of the overall reaction involved in the $\mathrm{GaN}$ growth from $\mathrm{Ga}$ and $\mathrm{NH}_{3}$ is calculated and compared to that of other vapor phase epitaxy processes. Studies on the catalytic decomposition of $\mathrm{NH}_{3}$ are presented in Appendix C. Error calculations are described in Appendix D. The hardware and software safety interlocks of the reactor, and the procedures for safe and stable operation are covered in Appendix E. 


\section{BACKGROUND}

$\mathrm{GaN}$ (also AlN and $\mathrm{InN}$ ) attracted tremendous interest for applications in blue/green diode lasers and LEDs, high temperature electronics, high-density optical data storage, and electronics for aerospace and automobiles. They cover an energy bandgap range of 0.7 to $6.2 \mathrm{eV}$ which covers a spectral range from infrared to ultraviolet. There is also great scientific interest in $\mathrm{GaN}$ and related materials because they appear to form the first semiconductor system in which extended defects do not severely affect the optical properties of devices [3].

Although GaN has been studied far more extensively than other group-III nitrides, the level of understanding necessary for technological improvements has not been achieved. Synthesis of p-type GaN has led to the demonstration of LEDs in the violet, blue, green and yellow bands of the visible spectrum with brightness suitable for outdoor displays, CW lasers, power Modulation Doped Field Effect Transistor (MODFETs), and UV detectors [4]; however, a large amount of work remains to be done in the determination of the fundamental physical properties of GaN. Information available in the literature regarding many of the physical properties of $\mathrm{GaN}$ is still in the process of evolution, and controversial. This is a result of measurements being made on samples of widely varying quality. 


\subsection{Properties of GaN}

\subsubsection{Chemical Properties of GaN}

The elements $\mathrm{B}, \mathrm{Al}, \mathrm{Ga}$, and In are forming compounds with $\mathrm{N}$ having the composition MN, where M represents a III-metal. The chemical bond of these compounds is predominantly covalent. Because of the large differences in electronegativity of the two constituents, there is a significant ionic contribution to the bond which determines the stability of these compounds. Hence, GaN is a highly stable compound even at elevated temperatures. It has a bond energy of $8.92 \mathrm{eV} /$ atom. In fact, this chemical stability combined with its hardness makes $\mathrm{GaN}$ an attractive material for protective coating. Currently, the majority of GaN researchers are interested in semiconductor device applications. While the thermal stability of GaN allows freedom of high temperature processing, the chemical stability of $\mathrm{GaN}$ results in a technological challenge. Conventional wet-etching techniques used in semiconductor processing have not been very successful for $\mathrm{GaN}$ device fabrication. It has been reported that $\mathrm{GaN}$ is insoluble in $\mathrm{H}_{2} \mathrm{O}$, acids, or bases at room temperature, but it dissolves in hot alkali solutions at a very slow rate [5]. Low-quality GaN has been etched at reasonably high rates in $\mathrm{NaOH}, \mathrm{H}_{2} \mathrm{SO}$, and $\mathrm{H}_{3} \mathrm{PO}_{4}$ by several researchers [7]. Although, these etches are useful for identifying defects and estimating their densities in GaN films, they are not very successful for fabrication of devices. Well established chemical etching processes are required for the device-technology development. Status of wet etching of group III nitrides was summarized by Pearton and Shul [8]. More promising possibilities are the 
various dry-etching processes under development and reviewed by Mohammad et al. [7].

In addition, photo-enhanced current (PEC) and reactive ion etching (RIE) have been investigated as potential tools for patterning of III-N heterostructures [9].

\subsubsection{Crystal Structure}

The group III nitrides GaN, AIN and InN can crystallize in the following three crystal structures: (1) wurtzite, (2) zinc-blende (3) rock-salt. At ambient conditions, the thermodynamically stable phase is the wurtzite structure. A phase transition to the rocksalt structure takes place at high pressure. In contrast, the zinc-blende is metastable and may be stabilized by heteroepitaxial growth on substrate reflecting structural compatibility.

The wurtzite structure has a hexagonal unit cell with $\mathrm{c} / \mathrm{a}=\sqrt{ }(8 / 3)=1.633$. As shown in Figure 1, this structure is composed of two hexagonal close packed (hcp) sublattices shifted with respect to each other along three-fold $c$ axis by the amount of $u=3 / 8$ in fractional coordinates. Both sublattices are occupied by one atomic species only, resulting in four atoms/unit cell. Locally, every atom of one kind is surrounded by four atoms of the other kind which are arranged at the edges of tetrahedron. The symmetry of the wurtzite structure is given by space group $\mathrm{P} 6_{3} \mathrm{mc}$, and the two inequivalent atom positions are $\left(\frac{1}{3}, \frac{2}{3}, 0\right)$ and $\left(\frac{1}{3}, \frac{2}{3}, u\right)$. For the III-nitrides, the axial ratios deviate considerably from the ideal value for hexagonal close packing of spheres, and hence, each lattice is distorted from the ideal geometry to some extent. 

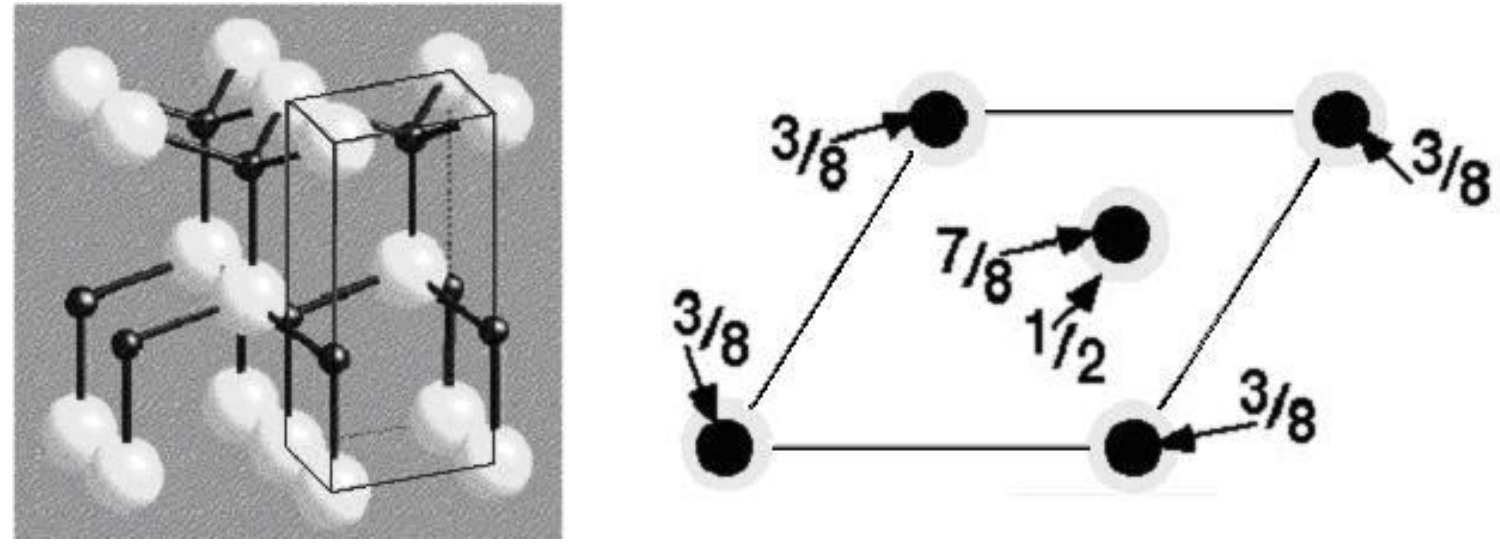

Figure 1. The wurtzite crystal structure: atoms of one specie are black, those of the other specie are white; and the unit cell is marked.

Table 1. Properties of wurtzite GaN

\begin{tabular}{ll}
\hline Property & Wurtzite GaN \\
\hline Bandgap (eV) & 3.4 \\
$\begin{array}{l}\text { Coefficient of Thermal Expansion } \\
\left(\mathrm{x} 10^{-6} \mathrm{~K}^{-1}\right)[12]\end{array}$ & $\alpha_{/ /}-5.59(300-900 \mathrm{~K})$ \\
& $\alpha_{\perp}-3.17(300-700 \mathrm{~K})$ \\
& $7.8(700-900 \mathrm{~K})$ \\
Young's Modulus $(\mathrm{GPa})[4]$ & $\mathrm{C}_{11}=396$ \\
& $\mathrm{C}_{12}=144$ \\
& $\mathrm{C}_{13}=100$ \\
& $\mathrm{C}_{33}=392$ \\
Bulk modulus $(\mathrm{GPa})[13]$ & 176 \\
Thermal conductivity $\left(\mathrm{Wcm}^{-1} \mathrm{~K}^{-1}\right)$ & 1.3 \\
Melting point $(\mathrm{K})[14]$ & 2791 \\
\hline
\end{tabular}




\subsubsection{Lattice Constant}

In general, single crystals are required for accurate measurements of the lattice constant and related properties. Because of the lack of GaN single crystals, most of the data acquired to date stems from nitride layers grown heteroepitaxially. As a result, lattice constants and associated thermal and mechanical properties were found to exhibit significant scattering [10]. The most widely accepted lattice constants of wurtzite GaN

are $a=3.189 \AA$ and $c=5.186 \AA$ [11]. Some of the relevant properties of wurtzite GaN are listed in Table 1.

\subsubsection{Polarity of the Structures}

None of the three structures in which GaN crystallizes possess a center of inversion. This means that, when defining an atom position on a closed packed plane with coordinates $(\mathrm{x}, \mathrm{y}, \mathrm{z})$, it is not invariant to the position $(-\mathrm{x},-\mathrm{y},-\mathrm{z})$ since inversion results in replacement of group III atoms by nitrogen atoms and vice versa. As a result of the lack of inversion symmetry, the crystal exhibits crystallographic polarity: $\{0001\}$ basal planes in the wurtzite structure differ from $\{000 \overline{1}\}$ planes. A variety of properties of the material depends on its polarity, for example, growth, etching, defect generation, plasticity and piezoelectricity. 


\subsubsection{Electrical properties and defects in $\mathrm{GaN}$}

Electrical properties of unintentionally doped GaN were reviewed extensively by Strite and Morkoc [15]. They pointed out that widely varying results reflect the different crystal quality and purity of material. The room temperature electron mobility values in bulk GaN grown with HVPE to a thickness of $60 \mu \mathrm{m}$ were reported to be $950 \mathrm{~cm}^{2} / \mathrm{Vs}$ [16] and that reported for MOCVD grown layers was also in excess of $900 \mathrm{~cm}^{2} / \mathrm{Vs}$ [17]. MBE grown films, however, produce much lower mobility values in the range of 100$300 \mathrm{~cm}^{2} / \mathrm{Vs}$ [18]; this has been attributed to both high dislocation density and point defects [19]. Other important electrical properties were reviewed by Nakamura et al. [2].

Following the successful growth of GaN on sapphire substrates in the late 1960s [5], it became quickly obvious that doping and defects would play a vital role in future development of GaN. The early unintentionally doped GaN was invariably n-type, which at the same time was believed to be due to nitrogen vacancies. The high n-type background carrier concentration on the order of $10^{18} \mathrm{~cm}^{-3}$ proved to be difficult to reduce and the absence of a shallow acceptor dimmed the prospects of a production scale GaN based device effort [3]. The search of p-type GaN was not successful until Akasaki and Amano demonstrated this feat in 1989 [20]. This was achieved by reducing the background n-type carrier density in unintentionally doped GaN films by the use of a low temperature AlN buffer layer, and by Mg-doping followed by an ex situ low energy electron beam irradiation treatment $[21,22]$. This remarkable discovery eventually led to the demonstration of a variety of bipolar devices. Even though much progress has been 
made in doping of GaN, there still exist significant challenges; especially with p-type doping. The low hole mobility and low achievable free hole concentration result in large sheet resistance preventing the fabrication of reliable Ohmic contacts with low contact resistance. These material challenges have prevented the use of the AlGaN/GaN system to its full potential in electronic applications. Furthermore, an immature p-type doping technology has led to lifetime problems and required that InGaN laser diodes operate at a higher than expected bias voltage [3].

\subsubsection{Optical Properties}

Maruska and Tietjen [5] were the first to accurately measure the direct band gap energy of $\mathrm{GaN}$ to be $3.39 \mathrm{eV}$. Pioneering work in this area was performed by Pankove et al. who reported on the low temperature photoluminescence (PL) spectrum of wurtzite GaN. Since the primary interest in GaN is for its potential as a blue and UV light emitter, a lot of effort has been devoted to determine its optical properties. The available data were reviewed by Akasaki and Amano [24], and by Strite and Morkoc [15]. 


\subsubsection{Summary of Properties}

Table 2 summarizes the most important properties of wurtzite GaN.

Table 2. Wurtzite GaN parameters

\begin{tabular}{|c|c|}
\hline Property [2] & Wurtzite GaN \\
\hline Density $\left(\mathrm{g} / \mathrm{cm}^{3}\right)$ & 6.15 \\
\hline Melting Temperature $\left({ }^{\circ} \mathrm{C}\right)$ & $>1700$ \\
\hline Lattice Constant, a ( $\AA$ ) & 3.189 \\
\hline Lattice Constant, c ( $\AA$ ) & 5.185 \\
\hline Electron mobility $\left(\mathrm{cm}^{2} / \mathrm{Vs}\right)$ & 1000 \\
\hline Hole mobility $\left(\mathrm{cm}^{2} / \mathrm{Vs}\right)$ & 30 \\
\hline Breakdown field (V/cm) & $>5 \times 10^{6}$ \\
\hline Thermal Conductivity (W/cmK) & 1.5 \\
\hline Energy Gap ( $\Gamma$ Valley) $(\mathrm{eV})$ & 3.39 \\
\hline Effective Mass $(\Gamma$ Valley $)\left(m_{e}\right)$ & 0.20 \\
\hline Deformation Potential (eV) & 8.3 \\
\hline Polar Optical Phonon Energy (meV) & 91.2 \\
\hline Piezoelectric Constant $\mathrm{e}_{14}\left(\mathrm{C} / \mathrm{m}^{2}\right)$ & 0.375 \\
\hline Static Dielectric Constant & 8.9 \\
\hline High Frequency Dielectric Constant & 5.35 \\
\hline Transverse Constant $\left(\mathrm{C}_{\mathrm{t}}\right)\left(\mathrm{dyn} / \mathrm{cm}^{2}\right)$ & $4.42 \times 10^{11}$ \\
\hline Longitudinal Constant $\left(\mathrm{C}_{1}\right)\left(\mathrm{dyn} / \mathrm{cm}^{2}\right)$ & $2.65 \times 10^{12}$ \\
\hline Transverse Sound Velocity $(\mathrm{cm} / \mathrm{s})$ & $2.68 \times 10^{5}$ \\
\hline Longitudinal Sound Velocity $(\mathrm{cm} / \mathrm{s})$ & $6.56 \times 10^{5}$ \\
\hline
\end{tabular}




\subsection{Growth of GaN}

The group of III-nitrides do not exist in nature and thus must be synthesized. Crystal growth of this group using standard methods (Czochralski, Bridgman) is extremely difficult because of the following factors:

1. the high melting temperature $(\sim 2800 \mathrm{~K}$ for $\mathrm{GaN})$;

2. the relatively low sublimation - decomposition temperature compared to the melting temperature;

3. the very high equilibrium nitrogen vapor pressure ( $\sim 40 \mathrm{kbar}$ at melting temperature) and

4. low solubility in acids, bases, and most other inorganic elements and compounds.

Thus, novel growth techniques must be employed for III-nitrides. GaN was first synthesized by Johnson et al. [25] in the early 1930s by passing $\mathrm{NH}_{3}$ gas over hot metallic Ga. Two decades later, Grimmeiss et al. [26] employed the same technique to produce small crystals of $\mathrm{GaN}$ for the purpose of measuring their photoluminescence spectra. Another decade later, Maruska and Tietjen used a chloride transport vapor technique to form an epitaxial layer of $\mathrm{GaN}$ on a sapphire substrate [5]. All these and, the employment of nucleation buffer layers by Amano et al. [21], Yoshida [27] and Moustakas et al. [23] are considered to be pivotal improvements in the growth of nitrides. 
Nearly every crystal growth technique, substrate type and orientation has been tried in an effort to grow high quality group III-nitride thin films [28].

Due to the lack of native $\mathrm{GaN}$ substrates, $\mathrm{GaN}$ based nitride semiconductors have been grown hetero-epitaxially. Efforts to produce GaN $[29,30]$ and AIN [31, 32] bulk materials for investigating their properties as well as potential use as substrates for epitaxy are at their early beginnings. Despite this limitation, remarkable progress in the growth of high quality epitaxial III-nitride films by a variety of methods such as Hydride Vapor Phase Epitaxy (HVPE) [5, 33], Metal Organic Vapor Phase Epitaxy (MOVPE) [21, 34], Reactive Molecular Beam Epitaxy (MBE) [35], and bulk or thick crystal growth by vapor phase transport $[36,37]$ and solution techniques at high pressure and high temperature have been achieved [38].

The most desirable methods of growing high purity single crystal Group III nitrides would be those in which these nitrides themselves are used as starting material. This has been a goal for many researchers. Slack and McNelly [39] suggested a technique in which high quality $\mathrm{AlN}$ powder from the $\mathrm{Al}$ metal using $\mathrm{AlF}_{3}$ as an intermediate product can be produced. The AlN powder can be converted to a single crystal by sublimation in a closed tungsten crucible or in an open tube with a gas flow. Over the years, physical vapor transport (PVT), which is the most popular technique for growth of bulk AIN, has been intensively explored. So far, the best results for the growth of bulk AlN were achieved using the PVT method [32, 40-42]. GaN is harder to grow due to a much higher nitrogen overpressure required to stabilize GaN at high growth temperatures. High quality, transparent and colorless platelets of $\mathrm{GaN}$ were grown from the in liquid gallium 
at high temperatures $\left(1400-1600^{\circ} \mathrm{C}\right)$ and high $\mathrm{N}_{2}$ pressures of upto $20 \mathrm{kbar}$; however, this method is not scaleable [38].

Since Johnson et al. [25] synthesized polycrystalline $\mathrm{GaN}$ deposits by the reaction of $\mathrm{NH}_{3}$ with molten $\mathrm{Ga}$, several researchers have employed similar methods to grow $\mathrm{GaN}$ single crystals. Ejder [36] studied the growth of GaN from the vapor phase by the reaction of $\mathrm{Ga}$ and $\mathrm{NH}_{3}$ to investigate the effect of the Ga partial pressure on crystal morphology. Callahan et al. [44] observed the formation of high aspect ratio crystals on the upper surface of the GaN crust, where the Ga vapor concentration presumably is low. Beneath the crust, growth was preferentially along the basal plane of GaN. The decomposition of a solid gallium tribromide-ammonia complex $\left(\mathrm{GaBr}_{3}: 4 \mathrm{NH}_{3}\right)$ in an ammonia, argon and hydrogen atmosphere was used for the deposition of gallium nitride on $\mathrm{SiC}$ substrates [45]. The deposition rate of gallium nitride in argon was considerably less than in ammonia. Pichugin and Yaskov [46] obtained needles of $5 \times 0.3 \mathrm{~mm}$ by flowing ammonia over the Ga in a quartz boat for several hours at 1 bar pressure and $1150^{\circ} \mathrm{C}$. A more detailed study aimed at determining the optimum conditions for the growth of GaN crystals was conducted by Elwell et al. [37, 47]. The largest crystal, 2.5 mm long, was nucleated on a silicon carbide rather than on a GaN seed. Manchon et al. [48] grew hexagonal needles up to $2 \mathrm{~mm}$ in length by heating GaN powder at 1150$1200^{\circ} \mathrm{C}$ in pure ammonia for $16 \mathrm{hrs}$. Zetterstrom [49] grew rather large crystals of up to 5 $\mathrm{mm} \times 1 \mathrm{~mm}$ by heating pre-synthesized $\mathrm{GaN}$ above $1100^{\circ} \mathrm{C}$ in an ammonia flow for about 72 hours. The needles were colorless as long as the temperature did not exceed $1200^{\circ} \mathrm{C}$. A more detailed series of studies of the morphology of GaN crystals formed primarily by sublimation was undertaken by Aoki and Ogino [50]. They compared the 
reaction between the ammonia and gallium in an open quartz boat with that in a partly closed quartz ampoule. Sakai et al. [51] have obtained GaN needles by sublimation of $\mathrm{GaN}$ powder in a $50 \mathrm{sccm}$ flow of $\mathrm{NH}_{3}$ via deposition onto sapphire substrates at a substrate temperature of $1050^{\circ} \mathrm{C}$. However, the crystal size was limited to small needles.

Balkas et al. [52] were successful in obtaining high quality GaN crystals up to $1 \mathrm{~mm}$ in length via sublimation with a growth rate of $0.5 \mathrm{~mm} / \mathrm{hr}$ in the direction perpendicular to the basal plane. They also found that the direction of the fastest growth and thus the crystal shape were controlled by changing the $\mathrm{Ga} / \mathrm{NH}_{3}$ flux ratio and the growth temperature. Kamler et al. [53] investigated GaN sublimation in a horizontal quartz tube reactor. They reported that the sublimation process was slower but more stable in terms of reactant transport as compared to Ga as the source material.

Growth by a modified vapor phase transport process called the sublimation sandwich method (SSM) was reported by Wetzel and co-workers [54, 55]. The GaN films were grown from the metallic Ga and activated ammonia on (0001) 6H-SiC, using a modified sandwich method originally described in [56]. A quartz reactor contained several deposition cells in a row, which shared the same ammonia gas stream. Each cell consisted of a Ga source and substrate, separated by a gap of only $5 \mathrm{~mm}$. The ammonia flow rate through the gap was 25 to $50 \mathrm{slm}$ at atmospheric pressure. Under these conditions, there was an effective mass transport of Ga vapor and activated nitrogen towards the substrates. At growth temperatures between 1170 and $1270^{\circ} \mathrm{C}$, single crystal layers of GaN were obtained at growth rates up to $300 \mu \mathrm{m} / \mathrm{h}$. Vodakov et al [57] succeeded in growing $\mathrm{GaN}$ on $6 \mathrm{H}-\mathrm{SiC}$ substrates by using the $\mathrm{SSM}$ technique with deposition rates up to $200-1100 \mu \mathrm{m} / \mathrm{h}$. GaN films with thicknesses between 70 and $100 \mu \mathrm{m}$ showed near- 
bandgap photoluminescence at $3.48 \mathrm{eV}$ with a FWHM of $8 \mathrm{meV}$. The FWHM of the (0002) $\omega$-scan was measured to be in the range of 270-300 arcsec, indicating good structural quality for films grown at very high rates.

\subsection{GaN growth from the Vapor Phase}

Growth of crystalline films from the vapor phase onto solid substrates, involves the physical transport of gas phase precursors to a solid surface where film constituents are incorporated and gaseous byproducts are released. The fundamental steps that occur in the process involve the transport of reactants to the reaction zone, which decompose or react with one another depositing a film on the substrate and transport of the reaction byproducts away from the reaction zone.

\subsubsection{Sublimed GaN vs. Evaporated Ga as Ga Source}

It is generally accepted that the process is called "sublimation" when the source material is pre-synthesized GaN and "evaporation-condensation" when pure Ga is used [51]. The sublimation process was reported to be slower but more stable in terms of transport of reactants [53]. However, the reasoning behind this is still not clear. In spite of its high growth rate and simplicity in apparatus, the sublimation technique has an inherent difficulty in that pre-synthesized GaN powder or crystals must be continuously supplied. On the other hand, the use of pure Ga as the source material provided the maximum growth rate, but resulted in poor stability $[58,59]$. The high GaN growth rate is thought 
to originate from Ga droplets generation due to instability of the Ga source [59]. Elwell et al. [37] reported the formation of a GaN crust on the molten Ga during the GaN crystal growth by the reaction between $\mathrm{Ga}$ and $\mathrm{NH}_{3}$. Subsequent studies revealed the cessation of growth is due to the crust formation [44]. Shin et al. [58] observed that the violent reaction at the molten Ga surface caused spattering of Ga and the contact of Ga droplets with already formed GaN crystals changed the growth kinetics. They also reported that the increase in the flow rate to $325 \mathrm{sccm}$ and above resulted in the formation of a thin crust of GaN on the source surface and the cessation of the violent reaction. With a controlled and stable Ga source continuous growth could be achieved within an appropriate processing window.

\subsubsection{Epitaxial Growth}

Attempts to grow free-standing $\mathrm{GaN}$ crystals in the $\mathrm{Ga}-\mathrm{NH}_{3}$ system without seed or substrate were not successful [60]. In the best case, only mm size needle or platelet crystals were obtained.

With the discovery of X-ray diffraction in 1912, the knowledge of internal crystal structure developed very rapidly and by the time Royer (1928) carried out his extensive and systematic studies of a wide variety of overgrowths, it was possible to examine the effect of the geometry of crystal structure on orientation. Royer introduced the term epitaxy ("arrangement on") [61]. Based on his results, he established the requirements for epitaxy. The most important is that oriented growth occurs only when it involves the parallelism of two lattice planes that have identical or quasi-identical structure and 
closely similar atomic spacing. The experiments indicated that epitaxy occured only if the misfit was no more than $15 \%$. The misfit was defined as $100(b-a) / a$, where $a$ and $b$ are the corresponding spacings in the substrate and overgrowth, respectively.

Over the past decades, epitaxy has left the laboratory and assumed crucial importance in the processing of electronic and optoelectronic devices. Two epitaxial processes are commonly applied: 1) homo-epitaxy and 2) hetero-epitaxy. In the homo-epitaxy the growth takes place on the substrate of the same material (native substrate). In the optimal conditions, the growth is two-dimensional and replicates the surface layer-by-layer with the same atomic arrangement as the substrate crystal. During the hetero-epitaxy however, single crystalline materials are grown on non-native substrates. In this case, the growth of the first layer takes place on a different crystal from the growing layer. The lattice mismatch and induced stress on the substrate surface cause the adatoms distribution to vary from the crystal structure, which is being grown. The first layer of adsorbed atoms on the surface tends to occupy those spots that give minimal surface stress [62]. During the growth of the first few layers, misfit dislocations are formed [63]. Buffer layers, grown at lower temperatures, have been routinely used in order to relax the stresses during the nucleation stage $[64,65]$.

\subsubsection{Substrates for Epitaxy}

The unavailability of native single crystalline substrates for homo-epitaxy has been the biggest problem in the growth of GaN and other III-N thin films. Therefore, the hetero-epitaxy was a practical necessity. The use of ammonia and operating temperatures 
above $1000^{\circ} \mathrm{C}$ additionally limited the choice of non-native substrates for growth of $\mathrm{GaN}$ in the $\mathrm{Ga}-\mathrm{NH}_{3}$ system. Sapphire has been by far the most popular choice owing to its low price, availability of large-area, high-quality crystals, its transparent nature and high temperature stability. Sapphire is not the best choice in terms of lattice mismatch $(17 \%$ mismatch with $\mathrm{GaN}$ ). However, it has been observed that the dislocations formed during $\mathrm{GaN}$ growth due to lattice mismatch with the substrate are not detrimental to the electrical and optical properties although the dislocation density is in the range of $10^{9}$ $10^{10} / \mathrm{cm}^{2}$. Both c-plane (0001) and r-plane $(1 \overline{1} 02)$ sapphire have been studied extensively [66]. GaN films grown on c-plane (0001) substrates grow (0001)-oriented. The low surface energy of this plane results in poor hetero-nucleation, resulting in rough film morphology, usually dominated by the sapphire's surface features or contaminants. In addition, due to a large lattice mismatch between the sapphire and $\mathrm{GaN}$, the stress relaxation occurs in a region close to the substrate-crystal interface and misfit dislocations form at a very high density $[64,67,68]$. The thermal expansion mismatch also introduces stresses during the cooling process, which may result in delamination and cracks of the layers grown on sapphire.

\subsubsection{Species Transport}

Fluid mechanics, heat transfer, and species transport are critical in determining both the transport of precursors to the growth interface and the degree of gas phase reactions occurring prior to the species participation in the surface growth reactions. The movement of precursors to the growth surface is determined by the geometry of the 
system involved as well as the pressure, temperature, and type of gas under consideration. It is therefore crucial to understand and control factors governing transport processes underlying crystal growth from the vapor phase.

At low gas densities, free molecular flow occurs. The chambers of high vacuum evaporators operate within the molecular flow regime. In this case the mean distance between molecular collisions is large compared to dimensions of the system. The kinetic theory of gases provides an accurate picture of molecular motion under such conditions. At higher pressures, however, the mean distance between successive molecular collisions is reduced, and they dominate relative to molecule - chamber wall collisions. The gas is said to be in a viscous flow regime. Compared to the molecular flow, viscous flow is quite complex. Criteria for distinguishing between the flow regimes are based on the magnitude of the Knudsen number, Kn, which is defined by the ratio of the gas mean free path $\left(\lambda_{m f p}\right)$ to a characteristic dimension $D_{p}$ of the system, i.e., $\mathrm{Kn}=\lambda_{m f p} / D_{p}$. At the atmospheric pressure, $\lambda_{m f p}$ of the gas is as small as several microns that the flow of the gas is limited by its viscosity. At very low pressures, where $\lambda_{\text {mfp }}$ is much larger then the dimensions of the vacuum enclosure, the flow is molecular and $\mathrm{Kn}>1$. In between, at intermediate, where $\lambda_{m f p}$ of the molecules is similar to the dimensions of the vacuum enclosure, the gas flow is governed by the viscosity as well as molecular phenomena. In the state where the gas is viscous, the flow can be laminar or turbulent. At low gas velocities, the flow is laminar and layered, parallel gas flow lines may be imagined. Under these conditions, the laminar flow velocity is zero at the walls of a tube, but it increases to a maximum at the tube axis. For higher flow velocities, the gas layers are no longer parallel but swirl. In this turbulent flow range, cavities of lower pressure develop 
between layers. The limit between the turbulent and laminar flow is defined by the value of Reynold's number. The Reynold's number is a dimensionless quantity expressed by $R_{e}=\rho v D / \eta$ where $\rho$ is the gas density, $v$ the velocity, $\eta$ the viscosity, and $D$ the diameter of the tube.

Models of crystal growth from the vapor consist of nonlinear, coupled partial differential equations that represent the conservation of momentum, energy, total mass, and individual species [70]. The general derivation and form of these equations is given in standard references in transport phenomena textbooks [71 - 73] and also explained in more detail in Appendix A. The general equations in the continuum regime apply for typical reactors operating at sufficiently high pressures and with large characteristic dimensions such as reactor height and substrate spacing, so that the mean free path is small relative to these characteristic dimensions.

\subsubsection{Thermodynamics and Kinetics of GaN Growth}

Thermodynamics addresses a number of important issues with respect to growth from the vapor. These calculations can provide information on the partial pressures of the involved gaseous species and the direction of transport in case of reversible reactions. Importantly, it provides an upper limit of what to expect and an estimate of the extent of departure from equilibrium under specific conditions. Epitaxial growth must take place under relatively low gas-phase supersaturations so that the reactant partial pressures do not deviate excessively from the equilibrium values. If the arrival rate of the reactant 
species greatly exceeds the nucleation and lattice incorporation rate at the crystal surface, poor crystal perfection will result [74].

Thermodynamics, on the other hand, does not address questions related to the speed of the reaction and the resulting growth rates. Indeed, processes that are thermodynamically possible frequently proceed at low rates because of both transport and reaction kinetics [75]. Generally, it is impractical to operate a vapor phase epitaxy process with so low flow rates that permit complete equilibration of the incoming reactants with the growing layer. Thus, a portion of the reactants must pass unreacted, and the overall epitaxial deposition rate may be limited by the rate of mass transfer of reactants from the main gas stream to the substrate surface where they undergo reaction. This is the classic diffusion or mass transport controlled process. A convenient working model assumes a hypothetical boundary layer or stagnant gas region near the substrate surface where the gas stream velocity approaches zero. Outside this boundary layer the reactant concentrations are at their bulk or mainstream values. This subject is discussed in more detail in Chapter 6.

Thurmond and Logan [76] calculated the equilibrium pressure of $\mathrm{N}_{2}$ above GaN. More recently, Karpinski et al. [77] used the partial decomposition of $\mathrm{GaN}$ in a high pressure apparatus to measure the equilibrium pressure of $\mathrm{N}_{2}$ over $\mathrm{GaN}$, over a wide range of temperatures. The equilibrium $\mathrm{N}_{2}$ pressure values were reported to be around $100 \mathrm{~atm}$ at $1100^{\circ} \mathrm{C}$. The nitrogen molecule with its highly stable N-N triple bond $(9.8 \mathrm{eV})$ is extremely difficult to break into its atomic constituents that are necessary for GaN formation. While this is not a barrier to growth of GaN crystals in high-temperature, high-pressure solution growth, it makes the growth of $\mathrm{GaN}$ impossible at pressures below 
atmospheric pressure. This high stability necessitates dissociation of $\mathrm{N}_{2}$ using various processes such as those utilized in plasma assisted molecular beam epitaxy (MBE), electron cyclotron resonance plasma assisted MBE, and radio frequency plasma MBE. All these approaches require modifications to the growth reactor and necessitate a significant investment. Even with the use of highly energetic nitrogen species, the thermal energy on the growing surface is important for the uptake of both $\mathrm{N}$ and Ga [78]. While all of the above techniques have demonstrated GaN growth, they are inadequate for bulk growth of $\mathrm{GaN}$ because of the low growth rates.

Because of these very high equilibrium nitrogen pressures, most crystal growth experiments have used ammonia as the source of nitrogen. Thermodynamically, almost all the $\mathrm{NH}_{3}$ is decomposed into $\mathrm{N}_{2}$ and $\mathrm{H}_{2}$ at temperatures higher than $300^{\circ} \mathrm{C}$. Calculation of the free energy of the reaction

$$
G a(g)+N H_{3} \Leftrightarrow G a N+\frac{3}{2} H_{2} \quad\left(\Delta G_{900^{\circ} \mathrm{C}}=-48.4 \mathrm{kcal} / \mathrm{mol}\right)
$$

showed that the formation of $\mathrm{GaN}$ is favored over the temperature region of interest. However, the growth rate of $\mathrm{GaN}$ is negligible at $900^{\circ} \mathrm{C}$, showing that the chemical reaction is kinetically controlled. Calculations of free energy in several GaN growth processes and their comparison with respect to $\mathrm{GaN}$ growth from $\mathrm{Ga}$ and $\mathrm{NH}_{3}$ can be found in Appendix B. It is also well known that $\mathrm{NH}_{3}$ decomposition is a catalytic process [79] and the extent of the decomposition strongly depends on the growth conditions and the equipment. A detailed study on $\mathrm{NH}_{3}$ decomposition is presented in Appendix $\mathrm{C}$.

The growth kinetics in growth from vapor phase is dependent on a number of factors associated with transport of reactants to the substrate surface and subsequent heterogeneous surface reactions that lead to crystal formation. Intimate microscopic 
details of these reactions are often unknown, thus growth kinetics is frequently modeled in macroscopic terms.

A growth model has been proposed for the formation of $\mathrm{GaN}$ from $\mathrm{Ga}$ and $\mathrm{NH}_{3}$ and is illustrated in Figure 2 [80]. In a first step, and in order to form the GaN molecule, the reaction barrier must be reduced either by an increase in the energy of the reactant molecules or thorough a feasible chemical reaction path. The first step of the proposed reaction sequence includes the adsorption of $\mathrm{NH}_{3}$ on a Ga site, either within the GaN surface or an adsorbed Ga atom on the substrate surface. The bonding between $\mathrm{Ga}$ and $\mathrm{N}$ is through the lone pair electrons of $\mathrm{NH}_{3}$. The second and third steps involve the formation of Ga-ammonia intermediate molecules coupled with the migration of $\mathrm{H}$ from the adsorbed ammonia to the surface and further reaction of Ga with the ammonia to replace $\mathrm{H}$ with $\mathrm{Ga}$. The final step involves the formation of $\mathrm{GaN}$ and liberation of $\mathrm{H}_{2}$ from the surface. The concept of on surface cracking (OSC) of ammonia has been introduced by Kamp and co-workers [81, 82].

Several other studies reveal that, following physisorption to the surface, $\mathrm{NH}_{3}$ instantaneously chemisorbs and releases a hydrogen atom at temperatures above $200 \mathrm{~K}$. At moderate temperatures, $\mathrm{NH}_{2}$ and $\mathrm{NH}$ are formed, and $\mathrm{H}_{2}$ is released from the surface. With increasing temperatures, the remaining $\mathrm{H}$ is stripped off and nitrogen forms a nitride with the surface [83-84]. 


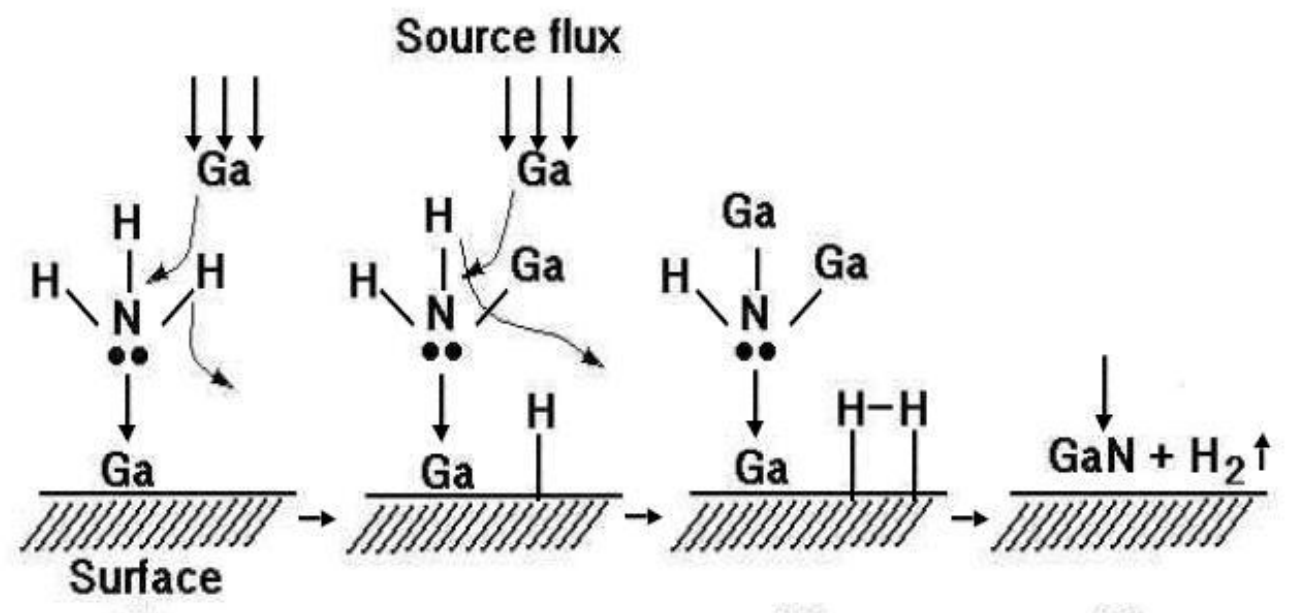

Figure 2. Schematic illustration of GaN formation on a solid surface starting with Ga and $\mathrm{NH}_{3}$ precursors. 


\section{EXPERIMENTAL SETUP}

Crystal growth experiments were conducted in a computer controlled growth system, custom designed for GaN growth. The growth system is shown schematically and pictorially in Figs. 3 and 4, respectively. The complete system consists of a stainless steel growth chamber, a chemical pump to maintain the growth pressure in the reactor tube, a mechanical pump to evacuate the outer chamber, a control tower including an in-situ monitoring facility, a gas delivery and control system, and a chiller for the outer chamber.

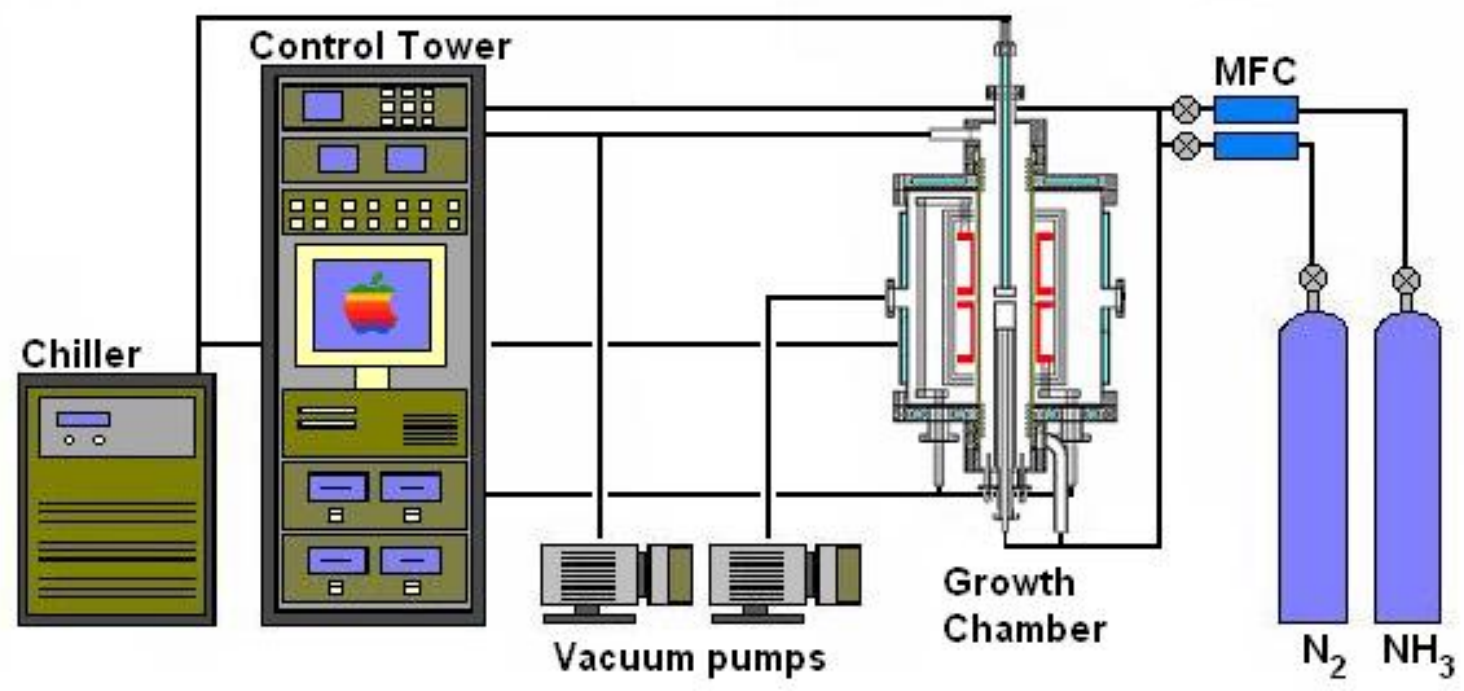

\section{Figure 3. Schematic diagram of the GaN growth system}

The growth furnace was operated using a PID controller programmed with LabView. A variety of safety features were employed. An interlock system was programmed to shut down the whole system and the flow of all gases in case of overheating, overpressure, or loss of cooling water. 


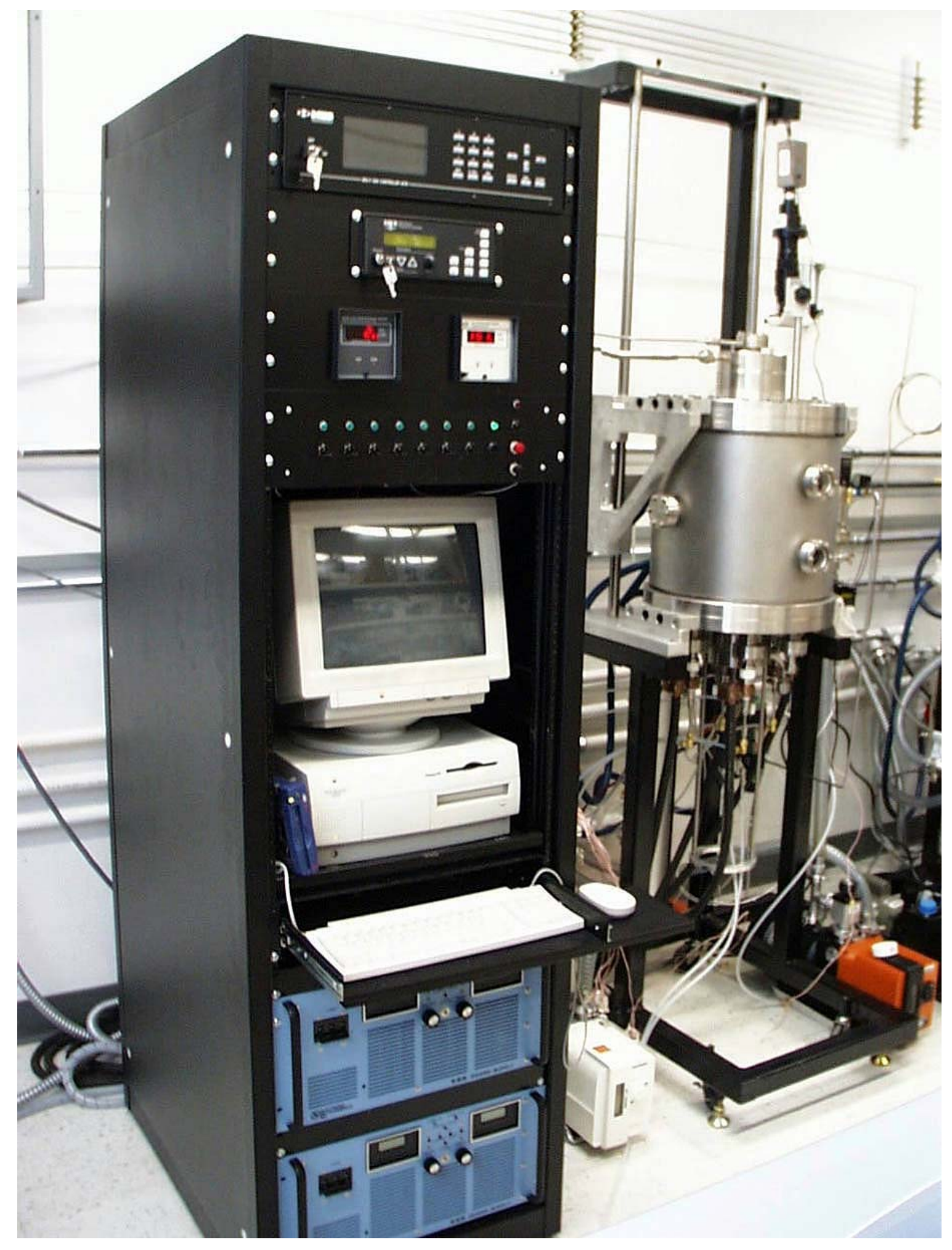

Figure 4. Picture of the GaN growth system 
Fig. 5 shows the system cross-section. The 16.5"-diameter, double-walled, water-cooled outer stainless steel growth chamber contained a 4"-diameter alumina reaction tube surrounded by two graphite heaters. The heaters were designed to have specific resistances at high temperatures to comply with the outputs of power supplies and were fabricated from a high purity grade of graphite $(>99 \%, 2020$ grade graphite from Carbone of America). Both graphite heaters are supported by and connected to water-cooled electrical feedthroughs. Radiation shields made of molybdenum sheets were placed around the two heaters to reflect the heat effectively toward the center of the alumina reactor tube. To monitor the temperature, two type-C thermocouples were inserted through small holes in the molybdenum radiation shields and placed $2 \mathrm{~mm}$ away from the center of each heater. The thermocouples were not in a direct contact with the heaters to avoid an abrupt change in reading in case of detachment of the thermocouple from the heater. 


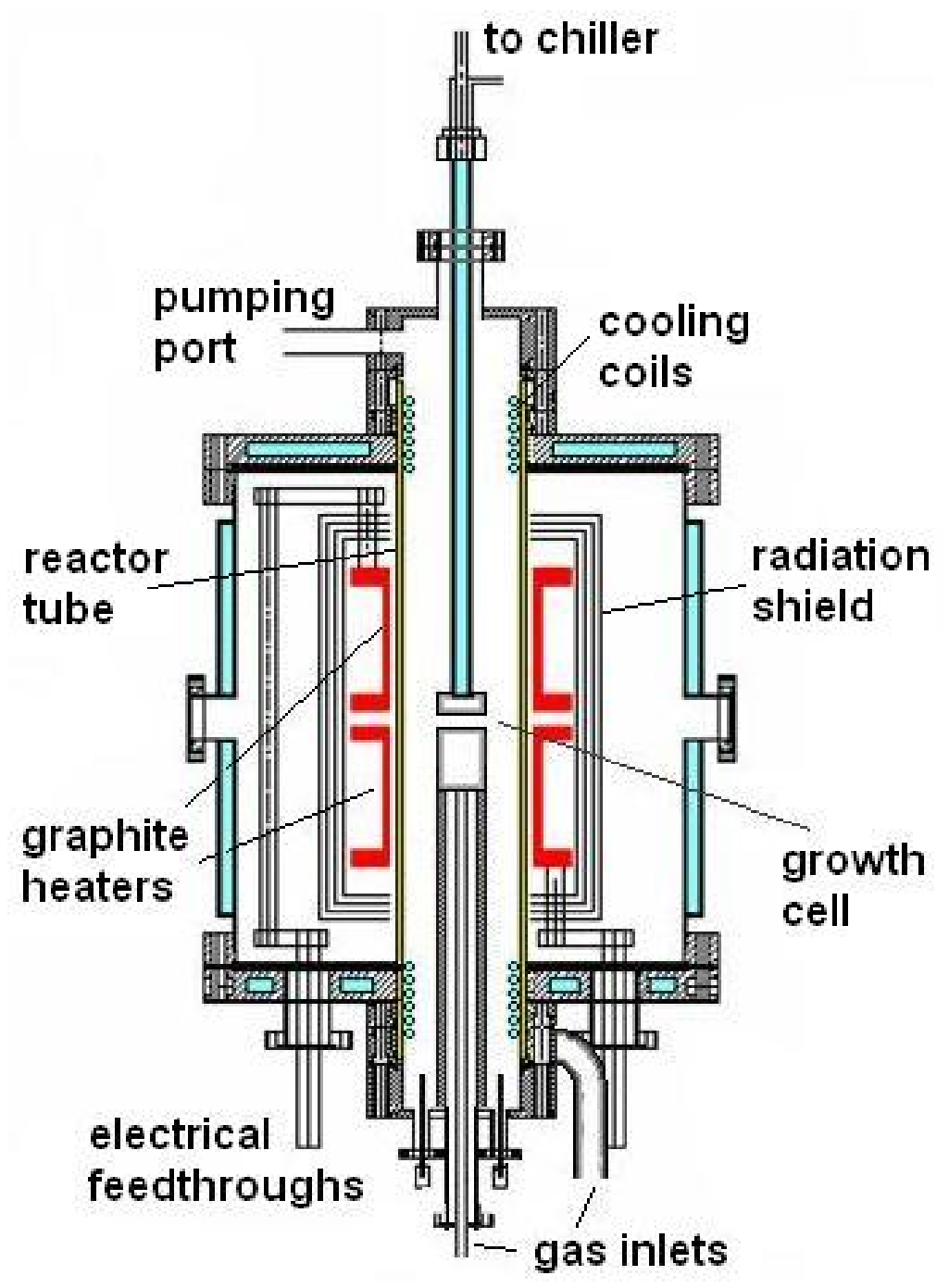

Figure 5. Schematic diagram of the GaN growth chamber.

The outer chamber was continuously evacuated by a mechanical pump to minimize the oxidation of graphite heaters and to prolong their lifetime. The pressure in the outer chamber was maintained below $3 \times 10^{-3}$ Torr even at a heater temperature of $1750^{\circ} \mathrm{C}$. The outer chamber was equipped with a water jacket around the outside as well as top and bottom flanges. Two viton O-rings were used to seal the gap between the alumina 
reaction tube and the outer chamber. To avoid O-ring deterioration at high temperatures, a water-cooled copper coil separately cooled the O-rings. A pneumatic cylinder was used to lift either the top flange or the chamber for maintenance.

All the fixtures inside the alumina reaction tube were manufactured from molybdenum (Mo) and hot pressed, binderless boron nitride (BN) due to high temperature stability and inertness of these materials to $\mathrm{NH}_{3}$. A chemical pump was used in tandem with a butterfly valve to maintain the desired pressure in the alumina reaction tube.

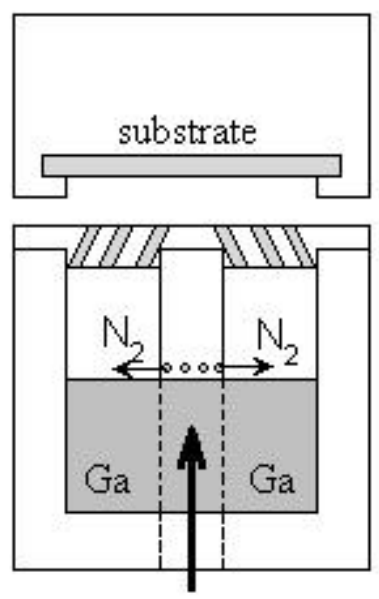

Figure 6. Schematic diagram of the growth cell with $\mathrm{N}_{2}$ flow over the molten $\mathrm{Ga}$ source.

The growth cell consisted of a Ga source and a substrate in a sandwich configuration as shown in Fig. 6. UHP-grade nitrogen $\left(\mathrm{N}_{2}\right)$ was flowed directly above the molten $\mathrm{Ga}$ source with a controlled flow rate to prevent contact between the molten Ga source and $\mathrm{NH}_{3}$ and to gain enhanced and controlled Ga evaporation and transport to the substrate. The Ga source holder was closed using a cap with holes to balance the gas flow velocities 
of $\mathrm{N}_{2}$ and $\mathrm{NH}_{3}$. The temperatures of each part of the growth cell were measured with type-C thermocouples. The temperature distribution can be seen in Appendix A. 


\section{GROWTH OF GAN CRYSTALS VIA PHYSICAL EVAPORATION: ON THE TRANSPORT OF GALLIUM}

\subsection{Outline}

The transport of gallium $(\mathrm{Ga})$ species in a vapor growth system for gallium nitride $(\mathrm{GaN})$ growth was investigated under different conditions. A simple mass-transport model based on total reactor pressure, gas flow rates and source temperature was developed and verified. Comparison between the experiential data and theoretical calculations indicated that Ga species transport in presence of ammonia $\left(\mathrm{NH}_{3}\right)$ is not solely by evaporation and diffusion. The reaction between the molten Ga and ammonia caused spattering of the Ga source and transport of Ga clusters. Subsequently, pure nitrogen $\left(\mathrm{N}_{2}\right)$ was flowed directly above the molten Ga source to prevent direct reaction between the molten $\mathrm{Ga}$ and $\mathrm{NH}_{3}$, to enhance $\mathrm{Ga}$ evaporation rate and, at the same time, to enable control of Ga transport to the substrate.

\subsection{Introduction}

Widely studied techniques in GaN bulk or thick film growth are high-pressure, hightemperature crystal growth $[29,89]$, hydride vapor phase epitaxy $[90,91]$ and growth via vapor phase transport $[53,92,58]$. Among these techniques, many advantages of growth via vapor phase transport have been reported including high growth rate, high crystal quality, use of the simplest source species, and high yield of the growth components [92]. 
In vapor phase transport technique, evaporated Ga metal or sublimed GaN powder is transported in $\mathrm{NH}_{3}$ atmosphere to the reaction zone in which deposition occurs. Advantages and disadvantages of the use of both pure GaN powder and Ga metal are discussed in Chapter two, section 2.3.1. In the previous studies high GaN growth rates for limited times were observed and it was thought to originate from Ga droplets generation and crust formation due to instability of the Ga source [59]. In fact, Shin et al. [58] observed that the violent reaction at the molten Ga surface caused spattering of Ga and the contact of Ga droplets with already formed GaN crystals changed the growth kinetics. They also reported on the formation of a thin crust of $\mathrm{GaN}$ on the source surface and subsequent cessation of the growth reaction. Hence, understanding the transport mechanism of $\mathrm{Ga}$ in ammonia - liquid Ga system is of great importance for the development of a stable and reproducible growth process.

Therefore, in this chapter, transport properties of Ga species during the GaN growth process and the role of ammonia - liquid Ga reactions on the transport properties were investigated. Experimental results were compared to theoretical predictions to quantify the mechanism of transport in vapor growth technique. The modification applied to the source holder in an effort to form reproducible and stable growth conditions was discussed.

\subsection{Experimental Procedure}

Experiments were conducted in the system described in Chapter 3. Two different sets of experiments were performed. The first set was employed to measure the amount of Ga 
transport under different conditions using the growth cell shown in Fig. 7 (a and b) where Ga source holder is a BN open cylindrical cup with 1" inner diameter. In some of the experiments, Ga source surface was heated with a hot tungsten filament with the purpose of cracking $\mathrm{NH}_{3}$ before reaching the source as shown in Fig. 7 (b) where the filament temperature was $1350^{\circ} \mathrm{C}$. It is well known from the early surface science studies that tungsten is an effective catalyst for ammonia decomposition [83]. All the experiments were conducted at a constant source temperature of $1250^{\circ} \mathrm{C}$. Four different experimental conditions were: 1) $\mathrm{N}_{2}$ atmosphere, 2) $\mathrm{NH}_{3}$ atmosphere, 3) vacuum (5mTorr), and 4) in $\mathrm{NH}_{3}$ with hot filament above the source. The reactor pressure and flow rates of gases were 750 Torr and $700 \mathrm{sccm}$, respectively in all experiments except the ones under vacuum. The source surface area was $5 \mathrm{~cm}^{2}$, and the source-to-substrate distance was constant at $2.5 \mathrm{~cm}$.

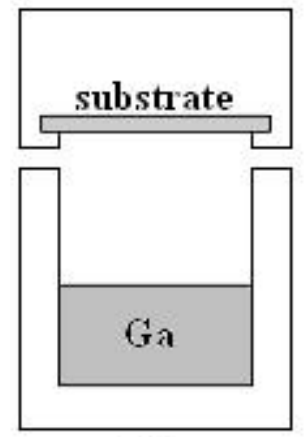

(a)

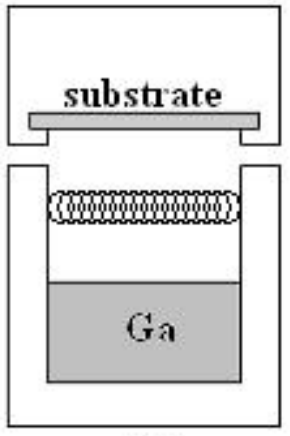

(b)

Figure 7. Schematic diagram of the growth cell. (a) BN cylindrical source holder. (b) Growth cell with the hot tungsten filament.

In the second experimental design, pure nitrogen $\left(\mathrm{N}_{2}\right)$ was flowed directly above the molten Ga source with a controlled flow rate to prevent the contact between the 
molten Ga and ammonia and to gain enhanced and controlled Ga evaporation rate and transport to the substrate. The source holder was closed using a cap with holes to balance the gas flow velocities of $\mathrm{N}_{2}$ and $\mathrm{NH}_{3}$ and to avoid any entry of $\mathrm{NH}_{3}$ gas inside of the source holder. A schematic figure of this growth cell can be seen in Fig. 6 .

\subsection{Theoretical calculations}

The general phenomenon of the vapor phase transport is complicated. The evaluation of the upper and lower limits of the vapor phase transport enabled the analysis of the transport mechanism in the GaN growth system. Steady state diffusion of $\mathrm{Ga}$ through a stationary gas $\left(\mathrm{N}_{2}\right.$ or $\left.\mathrm{NH}_{3}\right)$ forms the lower limit of mass transport in the system while free evaporation into vacuum forms the upper limit.

A one-dimensional diffusion model was used to calculate the lower limit of $\mathrm{Ga}$ transport. At the source surface, the liquid Ga is in equilibrium with its vapor, and the Ga partial pressure $P_{G a}$ is the equilibrium vapor pressure at a given temperature. This pressure decreases toward the substrate surface until it reaches $P_{G a}^{*}$. This provides the concentration gradient which is the driving force for diffusion of Ga. As shown in Figure 8 , diffusion occurs in the $\mathrm{x}$ direction due to the pressure decrease $P_{G a}-P_{G a}^{*}$ in the $\mathrm{x}$ direction over a distance $\mathrm{L}$. The gradients are assumed to be linear. 


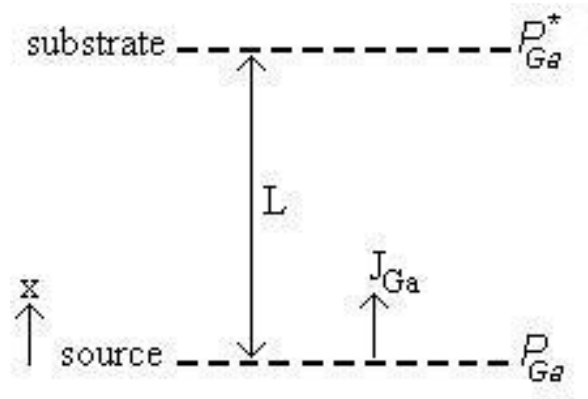

Figure 8. Illustration of mass transport by diffusion.

The diffusion flux of Ga illustrated in Figure 8 is represented by [93]

$$
J_{G a}=-D_{G a-i} \frac{\Delta P_{G a}}{\Delta x}
$$

where $\Delta P_{G a}=P_{G a}-P_{G a}^{*}$ and $D_{G a-i}$ is the diffusivity of $\mathrm{Ga}$ in $\mathrm{N}_{2}$ or $\mathrm{NH}_{3}$. At the source surface, $\mathrm{x}=0$, the pressure of $\mathrm{Ga}$ is simply equal to the vapor pressure of $\mathrm{Ga}$ at a given temperature and at the substrate level, $\mathrm{x}=\mathrm{L}$, assuming the complete depletion, the pressure of Ga is equal to zero.. The result from the kinetic theory, when corrected for the Maxwellian distribution of velocities and for velocity persistence, is [94]

$$
D_{G a-i}=\frac{8\left(\frac{2 k T}{\pi}\right)^{1 / 2}\left(\frac{1}{m_{G a}}+\frac{1}{m_{i}}\right)^{1 / 2}}{3 \pi\left(n_{G a}+n_{i}\right)\left(d_{G a}+d_{i}\right)^{2}}
$$

If the concentrations are replaced by $\mathrm{P} / \mathrm{kT}$ and a nitrogen or ammonia rich gas phase is assumed, diffusivity is approximately proportional to $\mathrm{T}^{1.5}$ and $\mathrm{P}^{-1}$. It is usual to represent the diffusivity in gases by

$$
D_{G a-i}=D_{0, G a-i}\left(\frac{P_{0}}{P}\right)\left(\frac{T}{T_{0}}\right)^{n}
$$


where $n$ is an empirical exponent in the range of $1.66-2.0[93,95,96] . D_{0, G a-i}$ is the diffusivity of $\mathrm{Ga}$ in $\mathrm{N}_{2}$ or $\mathrm{NH}_{3}$ at standard temperature $T_{0}=273 \mathrm{~K}$ and pressure $P_{0}=1$ atm. Typical values for $D_{0}$ span the range of $0.1-10 \mathrm{~cm}^{2} / \mathrm{s}$ [95]. Whenever measured values of diffusivities are available, they should be used. Typically, the measurement errors are less than those associated with the predictions [96]. For rough estimates, diffusivity values can be calculated via Eq. (2) with better than a factor of two accuracy [93]. $D_{0}$ and $n$ values were measured for the Ga- $\mathrm{N}_{2}$ system to be $0.131 \mathrm{~cm}^{2} / \mathrm{s}$ and 1.7 , respectively, using a measurement set-up shown in Figure 9. The set-up is simply a closed Ga container wih a small opening of a known geometry at the top, through which diffusion takes place.

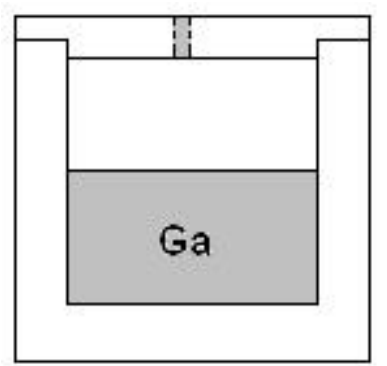

Figure 9. Schematic of diffusivity measurement set up.

In order to analyze the upper limit, Ga transport under vacuum was compared to the theoretical data obtained from Langmuir's mass evaporation rate calculation which estimates the evaporation from a free surface. Hertz stated that a liquid has a specific ability to evaporate and can not exceed a certain maximum evaporation rate at a given temperature, even if the supply of heat is unlimited [96]. Furthermore, the theoretical maximum evaporation rates are obtained only if as many evaporant molecules leave the 
surface as it would be required to exert the equilibrium pressure on the same surface while none of them must return. The latter condition means that a hydrostatic pressure of $P=0$ must be maintained. Langmuir investigated the evaporation of tungsten from filaments in evacuated glass bulbs and assumed that the evaporation rate of a material at a pressure below 1 Torr is the same as if the surface were in equilibrium with its vapor and thereby excluded the recondensation of evaporated species [97]. He derived the maximum mass evaporation rate per unit area as

$$
\Gamma=\left(\frac{m}{2 \pi k T}\right)^{1 / 2} P^{*}
$$

where $P_{G a}$ is the equilibrium vapor pressure of the material at temperature $T$. Therefore, themass evaporation rate of $\mathrm{Ga}$ in vacuum, where the ambient hydrostatic pressure acting upon the Ga in the condensed phase was $5 \times 10^{-3}$ Torr, was calculated based on Langmuir's mass evaporation studies. Ga vapor pressure data previously measured by Honig and Kramer [98] were used in the calculations.

\subsection{Results and discussion}

The lower limit of the mass transport was calculated from the transport rate via pure diffusion of $\mathrm{Ga}$ in stagnant $\mathrm{N}_{2}$ gas using the experimental parameters and geometry, and it was found to be $6.3 \times 10^{-3} \mathrm{~g} / \mathrm{h}$. On the other hand, upper limit was calculated to be $1.80 \pm 0.41 \mathrm{~g} / \mathrm{h}$ using Langmuir's mass evaporation rate. Transport data measured in the first set of experiments, where the Ga source surface was open to contact with $\mathrm{NH}_{3}$ as shown in Fig. 7(a), are tabulated in Table 3. The data show that Ga transport in $\mathrm{NH}_{3}$ gas, 
without a filament, was higher than that in $\mathrm{N}_{2}$ by a factor of 50 . It was even higher than the transport under vacuum by a factor of 2.5 . When this value is compared to the theoretical calculations, it is seen that there is a 2 orders of magnitude difference between the experimental and the calculated value. In the experiments with the hot filament above the molten Ga, as shown in Fig. 7(b), the measured Ga transport under the $\mathrm{NH}_{3}$ flow was approximately the same as that measured in $\mathrm{N}_{2}$ and below the value obtained under vacuum. It was also observed that under these conditions Ga droplet formation diminishes, source stays stable and the formation of the $\mathrm{GaN}$ crust over the source is avoided.

Table 3. Measured Ga mass transport rate under different conditions

\begin{tabular}{|l|c|}
\hline Experiment & Ga mass transport rate $\mathbf{( g / h})$ \\
\hline in $\mathrm{N}_{2}$ atmosphere & $7.2 \times 10^{-2}$ \\
\hline in $\mathrm{NH}_{3}$ atmosphere & 3.6 \\
\hline in $\mathrm{NH}_{3}$ atmosphere and filament assisted & $7.6 \times 10^{-2}$ \\
\hline under vacuum & 1.5 \\
\hline " source surface area $=5 \mathrm{~cm}^{2}, \mathrm{~T}=1250^{\circ} \mathrm{C}$, flow rate $=700 \mathrm{sccm}$ \\
\hline
\end{tabular}

The difference between the measured values and theoretical calculations for the $\mathrm{Ga}$ transport in $\mathrm{N}_{2}$ gas can be due to a number of factors such as deviations from the assumed conditions in the theoretical modeling and the effect of flow rate of $700 \mathrm{sccm}$ on the diffusion length, L. During the measurements, it was necessary to flow ammonia to be able to maintain a constant ammonia concentration, and in the measurements under $\mathrm{N}_{2}$, the same gas flow rate was employed in order to obtain comparable data. With the 
intention of investigating this effect further, similar mass transport measurements were carried out with the same set-up and parameters but under stagnant $\mathrm{N}_{2}$ atmosphere where Ga mass transport rate was measured to be $2.6 \times 10^{-2} \mathrm{~g} / \mathrm{h}$. The difference between this value and that measured under nitrogen and ammonia flows with the filament assisted source show the effect of $700 \mathrm{sccm}$ gas flow rate on the mass transport rate.

One drawback of heating the source surface with a filament is that due to a small source-to-substrate distances the filament affects the temperature of the substrate surface significantly, which in turn affects the crystals quality.

In order to obtain a stable and high transport of Ga species at moderate temperatures, a source holder design was employed as explained in the experimental procedure section. The results of Ga mass loss rate measurements under different flow rates of $\mathrm{N}_{2}$ and $\mathrm{NH}_{3}$ gases are presented in Fig. 10. In all experiments $1 \mathrm{slm}$ of $\mathrm{N}_{2}$ was flowed over the molten Ga source. After each experiment a clean Ga source surface, free of GaN crust, was obtained, indicating that the $\mathrm{NH}_{3}$ - liquid Ga surface reactions were suppressed. An enhanced evaporation rate of about $40 \mathrm{mg} / \mathrm{h}$ was obtained at a source temperature of $1250^{\circ} \mathrm{C}$. Ga mass loss rate under different flow rates of $\mathrm{N}_{2}$ show the consistency of the collected data and stability of the experimental set-up. 


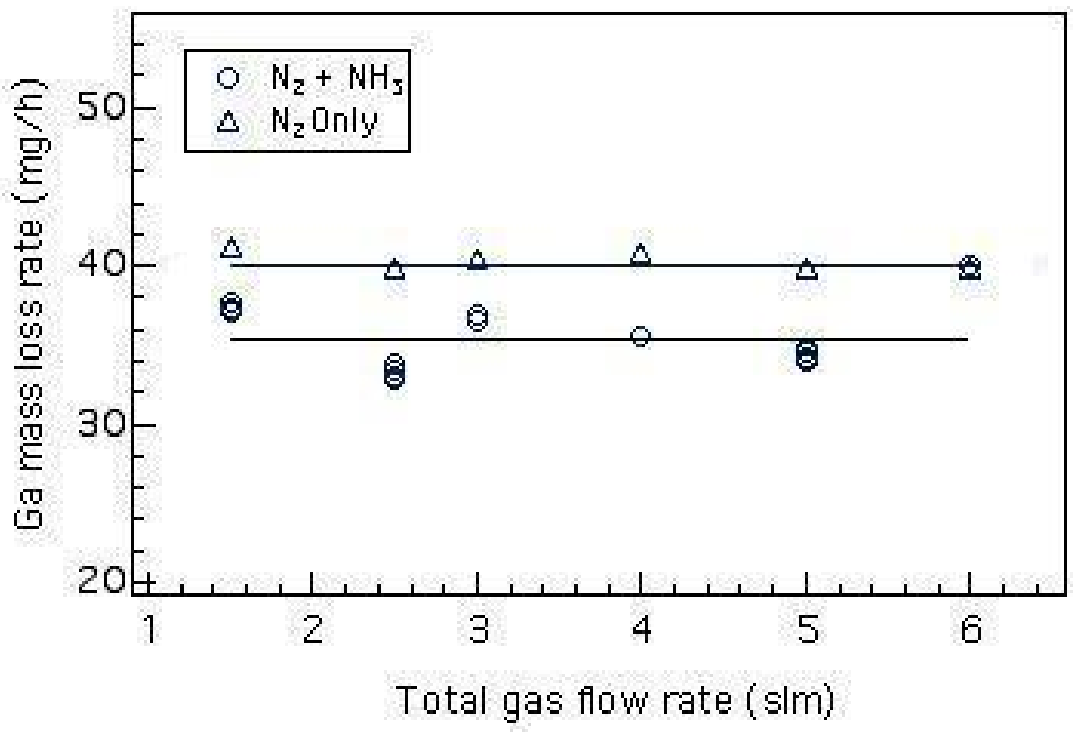

Figure 10. Ga mass loss rate as a function of total flow rate

When the combination of $\mathrm{N}_{2}$ and $\mathrm{NH}_{3}$ gases was flowed, lower Ga mass loss rate with some deviations was observed. The lower Ga mass loss rate obtained in this case could be a result of $\mathrm{GaN}$ deposition on the source holder and its effect on the mass loss rate measurements. The deviations could be controlled through keeping the total flow rate constant by using a gas mixture of appropriate amounts of $\mathrm{NH}_{3}$ and $\mathrm{N}_{2}$ in consecutive experiments. Results of these experiments are shown in Fig. 11. The plot shows that the Ga mass loss rate and in turn the transport of Ga species could be controlled and predicted for different flow rates of $\mathrm{NH}_{3}$ when the total flow rate of gases was kept constant. This allows the control of V/III ratio in the reactor in different experiments. 


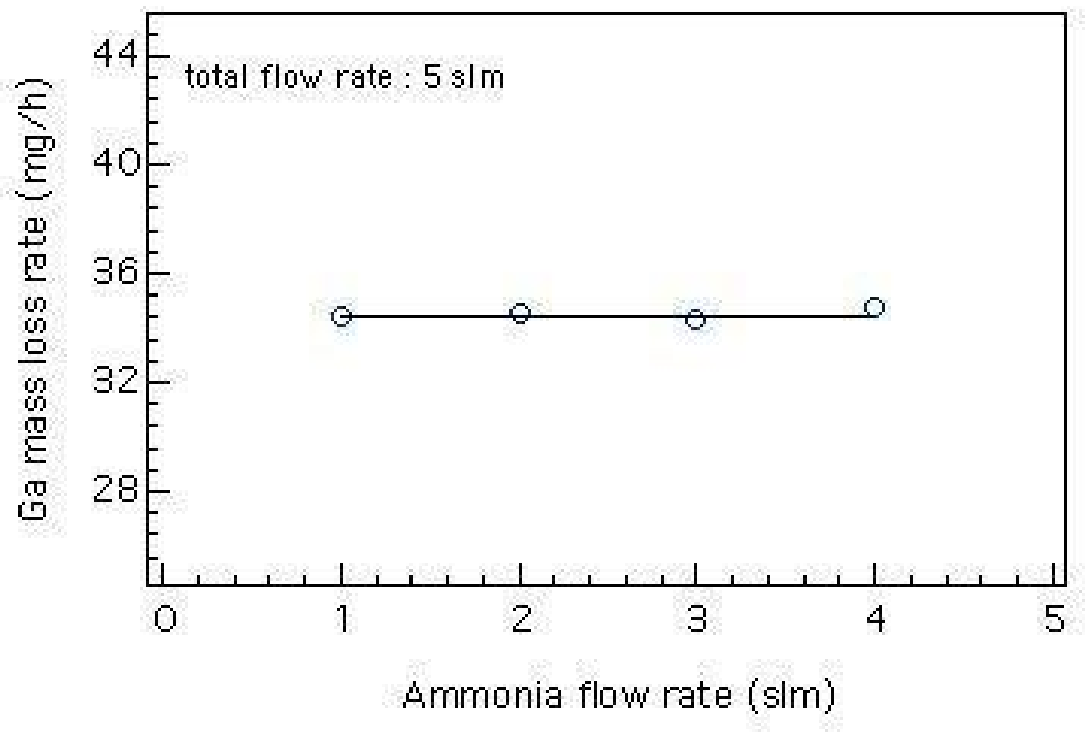

Figure 11. Ga mass loss rate as a function of $\mathrm{NH}_{3}$ flow rate at constant total flow

\subsection{Summary}

The transport of Ga species from source-to-substrate in a vapor growth system under different conditions was studied and experimental results were compared with respect to theoretical calculations. Despite the simplifications used in the theoretical estimations, calculated results show good agreement with the values measured experimentally. It was observed and quantified that under the $\mathrm{NH}_{3}$ atmosphere, Ga transport does not occur via the simple vapor phase transport. The use of a hot filament above the molten Ga resulted in suppression of $\mathrm{Ga}$ droplet formation, a stable source and source surface free from $\mathrm{GaN}$ crust. It was concluded that in order to obtain a steady vapor phase transport of Ga species, the contact between the molten $\mathrm{Ga}$ an $\mathrm{NH}_{3}$ must be avoided. It was shown experimentally that the novel source design prevented $\mathrm{NH}_{3}-$ molten $\mathrm{Ga}$ reaction, and $\mathrm{Ga}$ 
spattering and $\mathrm{GaN}$ crust formation on the source surface. A significantly enhanced $\mathrm{Ga}$ evaporation rate was achieved and it became possible to control Ga transport and V/III ratio in the system. 


\section{GROWTH OF GaN FROM ELEMENTAL GALLIUM AND AMMONIA VIA A MODIFIED SANDWICH GROWTH TECHNIQUE}

\subsection{Outline}

Gallium nitride $(\mathrm{GaN})$ thin films were grown on $(0001)$ sapphire substrates at $1050^{\circ} \mathrm{C}$ by controlled evaporation of gallium $(\mathrm{Ga})$ metal and reaction with ammonia $\left(\mathrm{NH}_{3}\right)$ at a total reactor pressure of 800 Torr. Pure nitrogen $\left(\mathrm{N}_{2}\right)$ was flowed directly above the molten Ga source. This flow prevented direct reaction between the molten Ga source and ammonia, which causes Ga spattering and $\mathrm{GaN}$ crust formation, substantially enhanced Ga evaporation rate and, at the same time, enabled control of Ga transport to the substrate. A growth rate of $1.4 \mu \mathrm{m} / \mathrm{h}$ was obtained at $1050^{\circ} \mathrm{C}, 800$ Torr, $3 \mathrm{slm}$ of ammonia, and $1250^{\circ} \mathrm{C} \mathrm{Ga}$ source temperature with a $24 \mathrm{~mm}$ source-to-substrate distance. XRD measurements revealed a full-width at half-maximum (FWHM) of $0.6 \mathrm{deg}$. for the (0002) GaN peak. Experimental variables and improvements in the overall growth process regarding the transport of species and the quality of the grown crystals are presented.

\subsection{Introduction}

$\mathrm{GaN}$ and its alloys with $\mathrm{AlN}$ and $\mathrm{InN}$ recently became the basic materials for shortwavelength optoelectronics, as described in Chapter 2; however, the development of GaN-based technology is still strongly limited by difficulties in obtaining high quality, large native substrates in large quantities. Due to the challenges in the growth of GaN 
crystals, novel techniques were employed as described in Section 2.2. Among the widely used techniques in GaN bulk or thick film growth, many advantages of the sandwich growth method have been reported and summarized in Chapter 2 .

In this chapter, the growth of $\mathrm{GaN}$ on sapphire with a modified sandwich growth method was investigated. Results regarding the stability of growth conditions and the quality of the grown crystals are discussed.

\subsection{Experimental}

Experiments were conducted in the system described in Chapter 3. Crystal growth of $\mathrm{GaN}$ was performed by evaporating high purity metallic $\mathrm{Ga}(99.999 \%)$ in a stream of UHP-grade $\mathrm{N}_{2}$ and $\mathrm{NH}_{3}$. In all experiments, the growth temperature was $1050^{\circ} \mathrm{C}$ while the total pressure and $\mathrm{NH}_{3}$ flow rate were varied from 50 to 800 Torr and 1 to $4 \mathrm{slm}$, respectively. In order to obtain stable and high Ga vapor phase transport at moderate temperatures, a novel source design was employed, as explained in Chapters 3 and 4. In all experiments $1 \mathrm{slm}$ of $\mathrm{N}_{2}$ was flowed over the molten Ga source. Experimental conditions are summarized in Table 4.

Table 4. Summary of experimental conditions for GaN growth

\begin{tabular}{|c|c|c|c|c|c|c|}
\hline $\begin{array}{l}\text { total } \\
\text { flow rate } \\
(\mathrm{slm})\end{array}$ & $\begin{array}{c}\mathrm{NH}_{3} \\
\text { flow rate } \\
\text { (slm) }\end{array}$ & $\begin{array}{c}\mathrm{N}_{2} \\
\text { flow rate } \\
(\mathrm{s} \operatorname{lm})\end{array}$ & $\begin{array}{c}\mathrm{N}_{2 \text { (source) }} \\
\text { flow rate } \\
\text { (slm) }\end{array}$ & $\begin{array}{c}\mathrm{P}_{\mathrm{T}} \\
\text { (Torr) }\end{array}$ & $\begin{array}{c}\mathrm{T}_{\text {substrate }} \\
\left({ }^{\circ} \mathrm{C}\right)\end{array}$ & $\mathrm{T}_{\text {source }}$ \\
\hline 5 & $1-4$ & $4-1$ & 1 & $50-800$ & 1050 & 1250 \\
\hline
\end{tabular}

Optical and scanning electron microscopes (SEM) were used to characterize the crystal surface morphology. X-ray diffraction (XRD) analysis was used to determine crystallinity of the deposited films. X-ray energy dispersive analysis (EDX) was 
employed for chemical characterization and Photoluminescence (PL) technique was used to evaluate the optical crystal quality.

\subsection{Results and Discussion}

\subsubsection{Stable Ga source}

In all experiments, $1 \mathrm{slm}$ of $\mathrm{N}_{2}$ was flowed over the molten Ga source. After each of these experiments a clean Ga source surface, free of $\mathrm{GaN}$ crust, was obtained indicating that the $\mathrm{NH}_{3}$ - liquid Ga surface reactions were suppressed [101]. An evaporation rate of about $35 \mathrm{mg} / \mathrm{h}$ was obtained at a source temperature of $1250^{\circ} \mathrm{C}$. The Ga mass loss rate was kept constant by keeping the $\mathrm{N}_{2}$ flow rate over the source constant.

Ga mass loss rate in the system depended on the source temperature, $\mathrm{N}_{2}$ flow rate above the molten $\mathrm{Ga}$ and the total pressure. The main temperature dependence is due to the exponential dependence of the equilibrium Ga vapor pressure on temperature. The effect of $\mathrm{N}_{2}$ (source) flow rate and the total pressure on the Ga mass flow rate is similar to that in precursor delivery systems used in CVD processes to introduce vapors of source reagents to the CVD tool. It was found that the Ga mass loss rate was directly proportional to the $\mathrm{N}_{2}$ (source) flow rate, but inversely proportional to the total pressure, $P_{T}[102,103]$. This behavior is plotted in Figure 12. 


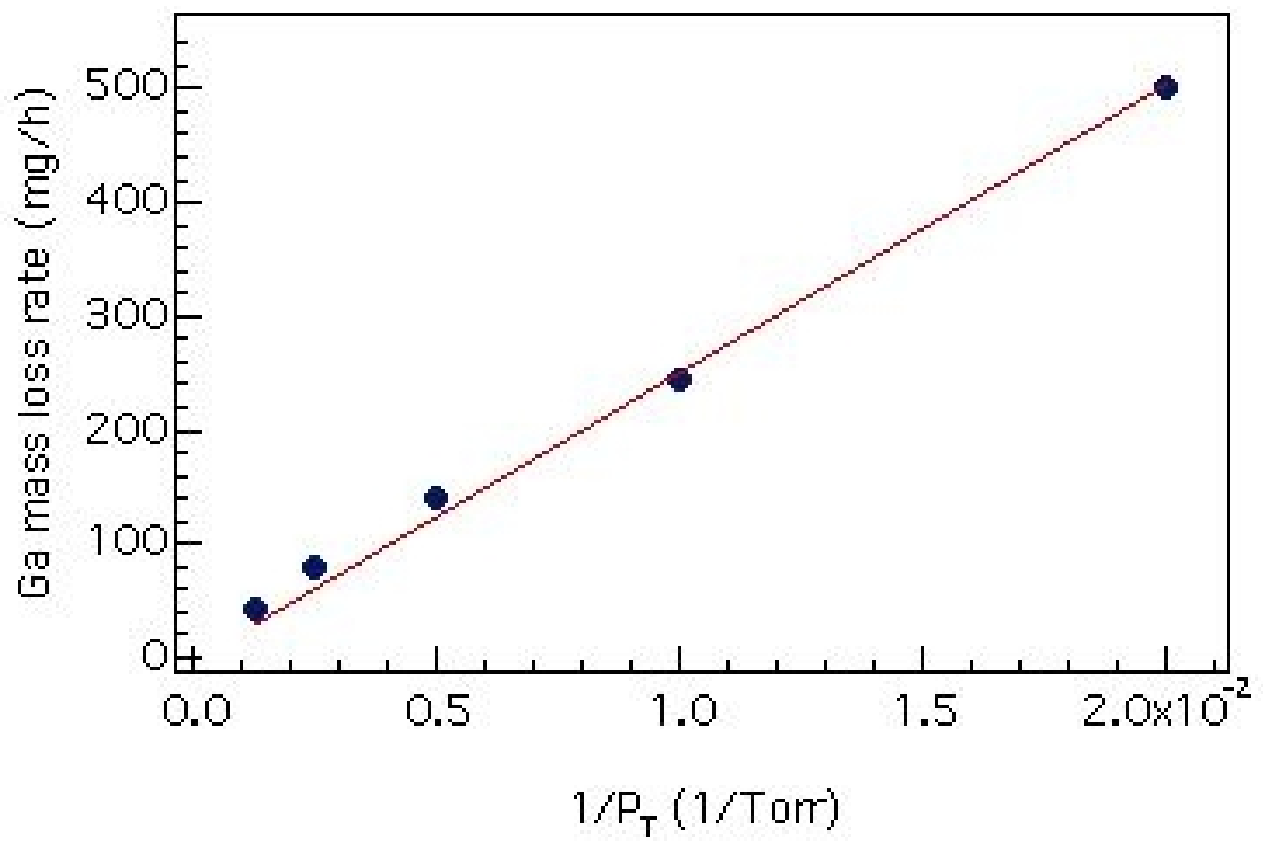

Figure 12. Plot of Ga mass loss rate vs. 1/total pressure, $1 / P_{T}$

\subsubsection{Growth Morphology and Kinetics}

Figure 13 shows the influence of the ammonia flow rate which represents the effect of $\mathrm{V} / \mathrm{III}$ ratios on crystal growth. GaN deposited under $\mathrm{NH}_{3}$ flow of $1 \mathrm{slm}$ consist of hexagonal islands. These islands tend to grow more laterally with increasing V/III ratio, compare Figures 13(b) and 13(c). A further increase of the V/III ratio results in growth of polycrystalline GaN.

A growth rate of $1 \mu \mathrm{m} / \mathrm{h}$ was obtained at $1050^{\circ} \mathrm{C}, 800$ Torr, $3 \mathrm{slm}$ of ammonia, $1250^{\circ} \mathrm{C} \mathrm{Ga}$ source temperature, a V/III ratio of 10000 and a $24 \mathrm{~mm}$ source-to-substrate distance. The growth rate increased slightly with increasing $\mathrm{NH}_{3}$ flow rate, as shown in Fig. 14. 

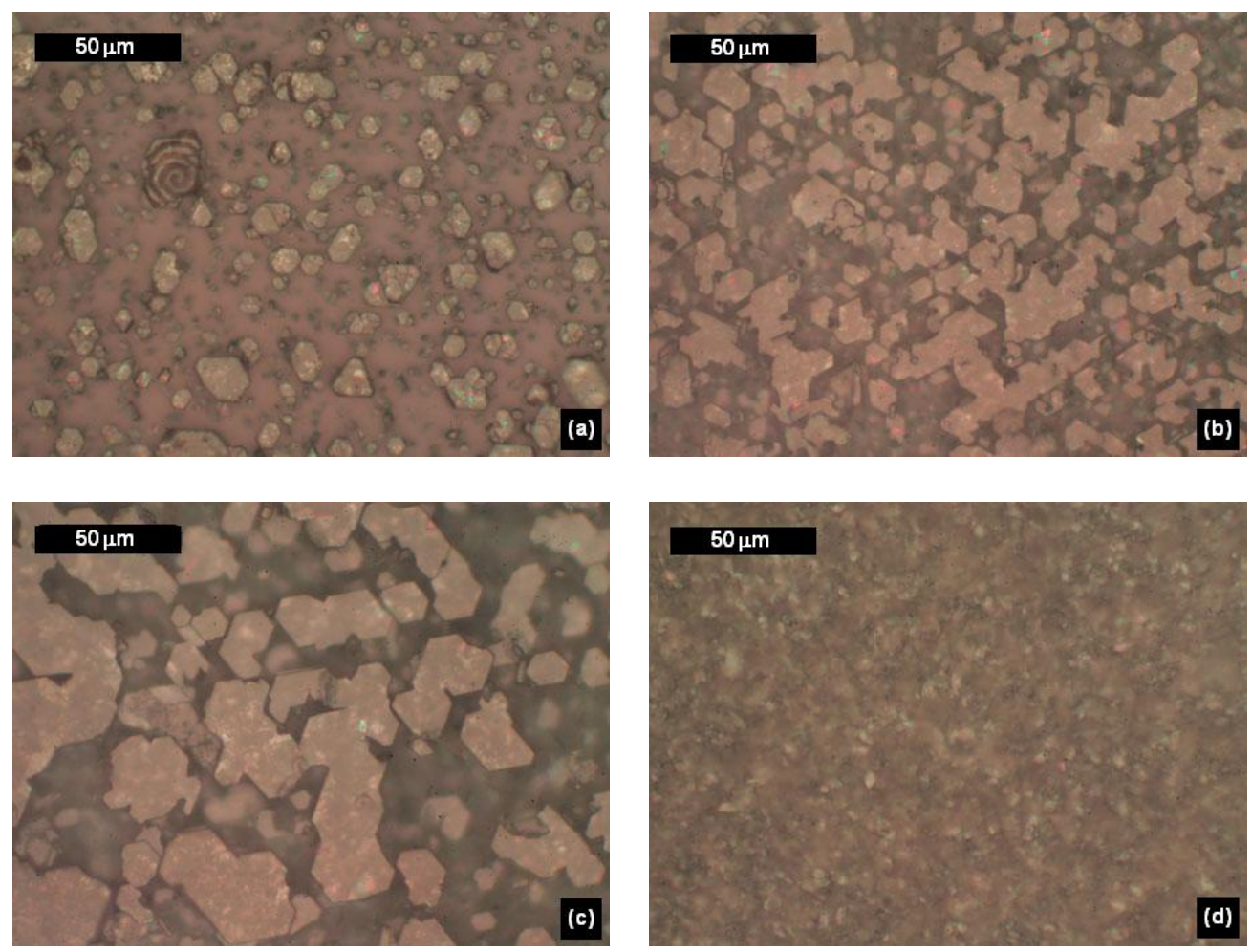

Figure 13. Surface morphologies of GaN deposited directly on sapphire under different $\mathrm{NH}_{3}$ flow rates (a) $1 \mathrm{slm}$, (b) $2 \mathrm{slm}$, (c) $3 \mathrm{slm}$, (d) $4 \mathrm{slm}$.

The growth rates obtained at different total pressures are presented in Fig. 15. The deposition rates up to $10 \mu \mathrm{m} / \mathrm{h}$ were obtained at a total reactor pressure of 50 Torr. It was also observed that the ratio of deposition rate to Ga mass loss rate for each experiment remained constant and evaporation normalized growth rate was found to be independent of the total reactor pressure. A detailed study on this subject together with the analysis of growth characteristics are covered in Chapter 6. 


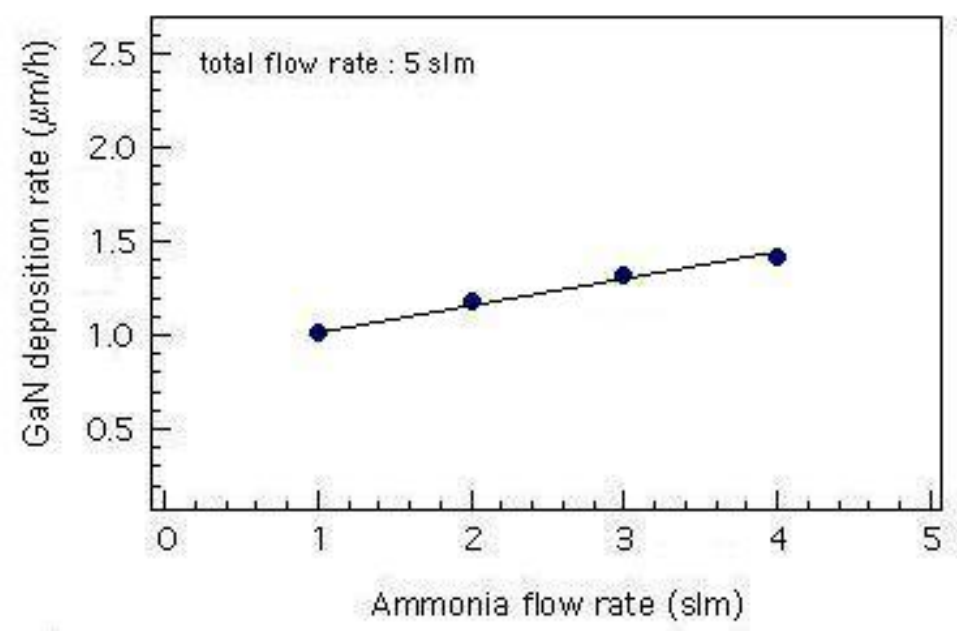

Figure 14. GaN deposition rate versus $\mathrm{NH}_{3}$ flow rate

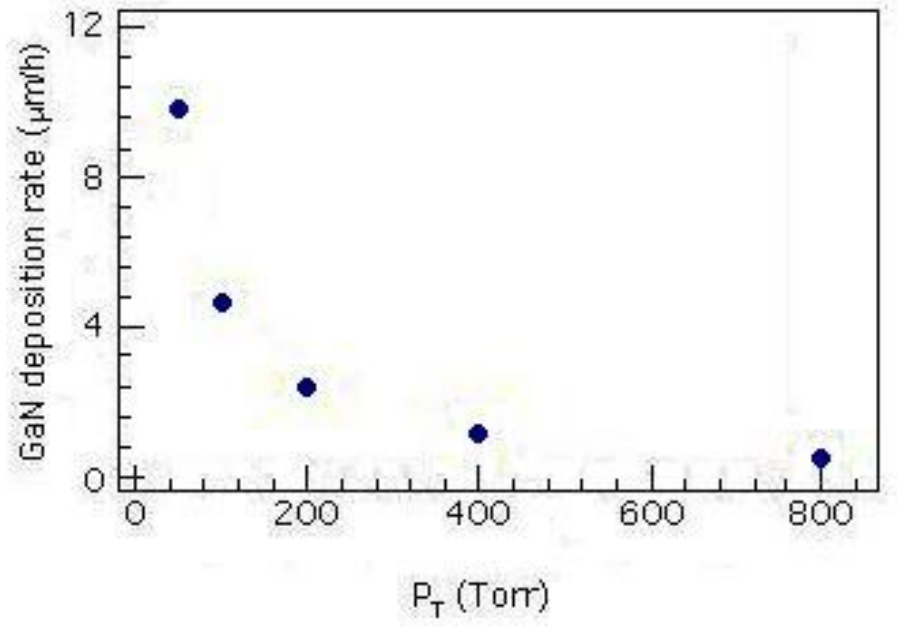

Figure 15. Plot of GaN deposition rate versus total pressure, $P_{T}$ 


\subsubsection{Crystal Characterization}

$\mathrm{XRD}$ analysis of the grown samples was performed using $\mathrm{CuK}_{\alpha}$ line and a representative result is presented in Fig. 16. The degree of in-plane crystallographic orientation was measured by the width of the diffraction peak in a $\chi$-scan. A FWHM of $0.6^{\circ}$ was obtained for the diffraction peak in a $\chi$-scan, Fig. 17

The EDX chemical analysis result presented in Fig. 18 shows only Ga and N peaks; the contamination is below the detection limits of the technique, 0.1 at. $\%$ [104].

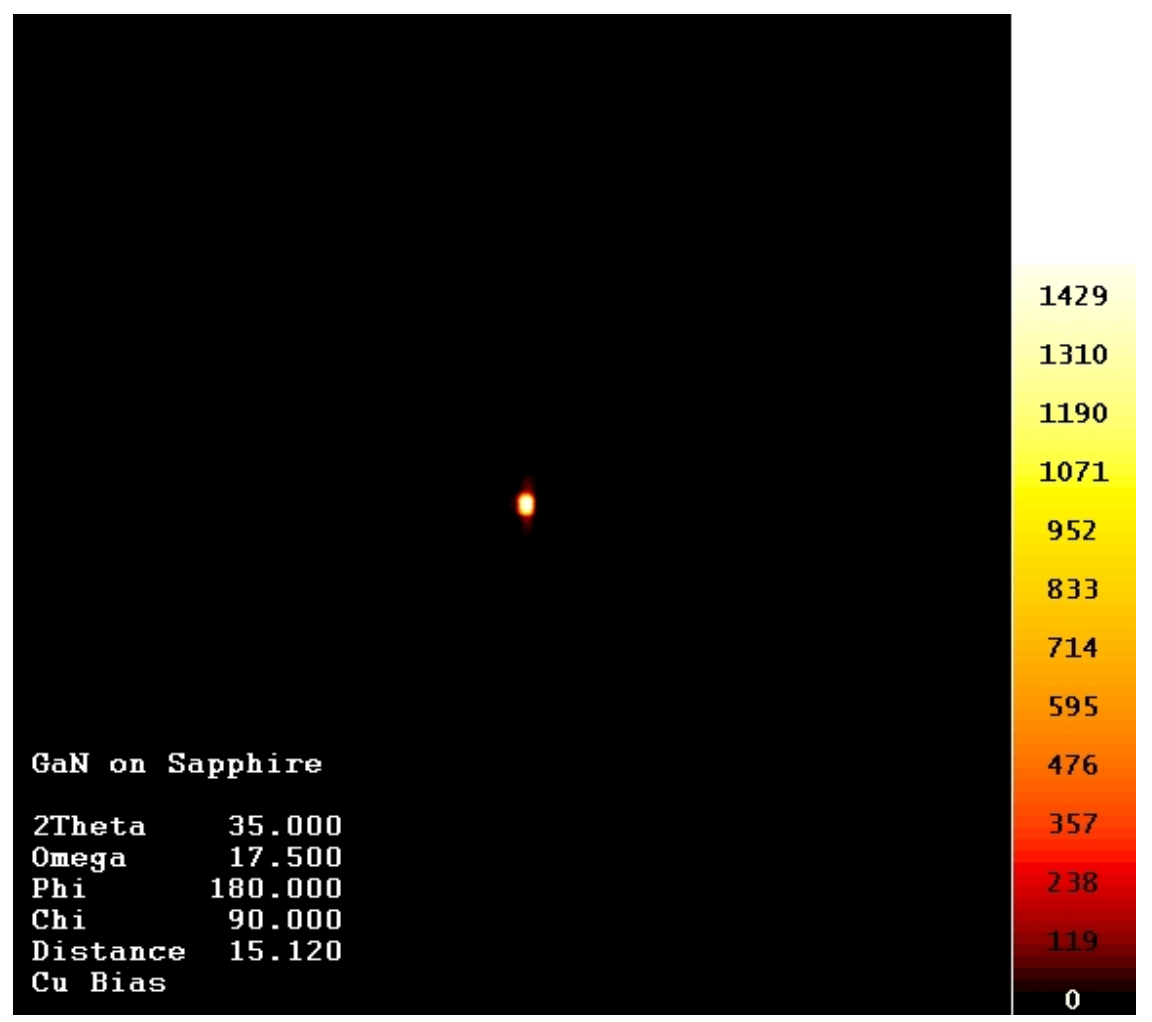

Figure 16. XRD analysis of a (0002) GaN epilayer deposited at $1050^{\circ} \mathrm{C}$ on $c$-plane sapphire 


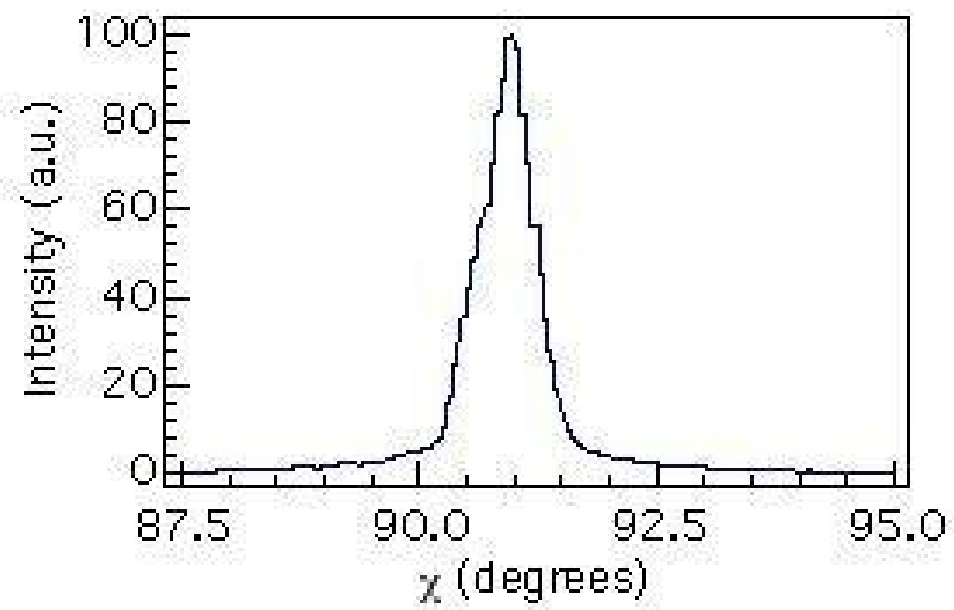

Figure 17. $\chi$-scan $\mathrm{X}$-ray diffraction of (0002) GaN epilayer deposited at $1050^{\circ} \mathrm{C}$ on cplane sapphire

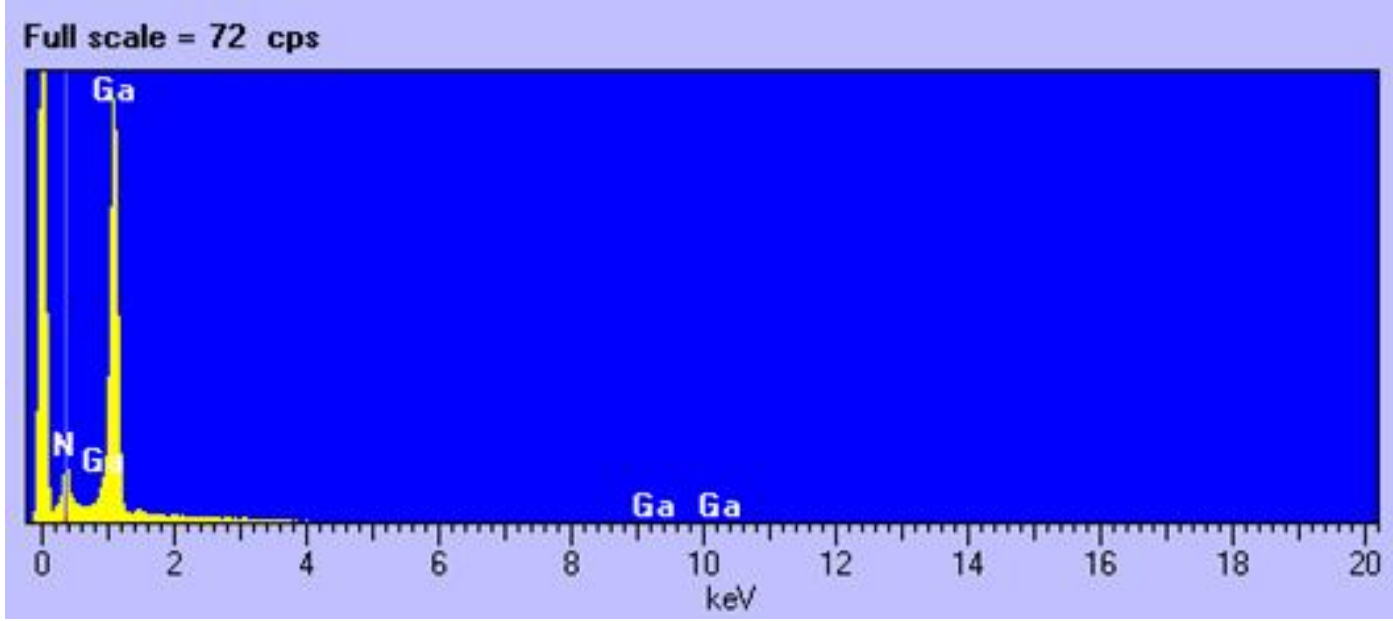

Figure 18. EDX of GaN epilayer deposited at $1050^{\circ} \mathrm{C}$ on c-plane sapphire. 
Fig. 19 shows a typical room temperature PL spectrum of GaN samples. A HeCd laser with a wavelength of $325 \mathrm{~nm}$ was used to excite the samples. Strong emission at $367 \mathrm{~nm}(\sim 3.4 \mathrm{eV})$ and an FWHM of $28 \mathrm{~nm}(255 \mathrm{meV})$ was observed. The yellow luminescence band is thought to be related to non-stoichiometric point defects [105].

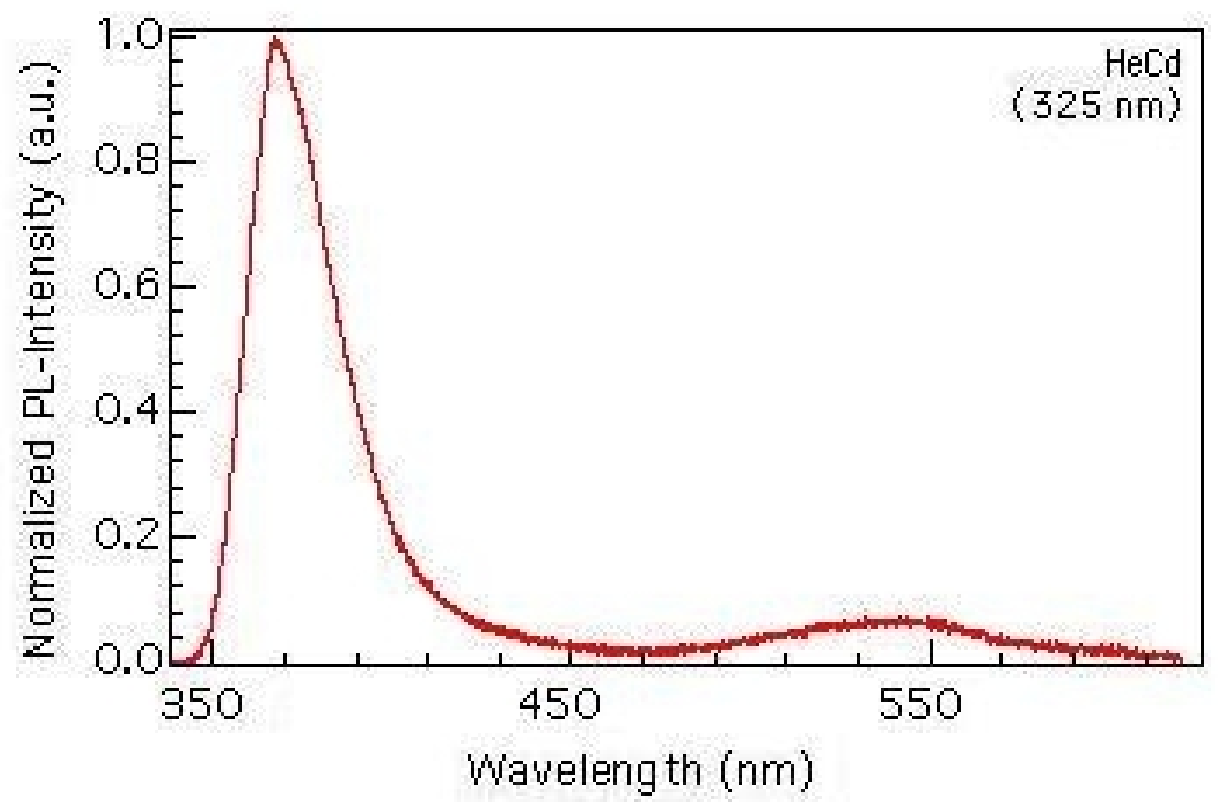

Figure 19. Photoluminescence spectrum of GaN epilayer deposited at $1050^{\circ} \mathrm{C}$ on cplane sapphire

\subsection{Summary}

Gallium nitride films were grown on (0001) sapphire substrates at $1050^{\circ} \mathrm{C}$ by controlled evaporation of Ga metal and reaction with $\mathrm{NH}_{3}$. Surface morphology of the deposited layers was examined by optical and scanning electron microscopy. XRD analysis was used to determine crystallinity of the deposited films and revealed that the 
grown material was single crystalline and epitaxially grown on the sapphire wafer. EDX analysis was employed for the chemical characterization of the samples and showed that the deposited material contained only Ga an N elements. Room temperature PL spectrum demonstrated the optical quality of the grown samples. The yellow band luminescence was attributed to the non-stoichiometric point defects such as $\mathrm{N}$ vacancies.

This work demonstrates the feasibility of the process for the growth of GaN epilayers. However, the process needs further improvement which would allow more efficient delivery of $\mathrm{NH}_{3}$ to the substrate region in order to increase the crystal quality and the growth rate. A more detailed discussion on this subject can be found in Chapter six. 


\section{MASS TRANSFER IN GaN GROWTH FROM ELEMENTAL GALLIUM AND AMMONIA VIA A MODIFIED SANDWICH GROWTH TECHNIQUE}

\subsection{Outline}

A one-dimensional mass transport model based on total reactor pressure, gas flow rates and source temperature was developed for the growth of $\mathrm{GaN}$ with a modified sandwich growth technique and verified with growth results. Theoretical calculations as well as growth rate measurements for different ammonia flow rates and source-tosubstrate distances showed that the maximum growth rate was controlled by transport of both Ga species and reactive ammonia to the substrate surface. A growth rate of $1.4 \mu \mathrm{m} / \mathrm{h}$ was obtained at $1050^{\circ} \mathrm{C}, 800$ Torr, $3 \mathrm{slm}$ of ammonia, and $1250^{\circ} \mathrm{C}$ Ga source temperature with a $24 \mathrm{~mm}$ source-to-substrate distance.

\subsection{Introduction}

The lack of III-Nitride substrates for homoepitaxial growth has been and remains to be the main technological issue in the development of III-Nitride based devices. For the bulk growth of GaN, high crystal growth rates and controlled crystal growth over a large area need to be achieved.

Among the various bulk/thick crystal growth techniques, vapor phase transport methods have been reported to be advantageous due to use of the simplest source species, high yield of the growth components and high growth rates [92]. In the vapor phase 
transport methods, understanding of the growth process is important for the control of the operating conditions as well as the cost of the process which makes the growth modeling an important tool. Significant progress in mathematical modeling of the vapor phase transport methods for bulk $\mathrm{SiC}$ growth have been reported in the literature [106-109]. Similar growth methods for bulk growth of AlN became subject of recent studies and many transport and thermodynamic studies on the sublimation growth of AlN have been reported [64, 110-115]. Encouraged by these achievements, analogous growth methods were employed to the GaN growth with slight modifications as explained in Section 2.2. Baranov et al. [60] have studied the gas dynamics and the supply of the main gaseous species into the growth cell in a reactor for GaN crystal growth by a sublimation sandwich technique (SST). More recently, Wu et al. [116] reported on the physical modeling of GaN growth using SST.

In this chapter, GaN growth characteristics and species transport properties were investigated in order to determine the GaN growth rate and consequently optimize the experimental parameters to obtain higher growth rates. Results regarding the growth conditions and the validity of the calculations were discussed.

\subsection{Growth Characteristics}

In the growth process, described in Chapter 3, Ga metal evaporates and travels towards the substrate by a forced flow of $\mathrm{N}_{2}$ (source) as shown in Figure 20. 


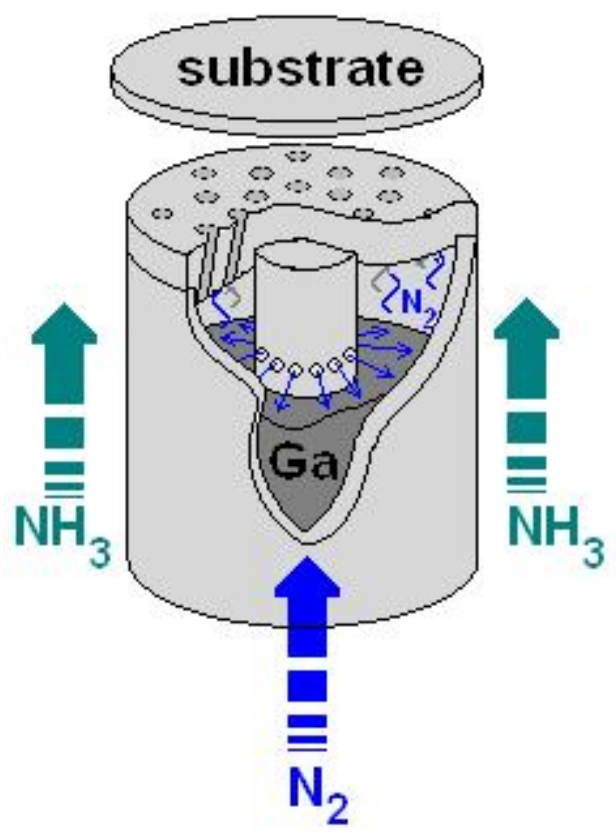

Figure 20. Schematic illustration of the modified sandwich configuration

Experimental results at different total pressures are presented in Fig. 21(a) and (b). It was observed that the ratio of deposition rate to Ga mass loss rate in each experiment remained constant. This showed that the process was mass transport limited.
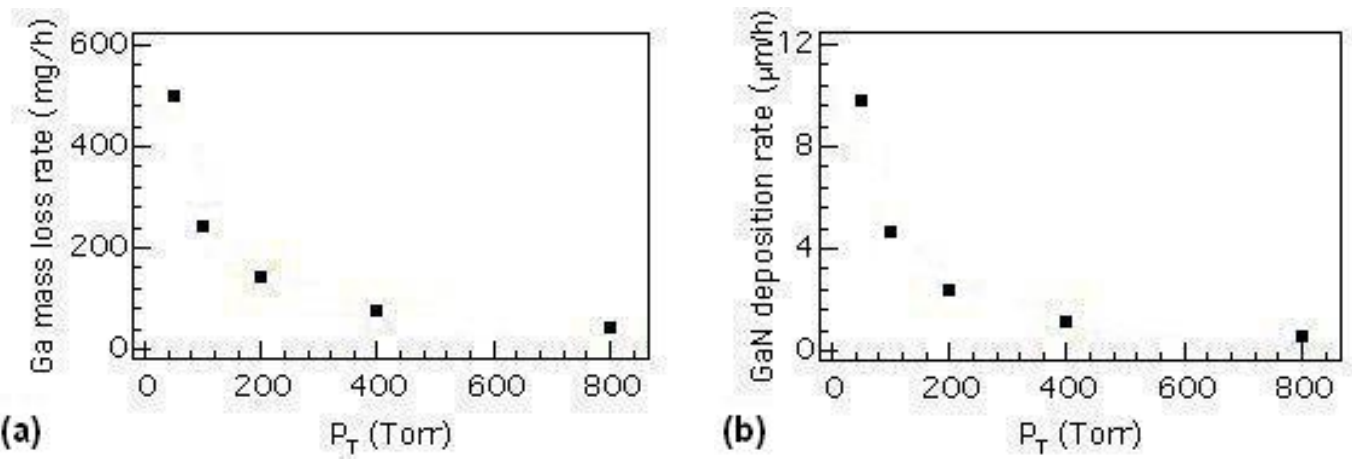

Figure 21. (a) Plot of Ga mass loss rate versus total pressure, $P_{T}$ (b) GaN deposition rate versus total pressure, $P_{T}$ 
Characteristic number calculations according to the experimental parameters and chamber geometry revealed that the state of the gas was viscous and the flow laminar (see Appendix A). In the viscous flow regime, the flow velocity drops rapidly to zero across the boundary layer near the substrate surface. According to the boundary layer approximation, the flow is nearly stagnant within the boundary layer. The mixing of gases is assumed to occur beyond the boundary layer, in the main gas stream. At the boundary layer edge, the reactant partial pressure is equal to $P_{i}$, where the reactants are $\mathrm{Ga}$ and $\mathrm{NH}_{3}$, and decreases toward the surface until it reaches an equilibrium value. This provides a concentration gradient $\Delta P_{i} / \delta_{o}$ that is the driving force for the diffusion of the $i^{\text {th }}$ specie. Consequently, the growth rate $\dot{G}_{G a N}$ in the system can be formulized in a linear approximation as

$$
\dot{G}_{\text {GaN }} \approx K(T) D_{i} \frac{\Delta P_{i}}{\delta_{o}}
$$

where $D_{i}$ is the diffusivity of reactants, $\delta_{o}$ the boundary layer thickness and $K(T)$ includes temperature dependent terms. Diffusivity in the boundary layer is inversely proportional to the total pressure $P_{T}$ and the boundary layer thickness depends on the kinematic viscosity and gas velocity as

$$
\begin{aligned}
& \delta_{o}=\left(\frac{v}{u}\right)^{1 / 2} \\
& \text { Kinematic viscosity: } v=\left(\frac{\eta}{\rho}\right) \quad \eta \text { : dynamic viscosity } \\
& \rho \text { : gas density }
\end{aligned}
$$


Gas velocity: $u=\frac{Q}{P_{T} A}$,

where $Q$ is the throughput, $P_{T}$ the total reactor pressure and $A$ the cross sectional area. Since both the kinematic viscosity and the gas velocity are inversely proportional to the total pressure $P_{T}$, it can be predicted form Eq (7) that the boundary layer thickness is independent of the total pressure. Assuming complete depletion of the reactants at the substrate surface, i.e. $P_{i}^{e q}=0$ and $\Delta P_{i} \cong P_{i}$, and relating the velocity of the gas and the partial pressure of the different species to the flow rates, the growth rate becomes

$$
\dot{G}_{G a N} \approx K(T) \frac{f_{i}}{\sqrt{f_{T}}} \quad \text { or } \quad \approx K(T) \frac{P_{i}}{P_{T}} \sqrt{f_{T}}
$$

where $f_{i}$ is the flow rate of the $i^{t h}$ specie, $f_{T}$ is the total flow rate and $K(T)$ includes temperature dependent terms. An evaporation rate-normalized growth rate defined as in Eq. (11) reveals that at a constant growth temperature and total flow rate, the normalized growth rate is independent of total pressure. The experimental verification of this behavior is presented in Fig. 22.

$$
\bar{G}(P) \approx \frac{\dot{G}_{G a N}}{f_{i}} \approx \frac{1}{\sqrt{f_{T}}}
$$

The model predicts that the maximum growth rate can be controlled by the transport of both Ga species and reactive ammonia to the substrate surface. However, the key problem in improving the crystal growth rate in present reactor was found to be the supply of sufficient amount of active nitrogen species to the substrate. As known, decomposition of $\mathrm{NH}_{3}$ is a mildly endothermic process and thermodynamically almost all the $\mathrm{NH}_{3}$ decomposes into $\mathrm{N}_{2}$ and $\mathrm{H}_{2}$ at temperatures higher than $300^{\circ} \mathrm{C}$ [117]. 


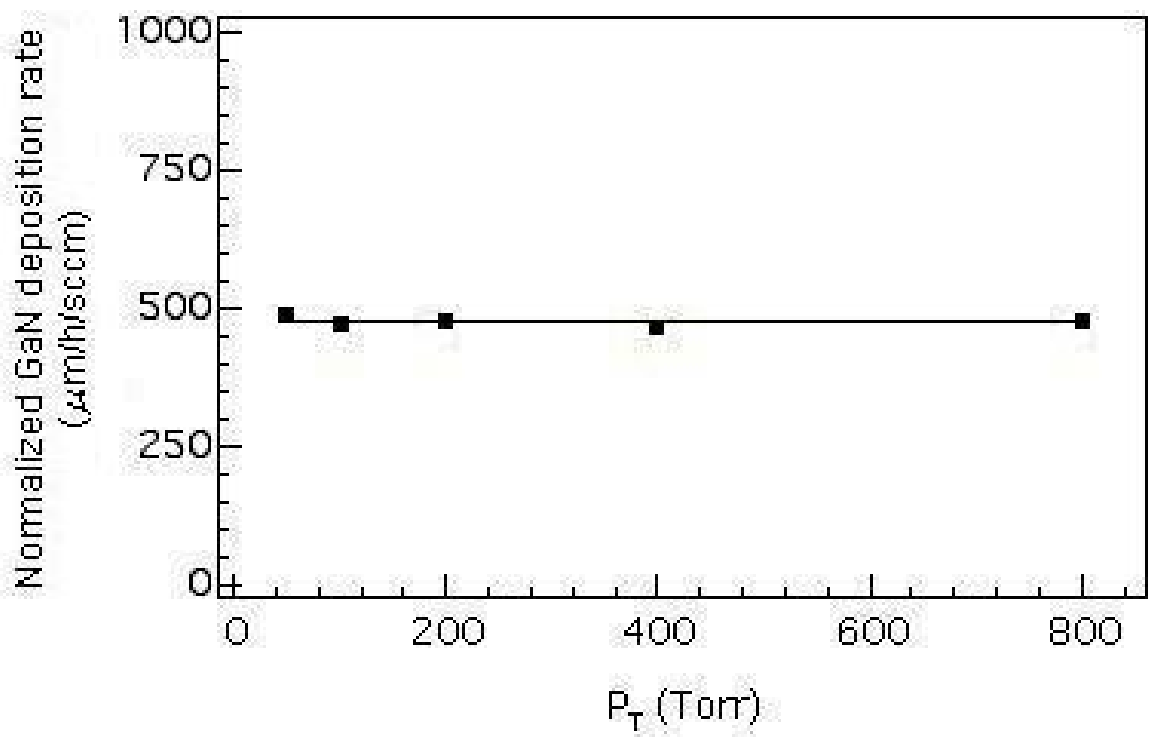

Figure 22. Plot of evaporation normalized growth rate versus total pressure, $P_{T}$

It is also well known that $\mathrm{NH}_{3}$ decomposition is a catalytic process [118] and the extent of the decomposition strongly depends on the growth conditions and the equipment. In the present growth system, alumina tube walls, BN and Mo-parts act as catalysts for the $\mathrm{NH}_{3}$ decomposition until it reaches the substrate. They change the activation energy of decomposition by providing an alternate pathway for the decomposition reaction. The decomposition rate has an exponential dependence on temperature determined by the Arrhenius equation. A heater temperature of $1650^{\circ} \mathrm{C}$ was employed to reach a source temperature of $1250^{\circ} \mathrm{C}$. This resulted in a temperature of around $1400^{\circ} \mathrm{C}$ on the inner surface of the alumina tube at which the extent of $\mathrm{NH}_{3}$ decomposition is enormous [119]. Optical microscopy characterization of the deposited films revealed that as the deposition rate increases by increasing reactant fluxes to the substrate at a constant V/III ratio, crystal color becomes darker, and in severe cases, 
results in Ga rich needle formation. A more detailed study on ammonia decomposition in the growth system can be found in Appendix C.

\subsection{Summary}

Gallium nitride films were grown on (0001) sapphire substrates at $1050^{\circ} \mathrm{C}$ by controlled evaporation of $\mathrm{Ga}$ metal and reaction with $\mathrm{NH}_{3}$ via a modified sandwich technique. Growth characteristics were described by a mass transport model based on process parameters and experimentally verified. Results showed that the maximum growth rate was controlled by the transport of both Ga species and reactive ammonia to the substrate surface. A growth rate of $1.4 \mu \mathrm{m} / \mathrm{h}$ was obtained at $1050^{\circ} \mathrm{C}, 800$ Torr, $3 \mathrm{slm}$ of ammonia, and $1250^{\circ} \mathrm{C} \mathrm{Ga}$ source temperature at a $24 \mathrm{~mm}$ source-to-substrate distance. It was found that the process required a more effective supply of $\mathrm{NH}_{3}$ to the substrate in order to increase the crystal quality and the growth rate. 


\section{SUMMARY AND FUTURE WORK}

This work mainly focused around the process development for the growth of GaN crystals from elemental $\mathrm{Ga}$ and $\mathrm{NH}_{3}$. One of the biggest challenges of working with $\mathrm{Ga}-$ $\mathrm{NH}_{3}$ system was the instability of molten Ga at elevated temperatures, especially between $1100-1200^{\circ} \mathrm{C}$. Preliminary experiments revealed that the eruptions on the molten $\mathrm{Ga}$ surface caused spattering of the Ga and the formation of macro-sized Ga droplets on the

growth surface. The contact of a spattered Ga droplet with an already formed GaN crystal disturbed the crystal growth. In addition, it was observed in the same experiments that the growth eventually ceased due to the formation of GaN crust on the molten Ga source surface. Therefore, in the first part of this study, transport characteristics of Ga species from source-to-substrate during the GaN growth process and the role of ammonia-liquid Ga reaction on the transport were investigated. Experimental results under different conditions were studied and compared to theoretical predictions to quantify the mechanism of transport in the vapor growth technique. It was observed and quantified that under the $\mathrm{NH}_{3}$ atmosphere Ga transport occurred predominantly by cluster rather than vapor phase transport.

In this work, the majority of the effort has been spent on a growth cell design that could prevent the direct reaction between the molten $\mathrm{Ga}$ and $\mathrm{NH}_{3}$ and enable reproducible and stable growth conditions. It was observed that in order to obtain steady vapor phase transport of $\mathrm{Ga}$ species the contact between the molten $\mathrm{Ga}$ an $\mathrm{NH}_{3}$ must be avoided. The use of a hot filament above the Ga resulted in suppressed Ga droplet formation, stable source and source surface free of GaN crust, which also supports the 
hypothesis. One drawback of this approach was that due to small source-to-substrate distances, the filament significantly affected the temperature of the substrate surface, which in turn affected the crystal quality.

Therefore, a novel Ga source design was employed in an effort to obtain a stable and high vapor phase transport of Ga species at moderate temperatures. In this design, pure $\mathrm{N}_{2}$ was flowed directly above the molten Ga source. This flow prevented the direct contact between the molten $\mathrm{Ga}$ and $\mathrm{NH}_{3}, \mathrm{Ga}$ spattering, and $\mathrm{GaN}$ crust formation on the source surface. A significantly enhanced Ga evaporation rate was achieved and it became possible to control Ga transport and V/III ratio in the system.

Gallium nitride films were grown on (0001) sapphire substrates at $1050^{\circ} \mathrm{C}$ by controlled evaporation of Ga metal and reaction with $\mathrm{NH}_{3}$. Experimental results under different ammonia flow rates demonstrated the effect of V/III ratio on the crystal growth. It was observed that the hexagonal $\mathrm{GaN}$ islands obtained under $1 \mathrm{slm}$ of $\mathrm{NH}_{3}$ flow rate tended to grow more laterally with increasing $\mathrm{NH}_{3}$ flow rate at a constant $\mathrm{Ga}$ evaporation rate. Further increase in V/III ratio resulted in polycrystalline growth of GaN. The surface morphology of the deposited layers was examined by optical and scanning electron microscopies. XRD analysis was used to determine crystallinity of the deposited films and revealed that the grown material was single crystalline and epitaxially grown on the sapphire wafer. EDX analysis was employed for the chemical characterization of the samples and showed that the deposited material contained only $\mathrm{Ga}$ an $\mathrm{N}$ elements. The room temperature PL spectrum demonstrated the optical quality of the grown samples. The observed yellow band luminescence was attributed to the non-stoichiometric point defects such as $\mathrm{N}$ vacancies. 
Growth characteristics were described by a mass transport model based on process parameters and experimentally verified. The results showed that the process was mass transport limited and the maximum growth rate was controlled by the transport of both Ga species and reactive ammonia to the substrate surface. A growth rate of $1.4 \mu \mathrm{m} / \mathrm{h}$ was obtained at $1050^{\circ} \mathrm{C}, 800$ Torr, $3 \mathrm{slm}$ of ammonia flow rate, and $1250^{\circ} \mathrm{C}$ Ga source temperature at a $24 \mathrm{~mm}$ source-to-substrate distance. It was found that the process required effective supply of $\mathrm{NH}_{3}$ to the substrate in order to increase the crystal quality and the growth rate.

This work demonstrates and discusses the feasibility of the process for growth of $\mathrm{GaN}$ from elemental $\mathrm{Ga}$ and $\mathrm{NH}_{3}$. The key challenge in improving the crystal growth rate in this system was found to be the supply of sufficient amount of active nitrogen species to the substrate. Calculations of the catalytic $\mathrm{NH}_{3}$ decomposition rate revealed that the extent of decomposition strongly depended on the growth conditions and equipment geometry. Alumina tube walls, $\mathrm{BN}$ and Mo-parts act as catalysts for $\mathrm{NH}_{3}$ decomposition. The decomposition rate had an exponential dependence on temperature determined by the Arrhenius equation. In the growth process a heater temperature of $1650^{\circ} \mathrm{C}$ was employed to reach a source temperature of $1250^{\circ} \mathrm{C}$. This resulted in a temperature of around $1400^{\circ} \mathrm{C}$ on the inner surface of the alumina tube at which the extent of $\mathrm{NH}_{3}$ decomposition is enormous.

Optical microscopy characterization of the deposited films revealed that as the deposition rate increased by increasing reactant fluxes to the substrate at a constant $\mathrm{NH}_{3} / \mathrm{Ga}$ ratio, crystal color became darker until a Ga rich needle formation was observed. The process needs further improvement which would allow the supply of active $\mathrm{NH}_{3}$ to 
the substrate region in order to achieve the growth of high quality thick GaN layers of high growth rates. 


\section{REFERENCES}

1. M. E. Levinshtein, S. L. Rumyantsev, M. S. Shur, "Properties of Advanced Semiconductor Materials", John Wiley \& Sons, Inc., NY (2001).

2. S. Nakamura, S. Pearton, G. Fasol, "The Blue Laser Diode: The Complete Story", Springer-Verlag, Berlin Heidelberg (2000).

3. M. O. Manasreh, in M. O. Manasreh (Ed.), "III-Nitride Semiconductors:

Electrical, Structural and Defect Properties”, Elsevier Science B.V., Amsterdam (2000).

4. H. Morkoc, in Y. S. Park (Ed.), "Semiconductor and Semimetals", 52, Academic Press, San Diego (1998).

5. H.P. Maruska, J.J. Tietjen, Appl. Phys. Lett. 15 (1969) 327.

6. H. Morkoc, "Nitride Semiconductors and Devices", Springer-Verlag, Berlin Heidelberg (1999).

7. S. N. Mohammad, A. Salvador, H. Morkoc, Proc. IEEE 83, 1306 (1995).

8. S.J. Pearton and R.J. Shul, in J. I. Pankove and T.D. Moustakas (Eds.) “Semiconductor and Semimetals", 50, Academic Press, San Diego (1998).

9. C.B. Vartuli, S. J. Pearton, C. R. Abernathy, and J. D. McKenzie, Solid State Electron., 41, 1947 (1997).

10. A. Trampert et al., J. I. Pankove and T.D. Moustakas (Eds.) "Semiconductor and Semimetals", 50, Academic Press, San Diego (1998). 
11. V. Bougrov et al., in M.E. Levinshtein, S.L. Rumyantsev, M.S. Shur (Eds.), "Properties of Advanced Semiconductor Materials", John Wiley \& Sons, Inc., NY (2001).

12. M. Leszczynski, T. Suski, P. Perlin, H. Tolsseyre, I. Grzegory, M. Bockowski, J. Jun, S. Porowski, and J. Major, J. Phys. D: Appl. Phys. 28, A149 (1995).

13. T Azuhata, T. Sota, and K. Suzuki, J. Phys: Condens. Mater. 8, 3111 (1996).

14. J. vanVetchen, Phys. Rev. B, 7, 1479 (1973).

15. S. Strite and H. Morkoc, J. Vac. Sci. Technol. B, 10(4) (1992) 1237.

16. D.C. Look, D.C. Reynolds, J.W. Hemsky, J. R. Sizelove, R.L. Jones and R.J. Molnar, Phys. Rev. Lett. 79 (1997) 2273.

17. S. Nakamura, T. Mukai, M. Senoh, J. Appl. Phys. 71 (1992) 5543.

18. H.M. Ng, D. Doppalapudi, T.D. Moustakas, N.G. Weimann and L.F. Eastman, Appl. Phys. Lett. 73 (1998) 821.

19. H. Morkoc, in F. Ren, J.C. Zolper (Eds.), "Wide Energy Bandgap Electronic Devices”, World Scientific Publishing Co., NJ (2003).

20. H. Amano, M. Kito, K. Hiramatsu and I. Akasaki, Jpn. J. Appl. Phys 28 (1989) L2112.

21. H. Amano, N. Sawaki, I. Akasaki and Y. Toyoda, Appl. Phys. Lett. 48 (1986) 353.

22. I. Akasaki, H. Amano, Y. Koide, K. Hitramnatsu and N.Sawaki, J. Crystal Growth 98 (1989) 209.

23. T.D. Moustakas, R.J. Molnar, T. Lei, G. Menon, and C.R. Eddy, Jr., Mat. Res. Soc. Proc., 242 (1992) 427. 
24. I. Akasaki and H. Amano, in J.H. Edgar (Ed.), "Properties of Group III Nitrides", INSPEC, Institution of Electrical Engineers, London (1994).

25. W.C. Johnson, J. B. Parsons and M.C. Crew, J. Phys. Chem. 36 (1932) 2651.

26. H.G. Grimmeiss and H. Koelmans, Phys. Rev. A 14 (1959) 264.

27. S. Yoshida, S. Misawa, S. Gonda, J. Vac. Sci. Technol. B 1 (1983) 250.

28. G. Popovici, H. Morkoc, in S. Pearton (Ed.), "GaN and Related Materials II", Gordon \& Breach Science Publishers, Amsterdam (2000).

29. S. Porowski, J. Crystal Growth, 189-190 (1998) 153.

30. K. Nishino, D. Kikuta and S. Sakai, J. Crystal Growth, 237-239 (2002) 922.

31. G. A. Slack. and T. F. McNelly, J. Crystal Growth, 34 (1976) 263.

32. R. Schlesser and Z. Sitar, J. Crystal Growth, 234 (2002) 349.

33. R. J. Molnar, W. Götz, L. T. Romano and N. M. Johnson, J. Crystal Growth, 178 (1997) 147.

34. I. Akasaki and H. Amano, J. Crystal Growth, 163 (1996) 86.

35. H. Morkoc, IEEE J. Selected Top. Quantum Electron., 4(3) (1998) 537.

36. E. Ejder, J. Crystal Growth, 22 (1974) 44.

37. D. Elwell, R. S. Feigelson, M. M. Simkins and W. A. Tiller, J. Crystal Growth, 66 (1984) 45.

38. M. Boćkowski, I. Grzegory, S. Krukowski, B. Łucznik, M. Wróblewski, G. Kamler, J. Borysiuk, P. Kwiatkowski, K. Jasik and S. Porowski, J. Crystal Growth, 270 (2004) 409.

39. G.A. Slack and T.F. McNelly, J. Crystal Growth, 34 (1976) 263. 
40. J. C. Rojo, G. A. Slack, K. Morgan, L. J. Schowalter, and M. Dudley, Mat. Res. Soc. Symp. Proc., 639 (2001) G1.10.

41. J.H. Edgar, L. Liu, B. Liu, D. Zhuang, J. Chaudhuri, M. Kuball, and S. Rajasingam, J. Crystal Growth, 246 (2002) 187.

42. Bickermann, M., B. M. Epelbaum, and A. Winnacker, Phys. Stat. Sol. (C), 0 (2003) 1993.

43. I. Grzegory et al., in P. Ruterana, M. Albrecht, Jorg Neugebauer, "Nitride Semiconductors, Handbook of Materials and Devices", Wiley_VCH Verlag GmbH \& Co. KGaA, Weinheim (2003).

44. M. Callahan, M. Harris, M. Suscavage, D. Bliss and J. Baily, MRS Internet J. Nitride Semicond. Res. 4 (1999) 10.

45. T. L. Chu, J. Electrochem. Soc., 118 (1971) 1200.

46. I.G. Pichugin and D.A.Yaskov, Neorg. Mat., 6 (1970) 1973.

47. D. Elwell and M. M. Elwell, Prog. Crystal Growth and Charact., 17 (1988) 53.

48. D. D. Manchon, A. S. Barker, P. J. Dean, and R. B. Zetterstrom, Solid State Comm., 8 (1970) 1227.

49. R. B. Zetterstorm, J. Mat. Sci., 5 (1970) 1102.

50. M. Aoki, M. Sano, and T. Ogino, Sago Shikenso Nempo, 34 (1975) 125.

51. S. Sakai, S. Kurai, K. Nishino, K. Wada, H. Sato, and Y. Naoi, Mat. Res. Soc. Proc., 449 (1997) 15.

52. C. M. Balkas, Z. Sitar, T. Zheleva, L. Bergman, I. K. Shmagin, J. F. Muth, R. Kolbas, R. Nemanich, and R. F. Davis, Mat. Res. Soc. Symp. Proc., 449 (1997) 41. 
53. G. Kamler, J. Zachara, S. Podsiadlo, L. Adamowicz, and W. Gebicki, J. Crystal Growth, 212 (2000) 39.

54. C. Wetzel, D. Volm, B.K. Meyer, K. Pressel, S. Nilsson, E.N. Mokhov and P.G. Baranov, Appl. Phys. Lett., 65 (1994) 1033.

55. S. Fischer, C. Wetzel, W.L. Hansen, E.D. Bourret-Chourchesne, B.K. Meyer and E.E. Haller, Appl. Phys. Lett., 69 (1996) 2716.

56. Y.A. Vodakov, M.I. Karklina, E.N. Mokhov and A.D. Roenkov, Inorgan. Mater., 17 (1980) 537.

57. Y. A. Vodakov, E. N. Mokhov, A. D. Roenkov, M.E. Boiko, and P. G. Baranov, J. Crystal Growth, 183 (1998) 10.

58. H. Shin, D.B. Thomson, R. Schlesser, R.F. Davis, Z. Sitar, J. Crystal Growth, 241 (2002) 404 .

59. H. Shin, Ph.D. Dissertation, North Carolina State University (2001).

60. P.G. Baranov, E.N. Morkov, A.O. Ostroumov, M.G. Ramm, V.V. Ratnikov, A.D. Roenkov, Yu. A. Vodakov, A.A. Wolffson, G.V. Saparin, S. Yu. Karpov, D.V. Zimina, Yu.N. Makarov and Holger Juergersen, MRS Internet J. Nitride Semicond. Res. 3 (1998) 50.

61. D.W. Pashley in J.W. Matthews (Ed.), "Epitaxial Growth, Part A", Academic Press, Inc., New York (1975).

62. R. Di Felice, J.E. Northup, and J.Neugebauer, Phys. Rev. B, 54 (1996) R17351.

63. S. Mahajan, Acta Mater., 48 (2000) 137.

64. L. Liu and J.H. Edgar, Mat. Sci. Eng. R, 37 (2002) 61. 
65. Gonsalves, M., W. Kim, V. Narayanan, and S. Mahajan, J. Crystal Growth, 240 (2002) 347.

66. R.J. Molnar in J.I. Pankove and T.D. Moustakas (Eds.), "Gallium Nitride II, Semiconductors and Semimetals, v57”, Academic Press, San Diego (1999).

67. O. Ambacher, J. Phys. D: Appl. Phys., 31 (1998) 2653.

68. D. Hull and D. J. Bacon, "Introduction to dislocations, 4th ed.", ButerworthHeinemann, Boston (2001).

69. A. Roth, "Vacuum Technology", Elsevier Science Publishers B.V., Amsterdam (1990).

70. K.F. Jensen in D.T.J. Hurle (Ed.), "Handbook of Crystal Growth 3, Thin Films and Epitaxy, Part B: Growth Mechanisms and Dynamics", Elsevier Science Publishers B.V., Amsterdam (1994).

71. D.R. Gaskell, "An Introduction to Transport Phenomena in Materials Engineering”, Macmillan Publishing Co., New York (1992).

72. H.H. Lee, "Fundamentals of Microelectronics Processing", McGraw-Hill, New York (1993).

73. S. Middleman and A.K. Hochberg, "Process Engineering Analysis in Semiconductor Fabrication”, McGraw-Hill, New York (1993).

74. D.W. Shaw in J.W. Matthews (Ed.), "Epitaxial Growth, Part A", Academic Press, London (1975).

75. M. Ohring, "Materials Science of Thin Films: Deposition and Structure, $2^{\text {nd }}$ Edition", Academic Press, San Diego (2002).

76. C. D. Thurmond and R. A. Logan, J. Electrochemical. Soc., 119(5) (1972) 622. 
77. J. Karpinski, J. Jun and S. Porowski, J. Cryst. Growth, 66 (1984) 1.

78. N. Newman, J. Ross, and M. Rubin, Appl. Phys. Lett., 62(11) (1993) 1242.

79. M. Grunze in D.A. King and D.P. Woodruff, "The Chemical Physics of Solid Surfaces and Heterogeneous Catalysis, Synthesis and Decomposition of Ammonia”, 4, Elsevier Scientific Publishing Company, Amsterdam (1982).

80. E. Kim, I. Berishev, and A. Bensaoula, J. Appl. Phys., 85(2) (1999) 1178.

81. M. Kamp, M. Mayer, A. Pelzmann, and K. J. Ebeling, Mat. Res. Soc. Symp. Proc., 449 (1997) 161.

82. M. Kamp, M. Mayer, A. Pelzmann, and K. J. Ebeling, MRS Internet J. Nitride Semicond. Res., 2 (1997) 26.

83. G. Ertl, M. Huber, J. Catal. 61 (1980) 537.

84. D. F. Davidson, K. Kohse-Hoinghaus, A. Y. Chang, and R. K. Hanson, Int. J. Chem. Kinetics, 22 (1990) 513.

85. D. Doppalapudi, T. D. Moustakas, in H.S. Nalwa (Ed.), "Handbook of Thin Film Materials, v4", Academic Press, San-Diego (2002).

86. F. A. Ponce, in S. J. Pearton (Ed.), "GaN and Related Materials II", Gordon \& Breach Science Publishers, Amsterdam (2000).

87. T. S. Zheleva, W. M. Ashmawi, O. H. Nam and R. F. Davis, Appl. Phys. Lett.,74 (1999) 15.

88. W. A. Doolittle, T. Kropewnicki, C. Carter-Coman, S. Stock, P. Kohl, N. M. Jokerst, R. A. Metzger, S. Kang, K. K. Lee, G. May, and A. S. Brown, J. Vac. Sci. Technol. B, 16 (1998) 1300. 
89. I. Grzegory, M. Bockowski, B. Lucznik, S. Krukowski, Z. Romanowski, M. Wróblewski and S. Porowski, J. Crystal Growth, 246 (3-4) (2002) 177.

90. R.J. Molnar, in J.I. Pankove and T.D. Moustakas (Eds.) "Semiconductor and Semimetals", 57, Academic Press, San Diego (1998).

91. P. R. Hageman, V. Kirilyuk, W. H. M. Corbeek, J. L. Weyher, B. Lucznik, M. Bockowski, S. Porowski and S. Müller, J. Crystal Growth 255 (3-4) (2003) 241.

92. M. Balkas, Z. Sitar, T. Zheleva, L. Bergman, I.K. Shmagin, J.F. Muth, R. Kolbas, R. Nemanich, R.F. Davis, J. Crystal Growth 208 (2000) 100.

93. D.L. Smith, "Thin Film Deposition: Principles and Practice" McGraw-Hill, New York (1995).

94. F.W. Sears, G.L. Salinger, "Thermodynamics, Kinetic Theory, and Statistical Thermodynamics", Addison-Wesley Publishing Co., Mass. (1975).

95. M. Ohring, "Materials Science of Thin Films", Academic Press, San Diego (2002).

96. R.H. Perry, D.W. Green (Eds.), “Perry's Chemical Engineers' Handbook (7th Edition)", McGraw Hill, New York (1997).

97. I. Langmuir, "Physikalische Zeitschrift” 14 (1913) 1273.

98. R.E. Honig, D.A. Kramer, RCA Review 30 (1969) 285.

99. M. Boćkowski, I. Grzegory, S. Krukowski, B. Łucznik, M. Wróblewski, G. Kamler, J. Borysiuk, P. Kwiatkowski, K. Jasik and S. Porowski, J. Crystal Growth, 270 (2004) 409.

100. Y.A. Vodakov, E.N. Mokhov, M.G. Ramm, A.D. Roenkov, A.G. Ostroumov, A.A. Wolfson, S.Yu. Karpov, Yu.N. Makarov and H. Jurgensen, MRS Symp. Proc. 482 (1998) 27. 
101. E. Berkman, R. Collazo, R. Schlesser, Z. Sitar, to be published.

102. B. Mayer, C.C. Collins, and M. Walton, J. Vac. Sci. Technol. A 19.1. (2001) 329.

103. R. J. Betsch, J. Cryst. Growth 77 (1986) 210.

104. J.I. Goldstein, D.E. Newbury, P. Echlin, D.C. Joy, A.D. Ronig, C.E. Lyman, C. Fiori, and E. Lifshin, "Scanning Electron Microscopy and X-Ray Microanalysis ( $2^{\text {nd }}$ Edition)" Plenum, New York (1992).

105. T. Ogino and M. Aoki, J. Appl. Phys. 19 (1980) 2395.

106. E. Kaldis, and M. Piechotka, in D. T. J. Hurle (Ed.) "Handbook of Crystal Growth, v2” Elsevier Science B.V., Amsterdam (1994).

107. R.H. Ma, H. Zhang, S. Ha, and M. Skronowski, J. Crystal Growth, 252 (2003) 523.

108. D. Hofmann, M. Heinze, A. Winnacker, F. Durst, L. Kadinski, P. Kaufmann, Yu. Makarov, and M. Schafer, J. Crystal Growth, 146 (1995) 214.

109. D. Hofmann, R. Eckstein, M. Kolbl, Yu. Makarov, St. G. Muller, E. Schmitt, A. Winnacker, R. Rupp, R. Stein, and J. Volkl, J. Crystal Growth, 174 (1997) 669.

110. S.Yu Karpov, D. V. Zimina, Yu. N. Makarov, E. N. Mokhov, A. D. Roenkov, M. G. Ramm, and Yu. A. Vodakov, Phys. Sat. Sol. A, 176 (1999) 435.

111. S.Yu. Karpov, A. V. Kulik, M. S. Ramm, E. N. Mokhov, A. D. Roenkov, Yu. A. Vodakov, Yu. N. Makarov, Mat. Sci.Forum, 353-356 (2001) 779.

112. S. Krukowski, J. Chem. Phys., 117 (2002) 5866.

113. A. S. Segal, S. Yu. Karpov, Yu. N. Makarov, E. N. Mokhov, A. D. Roenkov, M. G.Ramm, and Yu. A. Vodakov, J. Crystal Growth, 211(2000) 68.

114. R. Schlesser, R. Dalmau, and Z. Sitar, J. Crystal Growth, 241 (2002) 416. 
115. V. Noveski, R. Schlesser, S. Mahajan, S. Beaudoin, and Z. Sitar, J. Crystal Growth, 264 (2004) 369.

116. B. Wu, R. Ma, H. Zhang, J. Crystal Growth, 250 (2003) 14.

117. I. Barin, "Thermochemical Data of Pure Substances", VCH Publishers, Inc., Weinheim (1995).

118. M. Grunze in D.A. King and D.P. Woodruff, "The Chemical Physics of Solid Surfaces and Heterogeneous Catalysis, Synthesis and Decomposition of Ammonia”, 4, Elsevier Scientific Publishing Company, Amsterdam (1982).

119. G. Ertl and M. Huber, J. Catal., 61 (1980) 537.

120. N. Newman in J.I. Pankove and T. D. Moustakas, "Gallium Nitride (GaN) I, Semiconductors and Semimetals, v50" Academic Press, San Diego (1998).

121. R.C. Powell, N.-E. Lee, and J.E. Greene, Appl. Phys. Lett. 60 (1992) 2505.

122. Z. Yang, L.K. Li and W.I. Wang, Appl. Phys. Lett., 67 (1995) 1686.

123. V.S. Ban, J. Electrochem. Soc., 119 (1972) 761.

124. D.D. Rocasecca, R.H. Saul and O.G. Lorimor, J. Electrochem. Soc., 121 (1974) 962.

125. S.S. Liu and D.A. Stevenson, J. Electrochem. Soc., 125 (1978) 1161.

126. A. Nielsen (Ed.), “Ammonia: Catalysis and Manufacture”, Springer-Verlag, Berlin Heidelberg (1995).

127. M. Appl, “Ammonia: Principles and Industrial Practice”, Wiley-VCH, Weinheim (1999).

128. W.L. Guthrie, J.D. Sokol and G.A. Somorjai, Surf. Sci. 109 (1981) 390.

129. E. Shustorovich and A.T. Bell, Surf. Sci. Lett. 259 (1991) L791. 
130. G. Ertl and M. Huber, J. Catal. 61 (1980) 537.

131. D.G. Loffler and L.D. Schmidt, J. Catal. 44 (1976) 244.

132. Z. Kowalczyk, J. Sentek, S. Jodzis, M. Muhler and O. Hinrichsen, J. Catal. 169 (1997) 407.

133. M.C.J. Bradford, P.E. Fanning and M.A. Vannice, J. Catal. 172 (1997) 479.

134. R.W. McCabe, J. Catal. 79 (1983) 445.

135. W. Tsai and W.H.Weinberg, J. Phys. Chem., 91 (1987) 5302.

136. http://www.uyseg.org/catalysis/ammonia/amm4.htm.

137. http://www.uyseg.org/catalysis/principles/effect.htm.

138. E.F. Arkun, Degree of Master Report, North Carolina State University, 2002.

139. M. Kamp , M. Mayer, A. Pelzmann, and K. J. Ebeling, MRS Internet J. Nitride Semicond. Res., 2 (1997) 26. 


\section{APPENDIX A: REACTOR MODELLING}

A numerical simulation model was developed by Dr. Zhang's research group, in the Department of Mechanical Engineering at State University of New York (SUNY) at Stony Brook to study reactive transport phenomena inside the reactor.

\section{A.1. General Assumptions}

Based on the operating conditions and the system geometry presented in Fig. 23, the characteristic numbers were defined.

\section{A.1.1. State of the Gas}

The gas in a vacuum system can be in viscous state, in molecular state or in a state which is intermediate between these two. When a system is brought from the atmospheric pressure to "high vacuum", the gas in the system goes through all these states. The mean free path $\lambda$ of the gas molecules is small at atmospheric pressure [69] so that the flow of gas is limited by its viscosity. At low pressures, where the mean free path of the molecules is similar to the dimensions of the vacuum enclosure, the flow of gas is governed by molecular phenomena; this is the intermediate flow. At very low pressures where the mean free path is much larger than the dimensions of the vacuum enclosure, the flow is molecular. 


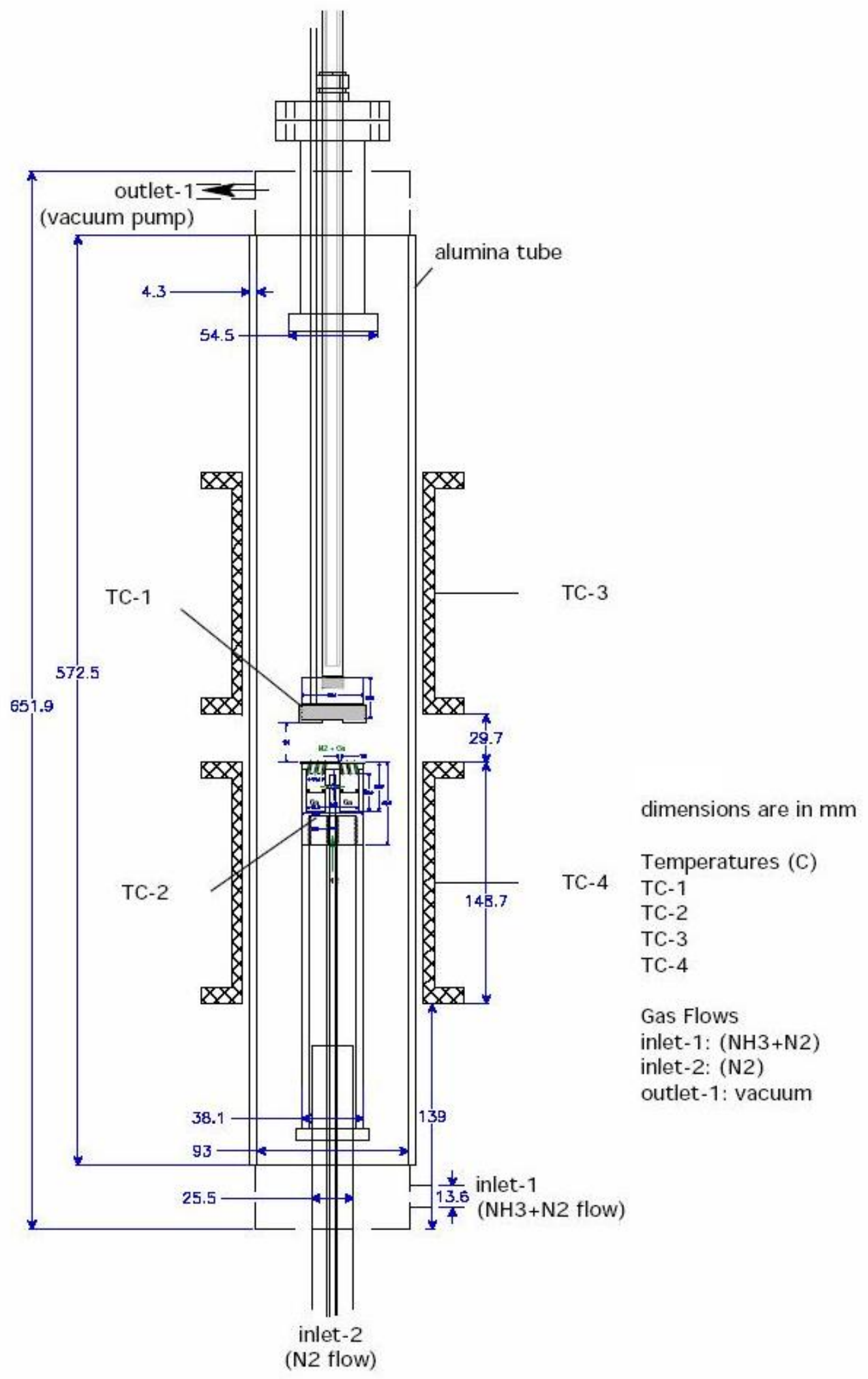

Figure 23. Drawing of the alumina reactor tube 
The state of gas is described by the Knudsen number described as

$$
\begin{aligned}
& K_{n}=\frac{\lambda}{L} \\
& \lambda=\frac{1}{\sqrt{2} \pi a^{2} n},
\end{aligned}
$$

where $\mathrm{L}$ is the characteristics distance, $\lambda$ mean free path, a molecular diameter and $n$ the number of molecules per unit volume. The viscous flow regime is operative when gas transport occurs at pressures above 20 Torr in deposition reactors of typical size [75]. For the GaN growth system studied in this work, the mean free path was calculated as 0.3 $\mu \mathrm{m}$; for the source-to-substrate distance of $2.5 \mathrm{~cm}$ as the characteristic dimension of the system, The Knudsen number was estimated as $\sim 10^{-5}$ revealing that the state of gas was viscous.

\section{A.1.2. Flow Regime}

In the state where the state of gas is viscous, the flow can be turbulent or laminar. The flowing fluid experiences two forces: inertial and viscous. The viscous forces tend to stabilize the unidirectional motion of the flow, while the inertial forces tend to disrupt the unidirectional motion. Consequently, the nature of the flow is determined by the relative magnitudes of the two forces. At low flow velocities the viscous forces dominate and the stabilizing influence causes laminar flow. However, with increasing velocity, tendency toward disruption of laminar flow increases.

The Reynold's number, the ratio of inertial forces to viscous forces, is a dimensionless quantity expressed by 


$$
\mathrm{Re}=\frac{\rho v D}{\eta}
$$

where $\rho$ is the density of gas, $v$ the velocity, $\eta$ the dynamic viscosity, and $D$ the diameter of the tube. For Reynold's numbers larger than 2100, the inertial effects are larger and the flow is entirely turbulent, while for $\operatorname{Re}<1100$, the viscous effect is larger and the flow is entirely laminar. The exact value of Re for which the flow changes from turbulent to laminar depends upon the roughness of the surface of the tube and other experimental factors.

The expression of the Reynold's number can be related to the throughput $Q$ which is defined as the quantity of gas flowing through a pipe, expressed in PV (pressure $\times$ volume) units per unit time. Thus

$$
Q=P v \frac{\pi D^{2}}{4} \quad \text { or } \quad v=\frac{4}{P \pi D^{2}} Q
$$

The ideal gas law is an appropriate equation of state relating the temperature, pressure and density at typical vapor deposition conditions. Thus, the gas density is equal to

$$
\rho=n m
$$

where $n$, the number of molecules per unit volume, equals to

$$
n=\frac{N_{A}}{R} \frac{P}{T}
$$

and $m$, the mass of a molecule, is

$$
m=\frac{M}{N_{A}}
$$

where $\mathrm{N}_{\mathrm{A}}$ is the Avogadro's number, $\mathrm{M}$ the molecular weight and $\mathrm{R}$ the universal constant $(\mathrm{R}=62.364$ Torr.liter/K.mole). From Eqs. 16 to 18 , it results that 


$$
\rho=\frac{M P}{R T}
$$

and the expression for the Reynold's number, Eq. 14, can be written as

$$
\mathrm{Re}=\frac{M P}{R T} \frac{4 Q}{P \pi D^{2}} \frac{D}{\eta}=\frac{4 M}{\pi R T \eta}\left(\frac{Q}{D}\right)
$$

If $Q$ is expressed in sccm, $\mathrm{T}$ in $\mathrm{K}, \eta$ in $\mu \mathrm{Pa} . \mathrm{sec}, D$ in meters, according to Eq. 20

$$
\mathrm{Re}=0.2588 \frac{M}{T \eta}\left(\frac{Q}{D}\right)
$$

For the operating conditions used in the experiments, the Reynold's number was estimated to be less than 25 confirming the laminar viscous characteristics of the gas flow in the system.

As a result of the characteristic number calculations, the following assumptions were made (which do not essentially limit the accuracy or the applicability of the model):

(a) The gas mixture is treated as a continuum;

(b) The gases are treated as ideal; and they obey the ideal-gas law and the Newton's law of viscosity;

(c) The gas flow is laminar;

(d) The gas mixture in the reactor is transparent for heat radiation; and

\section{A.2. Basic Equations}

Models of crystal growth from the vapor consist of nonlinear, coupled partial differential equations that represent the conservation of momentum, energy, total mass and individual species. The general derivation and form of these equations is given in 
references [71-73]. Numerous modifications of these equations have been used in models ranging from simple boundary-layer-type descriptions to complete three-dimensional models. The general equations are applicable to most crystal growth systems operating in the continuum regime. Since the reactor geometry is axisymmetric, the governing equations of the problem were written in cylindrical coordinates and in two dimensions ( $r$ in the radial direction and $x$ in the axial direction). The governing equations of mass, momentum, energy and species concentrations and the ideal gas law are described as follows:

Total Mass:

$$
\frac{\partial}{\partial x}(\rho u)+\frac{1}{r} \frac{\partial}{\partial r}(r \rho v)=0
$$

Momentum:

$$
\begin{array}{r}
\frac{\partial}{\partial x}(\rho u u)+\frac{1}{r} \frac{\partial}{\partial r}(r \rho u v)=\frac{\partial}{\partial x}\left(\mu \frac{\partial u}{\partial x}\right)+\frac{1}{r} \frac{\partial}{\partial r}\left(r \mu \frac{\partial u}{\partial r}\right) \\
-\frac{\partial P}{\partial x}+\frac{\partial}{\partial x}\left(\mu \frac{\partial u}{\partial x}\right)+\frac{1}{r} \frac{\partial}{\partial r}\left(r \mu \frac{\partial v}{\partial x}\right) \\
-\frac{2}{3} \mu \nabla \cdot \vec{V}+F_{\times} \\
\frac{\partial}{\partial x}(\rho u v)+\frac{1}{r} \frac{\partial}{\partial r}(r \rho v v)=\frac{\partial}{\partial x}\left(\mu \frac{\partial v}{\partial x}\right)+\frac{1}{r} \frac{\partial}{\partial r}\left(r \mu \frac{\partial v}{\partial r}\right) \\
-\frac{\partial P}{\partial r}+\frac{\partial}{\partial x}\left(\mu \frac{\partial u}{\partial x}\right)+\frac{1}{r} \frac{\partial}{\partial r}\left(r \mu \frac{\partial v}{\partial r}\right) \\
-\frac{2}{3} \mu \nabla \cdot \vec{V}-\mu \frac{2 v}{r^{2}}+F_{r}
\end{array}
$$


Energy:

$$
\frac{\partial}{\partial x}(\rho u h)+\frac{1}{r} \frac{\partial}{\partial r}(r \rho v h)=\frac{\partial}{\partial x}\left(\frac{k}{C_{p}} \frac{\partial h}{\partial x}\right)+\frac{1}{r} \frac{\partial}{\partial r}\left(r \frac{k}{C_{p}} \frac{\partial h}{\partial r}\right)
$$

Species:

$$
\frac{\partial}{\partial x}\left(\rho u Y_{i}\right)+\frac{1}{r} \frac{\partial}{\partial r}\left(r \rho v Y_{i}\right)=\frac{\partial}{\partial x}\left(D_{i} \frac{\partial Y_{i}}{\partial x}\right)+\frac{1}{r} \frac{\partial}{\partial r}\left(r D_{i} \frac{\partial Y_{i}}{\partial r}\right)
$$

Ideal gas law:

$$
P=\rho R T \sum_{i} \frac{Y_{i}}{W_{i}}
$$

The integro-differential radiative heat transfer equation:

$$
\begin{aligned}
(\Omega \cdot \nabla) I(r, \Omega)= & -(\kappa+\sigma) I(r, \Omega)+\kappa I_{b}(r) \\
& +\frac{\sigma}{4 \pi} \int_{\Omega^{\prime}=4 \pi} I(r, \Omega) \Phi\left(\Omega^{\prime} \rightarrow \Omega\right) d \Omega
\end{aligned}
$$

where $u$ is the axial velocity, $v$ the radial velocity, $\rho$ the density, $\mu$ the dynamic viscosity, $\mathrm{F}_{\mathrm{x}}$ and $\mathrm{F}_{\mathrm{r}}$ the gravitational acceleration vectors in the $x$ and $r$ co-ordinates, respectively, $P$ the pressure, $h$ the enthalpy $\left(h=C_{p} T\right), k$ the thermal conductivity, $C_{p}$ the specific heat, $D_{i}$ the binary diffusion coefficient of reactants in carrier gases, $Y_{i}$ the mass fraction and $W_{i}$ the molecular weight of the $i^{\text {th }}$ specie. In the radiative heat transfer equation, $\Omega$ is the direction of propagation of the radiation beam, $I$ the radiation intensity, $\kappa$ the absorption coefficient, $\sigma$ the scattering coefficient, $I_{b}$ the intensity of the black body, $\Phi$ the phase function of the energy transfer from the incoming $\Omega^{\prime}$ direction to the outgoing direction $\Omega$. 
The solution of the conservation equations for total mass (Eq. 22) and momentum (Eqs. 23a and 23b) gives the pressure and velocity distribution throughout the reactor enclosure. The temperature distribution is given by the solution to the energy balance (Eq. 24).

\section{A.3. Boundary Conditions}

Boundary conditions must be specified for the above equations, in order to simulate the reactor configuration. The following boundary conditions have been specified.

Walls of the reactor tube surrounded by the graphite heaters:

$$
\begin{aligned}
& \vec{V}=0 \\
& h=h_{\text {graphite }} \\
& \frac{\partial Y_{i}}{\partial r}=0,(i=1-3)
\end{aligned}
$$

Reactor inlets:

$$
\begin{aligned}
& \vec{V}=\vec{V}_{i n} \\
& h=h_{\text {in }} \\
& P=P_{r e f} \\
& Y=Y_{\text {in }},(i=1-3)
\end{aligned}
$$


Mass diffusion is cut at gas inlets by setting diffusion coefficient as $D=0$.

Reactor outlet:

$$
\begin{aligned}
& \frac{\partial u}{\partial x}=0 \\
& \vec{V}=0 \\
& \frac{\partial h}{\partial x}=0 \\
& \frac{\partial^{2} Y_{i}}{\partial x^{2}}=0,(i=1-3)
\end{aligned}
$$

Symmetry axis:

$$
\begin{aligned}
& \frac{\partial u}{\partial x}=0 \\
& \vec{V}=0 \\
& \frac{\partial h}{\partial r}=0 \\
& \frac{\partial Y_{i}}{\partial r}=0,(i=1-3)
\end{aligned}
$$

Other solid walls:

$$
\begin{aligned}
& \vec{V}=0 \\
& \frac{\partial h}{\partial r}=0 \\
& \frac{\partial Y_{i}}{\partial r}=0,(i=1-3)
\end{aligned}
$$

\section{A.4. Discretization and solution of the governing equations}

The Finite Volume Method was used to divide the solution domain into a number of cells known as control volumes. The first order up-wind differencing scheme (70\%) blending with the 3 rd-order differencing scheme (30\%) is used to discrete variables in the 
transport equations. For each of the solved variables and for the auxiliary variables, the under-relaxation method is used to maintain the stability of the coupled, nonlinear system of equations.

The grid number $\left(\mathrm{N}_{x} \times \mathrm{N}_{r}\right)$ of the calculated domain is $191 \times 63$. The power law is used to dense the grid near the gas inlets and substrate surface. The calculation of the problem typically requires 3000 iterations (approximately 30 minutes CPU time using a Dell P41.7GHz computer). A finer grid size has been used and grid independent results have been obtained.

\section{A.5. Results and Discussion}

Fig. 24 (a) and (b) show the calculation domain and the grid system of the GaN growth reactor employed in this study.

Figure 25 shows the temperature distribution inside the reactor.

Figures 26 (a) and (b) show the velocity distribution and the velocity streamline distribution inside the reactor. 


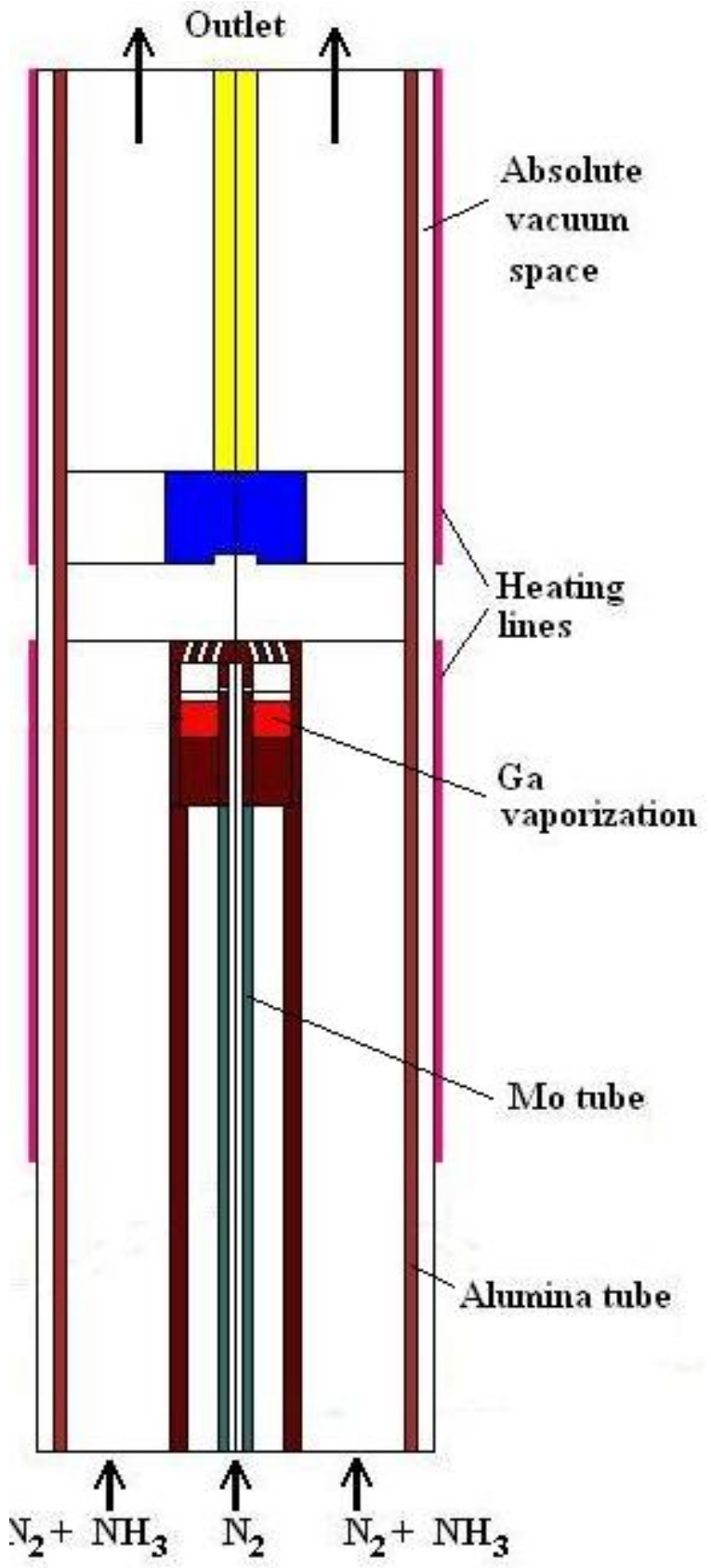

(a)

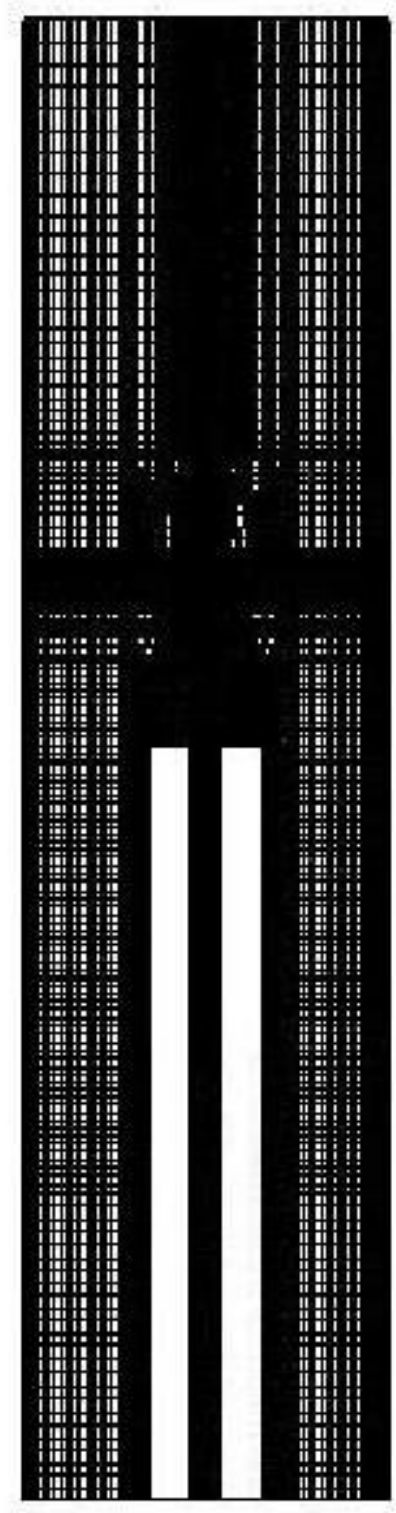

(b)

Figure 24. (a) Calculation geometry and (b) the grid system of the GaN growth reactor tube 


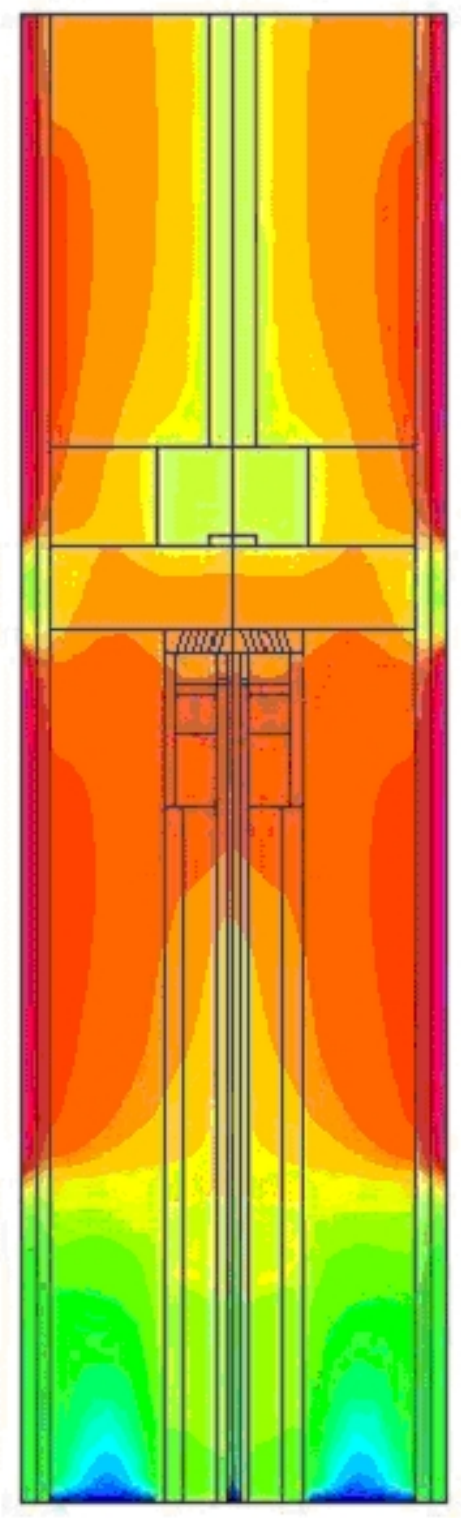

$$
\begin{aligned}
& T-\text { degK } \\
& 1900-- \\
& 1800- \\
& 1700- \\
& 1600- \\
& 1500- \\
& 1400- \\
& 1300- \\
& 1200- \\
& 1100- \\
& 900- \\
& 800- \\
& 700- \\
& 600- \\
& 500- \\
& 400- \\
& 300- \\
& 300
\end{aligned}
$$

Figure 25. Temperature distribution in the reactor tube 


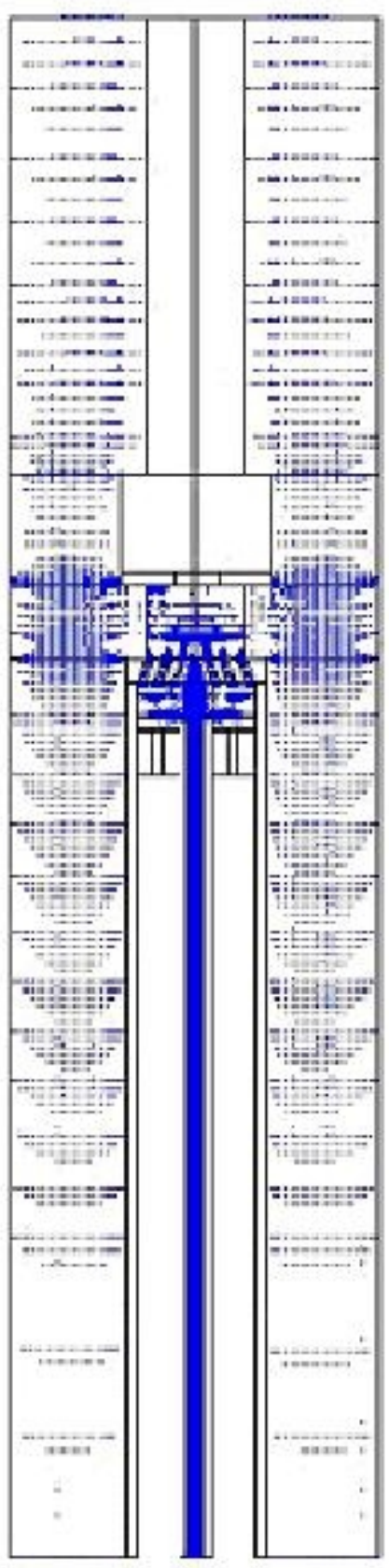

(a)

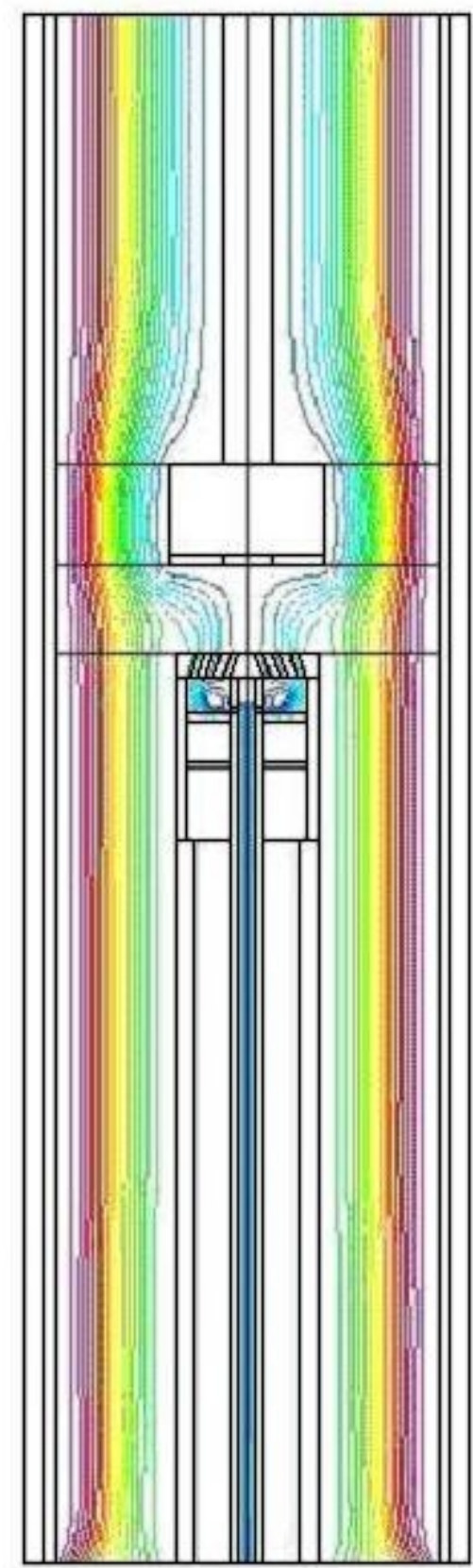

(b)

Figure 26. (a) Velocity distribution and (b) Streamline distribution in the reactor tube 
It can be seen in Fig. 25 that the achieved mixing gas temperature right below the substrate is about $1050^{\circ} \mathrm{C}(1323 \mathrm{~K})$. The temperature on the Ga source surface is $1250^{\circ} \mathrm{C}$ $(1523 \mathrm{~K})$. It is observed that the temperature of the $\mathrm{N}_{2}$ and $\mathrm{NH}_{3}$ gases increases up to about $1350^{\circ} \mathrm{C}(1623 \mathrm{~K})$ before they reach the growth cell and mix with Ga vapor.

In the system there are three inlets and one outlet as shown in Fig. 23.

Inlet 1: $\mathrm{N}_{2}+\mathrm{NH}_{3}$

Inlet 2: $\mathrm{N}_{2}$

Inlet 3: Ga Vapor

For the streamline calculations, the reactor pressure was 800 Torr. The source-tosubstrate distance was $24 \mathrm{~mm}$. The Ga mass loss rate was $28 \mathrm{mg} / \mathrm{h}$. The flow rates of $\mathrm{NH}_{3}$ and $\mathrm{N}_{2}$ at inlet 1 and $\mathrm{N}_{2}$ at inlet 2 are listed in the Table 5. No reactions were considered. Fig. 26(b) shows that there was no reverse flow observed between the source and the substrate.

Table 5. Flow rates of $\mathbf{N H}_{3}$ and $\mathbf{N}_{2}$ at inlet 1 and $\mathbf{N}_{2}$ at inlet 2

\begin{tabular}{|c|c|c|c|}
\hline \multirow{2}{*}{ Case No. } & \multicolumn{2}{|c|}{ Inlet 1 (slm) } & \multirow{2}{*}{$\begin{array}{c}\mathrm{N}_{2} \text { flow rate at inlet } 2 \\
(\mathrm{slm})\end{array}$} \\
\cline { 2 - 3 } & $\mathrm{NH}_{3}$ & $\mathrm{~N}_{2}$ & \\
\hline 1 & 3 & 1 & 1 \\
\hline
\end{tabular}




\section{APPENDIX B: REACTION ENERGIES (After Ohring [75])}

Thermodynamics provides an upper limit of expected values under specified conditions; it implies that chemical equilibrium has been attained. Although this may occur in a closed system, it is generally not the case in an open or flow reactor where gaseous reactants and products are continuously introduced and removed. In general this type of systems may be treated empirically with the use of thermodynamic guidelines.

Thermodynamic analysis of potential vapor phase epitaxial processes provides an important estimate of the extent of departure from equilibrium or the supersaturation of the gas stream in the growth region under various conditions. Typically, deposition processes for coatings or similar applications operate with large departures from equilibrium in the deposition region in order to produce uniform coatings at maximum deposition rates. Epitaxial growth, on the other hand, must take place under relatively low gas phase supersaturations so that the reactant partial pressures do not deviate excessively from the equilibrium values. If the arrival rate of reactant species greatly exceeds the nucleation and lattice incorporation rates at the crystal surface, poor crystal perfection will result. High fluxes of reactants to the surface increase the probability of misoriented two-dimensional nucleation and, in severe cases, result in polycrystalline layers. In addition, excessive supersaturation may lead to three-dimensional nucleation in the gas phase with the resultant nuclei falling onto the substrate surface to produce misoriented regions within the layers.

Provided that the free-energy change, $\Delta \mathrm{G}$, can be approximated by the standard freeenergy change, $\Delta \mathrm{G}^{\circ}$, many simple consequences of thermodynamics with respect to 
vapor phase deposition can be understood. For the epitaxial growth, it is essential that a single nucleus forms as an oriented seed for subsequent growth. According to elementary nucleation theory, a small negative value of $\Delta \mathrm{G}$, the chemical free energy per unit volume, is required to foster a low nucleation rate of large critical-sized nuclei. This is in turn would require a $\Delta \mathrm{G}$ value close to zero. When this happens, large amounts of reactants and products are simultaneously present. If $\Delta \mathrm{G}$ were large and negative, however, the likelihood of a high rate of heterogeneous nucleation, or even homogeneous nucleation of solid particles within the gas phase, would be enhanced, as mentioned before. The large driving force for chemical reaction tends to promote polycrystal formation in this case.

The following is a comparison of free energy of the overall reaction involved in the GaN growth from $\mathrm{Ga}$ and $\mathrm{NH}_{3}$ with that of other vapor phase epitaxy processes. Data used in the calculations were taken from Ref. [117].

Formation of $\mathrm{GaN}$ from $\mathrm{Ga}$ and $\mathrm{NH}_{3}$ :

$$
\mathrm{Ga}(\mathrm{g})+\mathrm{NH}_{3} \Leftrightarrow \mathrm{GaN}+\frac{3}{2} \mathrm{H}_{2} \quad \Delta G_{1300 \mathrm{~K}}^{\circ}=-51.81 \mathrm{kcal} / \mathrm{mol}
$$

Iodine-transport vapor phase epitaxy:

$$
\begin{aligned}
& \mathrm{GaI}(g)+\mathrm{NH}_{3}(g) \Leftrightarrow \mathrm{GaN}+\mathrm{HI}(\mathrm{g})+\mathrm{H}_{2}(\mathrm{~g}) \quad \Delta G_{1300 \mathrm{~K}}^{\circ}=-3.19 \mathrm{kcal} / \mathrm{mol} \\
& \mathrm{GaI}_{3}(g)+\mathrm{NH}_{3}(g) \Leftrightarrow \mathrm{GaN}+3 \mathrm{HI} \quad \Delta G_{1300 \mathrm{~K}}^{\circ}=-19.36 \mathrm{kcal} / \mathrm{mol}
\end{aligned}
$$

Chlorine-transport vapor phase epitaxy:

$$
\operatorname{GaCl}(g)+\mathrm{NH}_{3}(g) \Leftrightarrow \mathrm{GaN}+\mathrm{HCl}(g)+H_{2}(g) \quad \Delta G_{1300 \mathrm{~K}}^{\circ}=1.49 \mathrm{kcal} / \mathrm{mol}
$$




$$
\begin{gathered}
3 \mathrm{GaCl}(g)+2 \mathrm{NH}_{3}(g) \Leftrightarrow 2 \mathrm{GaN}+\mathrm{GaCl}_{3}(g)+3 \mathrm{H}_{2}(\mathrm{~g}) \\
\Delta G_{1300 \mathrm{~K}}^{\circ}=96.45 \mathrm{kcal} / \mathrm{mol} \\
\mathrm{GaCl}_{3}(g)+\mathrm{NH}_{3}(g) \Leftrightarrow \mathrm{GaN}+3 \mathrm{HCl}(\mathrm{g}) \quad \Delta G_{1300 \mathrm{~K}}^{\circ}=-2.79 \mathrm{kcal} / \mathrm{mol}
\end{gathered}
$$

There are several different results for the chlorine-transport reaction in the literature and the accuracy of the results was discussed in detail by Newman [120].

\section{Molecular Beam Epitaxy:}

When $\mathrm{NH}_{3}$ gas is used as the nitrogen source in MBE synthesis of GaN, the additional energy of $\mathrm{Ga}(\mathrm{g})$ is found to be important in driving the forward reaction $[121$, 122]. In this case, $\mathrm{GaN}$ is able to form in the unstable region of the $\mathrm{GaN}(\mathrm{s})$ and $\mathrm{Ga}(\mathrm{l}) / \mathrm{NH}_{3}(\mathrm{~g})$ phase diagram. Fig. 27 illustrates the typical thin film growth conditions [120].

In the growth of $\mathrm{GaN}$, the $\mathrm{GaN}$ decomposition reaction into $\mathrm{Ga}(\mathrm{l})$ and $1 / 2 \mathrm{~N}_{2}(\mathrm{~g})$ may also play a role in limiting the growth parameters. Another competing reaction involves the decomposition of $\mathrm{NH}_{3}$. This turns out to be an important factor and is discussed in Appendix C. 


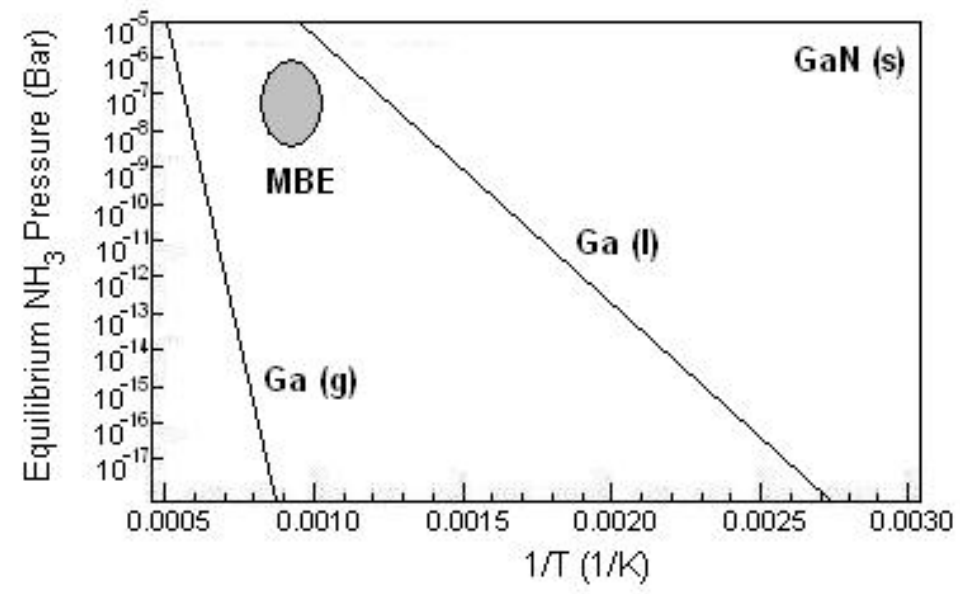

Figure 27. Change in Gibbs free energy and equilibrium pressure for the following reactions (1) Ga(l) $+1 / 2 \mathbf{N}_{2}(\mathrm{~g})=\mathrm{GaN}(\mathrm{s}),(2) \mathrm{Ga}(\mathrm{g})+1 / 2 \mathbf{N}_{2}(\mathrm{~g})=\mathrm{GaN}(\mathrm{s})$ 


\section{APPENDIX C: AMMONIA DECOMPOSITION (After Grunze [79])}

Despite the apparent simplicity of the $\mathrm{GaN}$ synthesis from elemental $\mathrm{Ga}$ and $\mathrm{NH}_{3}$, the chemistry of the process is nontrivial due to one critical factor; ammonia is thermodynamically unstable at elevated temperature used in the growth. The ammonia decomposition reaction results in the production of $\mathrm{N}_{2}(\mathrm{~g})$; a chemical specie which does not react with $\mathrm{Ga}(\mathrm{g})$ in the reactor environment. For this reason, the extent of ammonia decomposition in the reactor must be studied carefully to facilitate $\mathrm{GaN}$ synthesis.

Decomposition of ammonia is a mildly endothermic process, yielding hydrogen and nitrogen and it is accompanied by an increase in volume [79]:

$$
\mathrm{NH}_{3}(g) \leftrightarrow \frac{1}{2} N_{2}(g)+\frac{3}{2} H_{2}(g) \quad \Delta H_{273}^{\circ}=46 \mathrm{~kJ} / \mathrm{mol}
$$

The reaction is a reversible reaction, that is, it can proceed both in forward and backward directions. Fig. 28 illustrates the change in $\Delta \mathrm{G}^{\circ}$ and $\Delta \mathrm{H}^{\circ}$ with temperature [117]. The figure shows that ammonia is thermodynamically unstable and all the $\mathrm{NH}_{3}$ is decomposed into $\mathrm{N}_{2}$ and $\mathrm{H}_{2}$ at temperatures higher than $300^{\circ} \mathrm{C}$. However, it is well known that the decomposition rate is slow without a catalyst and the extent of decomposition strongly depends on the growth conditions and the equipment.

The rate of disassociation reaction is sluggish due to the kinetic barrier of breaking the N - H bond. Experimentally, Ban [123], Rocasecca et al. [124], Liu and Stevenson [125] also found that the decomposition rate increases with temperature, although with varying efficiency, depending on the catalyst. Tungsten, platinum and iron are commonly used for catalyzing the decomposition of ammonia [79]. The combination of $\mathrm{Ga}(1)$ or 
$\mathrm{GaN}(\mathrm{s})$ is found to be surprisingly effective as a catalyst, although $\mathrm{Ga}(\mathrm{l})$ or $\mathrm{GaN}(\mathrm{s})$ alone were not found to increase the decomposition rate [120].

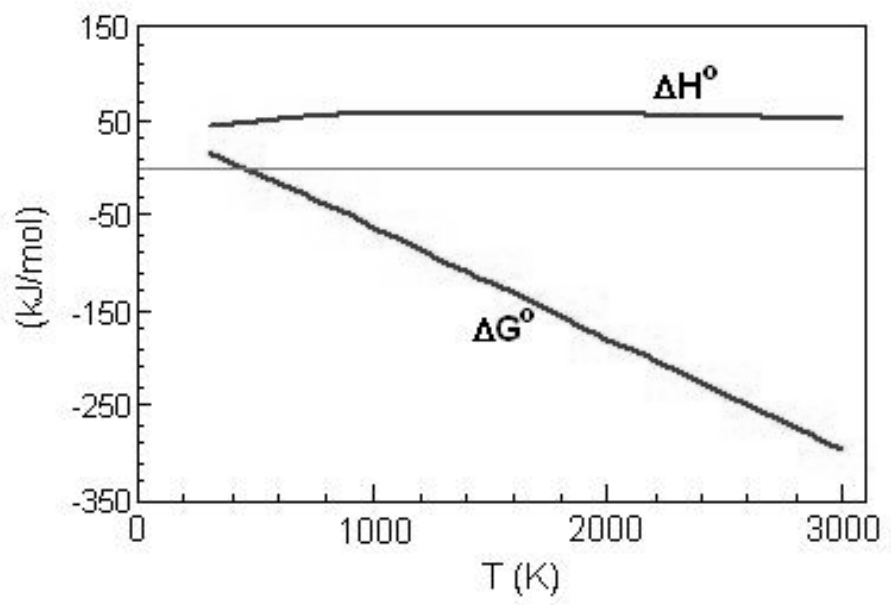

Figure 28. Gibbs free energy and enthalpy change versus temperature for ammonia decomposition reaction.

In the $\mathrm{GaN}$ growth chamber, alumina tube walls and Mo-parts act as catalysts for the $\mathrm{NH}_{3}$ decomposition. These parts interact with $\mathrm{NH}_{3}$ in a cyclic manner promoting perhaps many reactions at the molecular level. They change the activation energy, $E_{a}$, of decomposition by providing an alternate pathway for the reaction. The rate constant $k$ of a reaction is related to $E_{a}$ in the following way

$$
k=A e^{\left(-E_{a} / R T\right)}
$$

where $A$ is a constant related to collision rates and the rate is equal to $k \times$ function of concentration . Thus, a change in $E_{a}$ changes the rate of a reaction. In this case, alumina tube walls and Mo-parts are said to be heterogeneous, or contact, catalysts because they are in a separate phase from the gas. 
The interaction of ammonia with different material surfaces has been thoroughly investigated [126-135]. These studies have been undertaken primarily to acquire insights into the industrially important ammonia synthesis process. Figure 29 shows the energy profiles for ammonia synthesis in absence and presence of the iron catalyst [136]. The arrows in the diagram show the activation energies of each of the steps. The exact values vary depending on the catalyst.

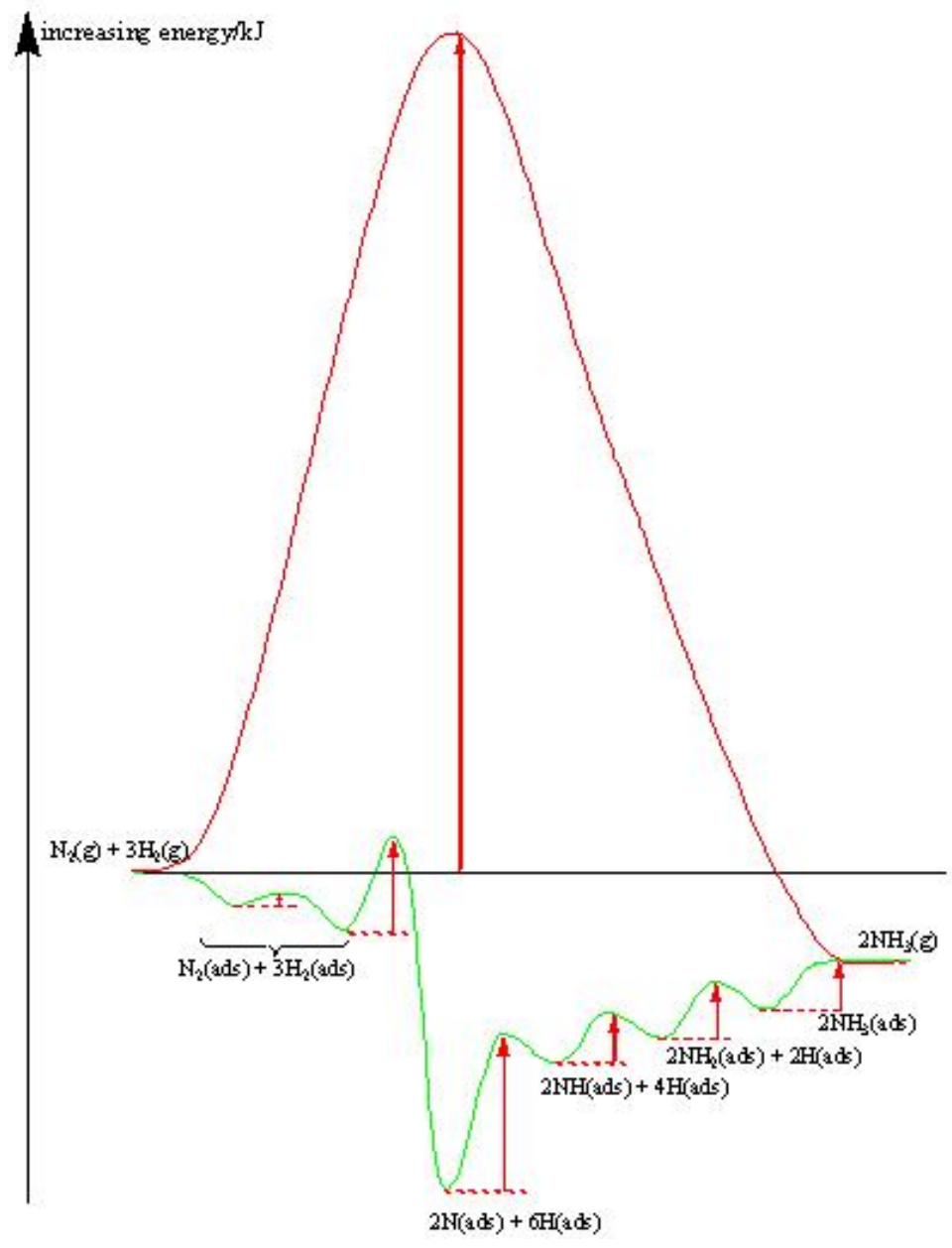

Figure 29. Energy changes in ammonia decomposition reaction 
The reaction of $\mathrm{NH}_{3}$ decomposition on a catalytic surface can be expressed by the following sequence of molecular steps [79].

$$
\begin{aligned}
& N_{3}(g) \underset{k_{-1}}{\stackrel{k_{1}}{\Leftrightarrow}} N H_{3}(a d) \underset{k_{-2}}{\stackrel{k_{2}}{\Leftrightarrow}} N H_{2}(a d)+H(a d) \underset{k_{-3}}{\stackrel{k_{3}}{\Leftrightarrow}} N H(a d)+2 H(a d) \underset{k_{-4}}{\stackrel{k_{4}}{\Leftrightarrow}} N_{2}(a d)+3 H(a d) \\
& 2 H(a d) \stackrel{k_{5}}{\rightarrow} H_{2}(g) \\
& 2 N(a d) \stackrel{k_{6}}{\rightarrow} N_{2}(g)
\end{aligned}
$$

The rates $k_{2}$ and $k_{3}$ are different on the individual surfaces. The effect of several metallic catalysts on the activation energy for the decomposition of ammonia can be seen in the Table 6.

\section{Table 6. Activation energy of ammonia decomposition reaction on different surfaces}

\begin{tabular}{ll}
\hline Catalyst & $\boldsymbol{E}_{\boldsymbol{a}}(\mathbf{k J} / \mathbf{m o l})$ \\
\hline None $^{[137]}$ & 335 \\
Tungsten $^{[137]}$ & 163 \\
Alumina $\left(\mathrm{Al}_{2} \mathrm{O}_{3}\right)^{[138]}$ & 127 \\
Molybdenum $^{[139]}$ & 116 \\
\hline Data are from different references where the conditions are slightly different
\end{tabular}

Ertl and Huber [119] studied the steady state decomposition reaction at $P_{\mathrm{NH}_{3}}=5 \times 10^{-6}$ Torr on an iron $(\mathrm{Fe})$ wire under flow conditions with a high pumping speed to keep the partial pressure of $\mathrm{N}_{2}$ and $\mathrm{H}_{2}$ so small that the reverse reaction could be neglected. The activation energy, $E_{a}$ was determined from the Arrhenius plot for the rate of stationary $\mathrm{N}_{2}$ production. Up to temperatures of $640 \mathrm{~K}, E_{a}$ was determined as 188 $\mathrm{kJ} /$ mole for elevated temperatures, it was found that $E_{a}$ decreases continuously and the rate becomes nearly temperature independent $\left(E_{a}=0\right)$ at around $850 \mathrm{~K}$. The reaction order 
with respect to $P_{\mathrm{NH}_{3}}$ at low temperatures is $n=0$ and increases with temperature to $n=1$.

If the temperature is high enough and/or the $\mathrm{NH}_{3}$ pressure small, the delivery of $\mathrm{NH}_{3}$ from the gas phase will be limiting. With the reaction sequence (38), the rate of decomposition is described by [79]

$$
\text { rate }=\frac{k_{1} k_{2} P_{\mathrm{NH}_{3}}}{\left(k_{-1}+k_{2}\right)}
$$

Since $k_{2}>>k_{1}[83]$ the rate is given by

$$
\text { rate }=k_{1} P_{\mathrm{NH}_{3}}
$$

The experimental results [119] support these conclusions. At higher temperatures, the activation energy decreases to $E_{a}=0$ and the order is $n=1$ with respect to $P_{\mathrm{NH}_{3}}$.

The rate of ammonia decomposition at elevated temperatures and under conditions far from thermodynamic equilibrium (where the ammonia formation can be neglected) can be simply described by

$$
\text { rate }=-\frac{d\left[\mathrm{NH}_{3}\right]}{d t}=k P_{\mathrm{NH}_{3}}
$$

If the reactions in both forward and backward directions are considered, rate expressions become

$$
\begin{aligned}
& \frac{d\left[\mathrm{NH}_{3}\right]}{d t}=-k_{\mathrm{F}} P_{\mathrm{NH}_{3}}+k_{B} P_{\mathrm{H}_{2}}^{3 / 2} P_{N_{2}}^{1 / 2} \\
& \frac{d\left[\mathrm{H}_{2}\right]}{d t}=-k_{B} P_{\mathrm{H}_{2}}^{3 / 2} P_{N_{2}}^{1 / 2}+k_{F} P_{N_{3}} \\
& \frac{d\left[N_{2}\right]}{d t}=\frac{d\left[\mathrm{H}_{2}\right]}{d t}
\end{aligned}
$$


where $k_{F}$ is the rate constant of forward reaction in ammonia decomposition reaction (36), and $k_{B}$ is the rate constant of the backward reaction. At an equilibrium condition we would expect the rate to be equal to

$$
\begin{gathered}
\frac{d\left[\mathrm{NH}_{3}\right]}{d t}=0=-k_{\mathrm{F}} P_{\mathrm{NH}_{3}}+k_{\mathrm{B}} P_{\mathrm{H}_{2}}^{3 / 2} P_{N_{2}}^{1 / 2} \\
\text { or } \frac{k_{F}}{k_{B}}=\frac{P_{\mathrm{H}_{2}}^{3 / 2} P_{N_{2}}^{1 / 2}}{P_{\mathrm{NH}_{3}}}
\end{gathered}
$$

This is the equilibrium constant $K_{e q}$ of the reaction (36), and this sets the limit to the decomposition process.

$$
K_{e q}=\frac{P_{H_{2}}^{3 / 2} P_{N_{2}}^{1 / 2}}{P_{N_{3}}}
$$

From the tabulated data [117], the equilibrium $\mathrm{NH}_{3}$ concentrations can be calculated. Assuming the input gas is only ammonia, at $1500 \mathrm{~K}$ and a $\mathrm{N}_{2}: \mathrm{H}_{2}$ ratio of 1:3, a pressure of 200 Torr would yield an equilibrium $\mathrm{NH}_{3}$ pressure of $2.4 \times 10^{-3}$ Torr.

Using the simple rate description, Eq.(41), $\mathrm{NH}_{3}$ decomposition rate in the $\mathrm{GaN}$ growth reaction tube was estimated roughly, in order to have an idea on the extend of decomposition and to understand the simulation results better.

Below set of equations shows how the distance along the tube was included in the equations.

$$
\begin{aligned}
& \frac{d n_{\mathrm{NH}_{3}}}{d t}=-k\left(n_{\mathrm{NH}_{3}}\right)_{i} \\
& \frac{d n_{\mathrm{NH}_{3}}}{d x} \underbrace{\frac{d t}{d t}}_{\text {gas velocity }, v}=-k\left(n_{\mathrm{NH}_{3}}\right)_{i} \\
& \frac{d n_{\mathrm{NH}_{3}}}{\left(n_{\left.\mathrm{NH}_{3}\right)_{i}}\right.}=-1 / v k d x
\end{aligned}
$$




$$
\frac{n_{N_{3}}}{\left(n_{N_{3}}\right)_{i}}=e^{-k x / v}
$$

where $x$ is the distance along the tube, $n_{\mathrm{NH}_{3}}$ is the ammonia concentration. Eq. (49) was calculated and plotted as shown in Fig. 30. In calculations, a gas velocity of $5 \mathrm{~cm} / \mathrm{sec}$ and a temperature of $1250^{\circ} \mathrm{C}$ were used. Fig. 30 shows the extent of ammonia decomposition in the reactor where the majority of ammonia decomposes after traveling a few millimeters along the tube in the hot zone.

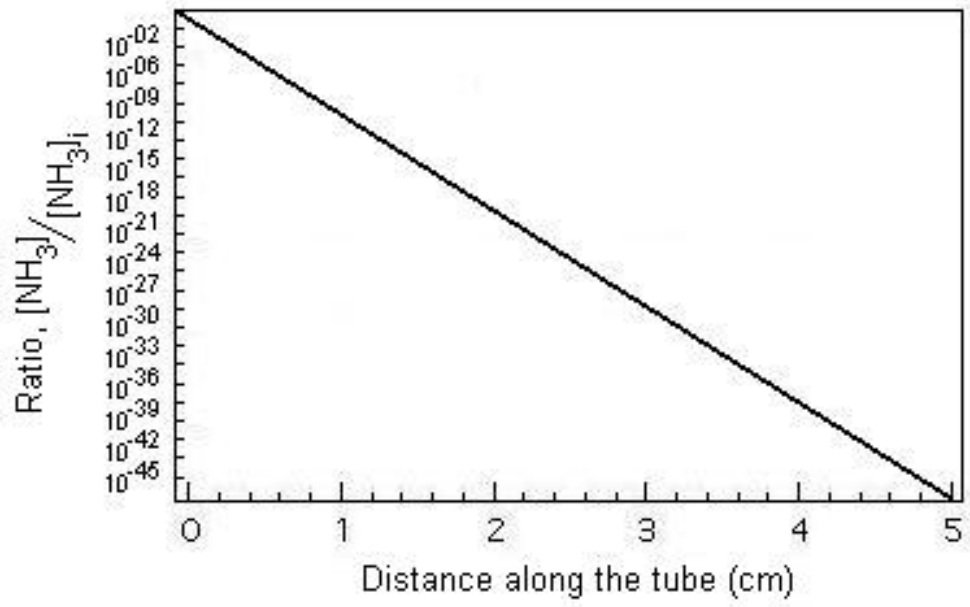

Figure 30. Ratio of ammonia concentration to the initial concentration versus distance. 


\section{APPENDIX D: ERROR CALCULATIONS}

Only few physical quantities can be measured directly, like length, time, temperature, mass, voltage etc. All other quantities can only be measured indirectly, so that one has to derive their value from other quantities whose value can be measured directly. As these quantities can only be measured with a limited precision, their combined errors (uncertainties) determine the error of the indirectly measured quantity. This error depends on the precision of the individual measurement and the mathematical relation between the directly measured quantities and the indirectly measured quantity.

For quantities which can not be determined, error can be calculated according to the theory of error propagation. Consider a quantity $y$ which depends on a number of quantities $x_{1}, x_{2}, \ldots x_{N}$ which are measured individually.

$$
y=y\left(x_{1}, x_{2}, \ldots x_{N}\right)
$$

Then the average error $\overline{\Delta y}$ of $y$ is given by

$$
\overline{\Delta y}=\sqrt{\left(\frac{\partial y}{\partial x_{1}}\right)^{2} \Delta x_{1}{ }^{2}+\left(\frac{\partial y}{\partial x_{2}}\right)^{2} \Delta x_{2}{ }^{2}+\cdots+\left(\frac{\partial y}{\partial x_{N}}\right)^{2} \Delta x_{N}{ }^{2}}
$$

where $\frac{\partial y}{\partial x_{i}}$ are partial derivatives of $y$ with respect to the variable $x_{i}$. Eq. (51) takes care of the fact that individual errors $\Delta x_{i}$ may cancel each other. A more conservative estimate is the absolute error $\Delta y$, which is given by

$$
\Delta y=\left|\frac{\partial y}{\partial x_{1}}\right| \Delta x_{1}+\left|\frac{\partial y}{\partial x_{2}}\right| \Delta x_{2}+\cdots+\left|\frac{\partial y}{\partial x_{N}}\right| \Delta x_{N}
$$


Error Calculation in Ga Vapor Pressure

$$
\begin{aligned}
& P_{G a}(T)=185.33 \exp \left(15.55-\frac{32199}{T}-0.31413 \ln (T)\right) \\
& \frac{\partial\left(P_{G a}(T)\right)}{\partial T}=\left(\frac{32199}{T^{2}}-\frac{0.3413}{T}\right) P_{G a}(T) \\
& \Delta P_{G a}(T)=\left|\frac{\partial\left(P_{G a}(T)\right)}{\partial T}\right| \Delta T
\end{aligned}
$$

Fig. 31 shows the plot of Eq. (55).

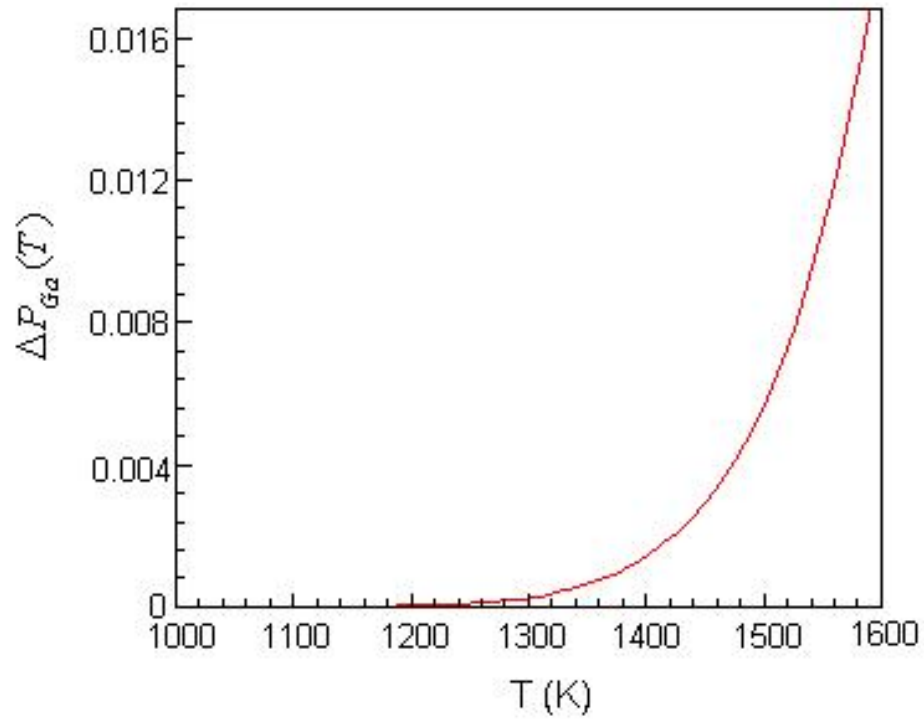

Figure 31. Plot of $\Delta P_{G a}(T)$ versus $\mathbf{T}$

Therefore, at $1250^{\circ} \mathrm{C}$ source temperature, error in Ga vapor pressure was found as

$$
\begin{aligned}
& T=1250 \pm 10^{\circ} \mathrm{C} \\
& P_{G a}=0.056(1 \pm 0.125) \text { Torr }
\end{aligned}
$$


Similar error calculations have been applied to the Langmuir mass evaporation rate of Ga, Eq. (5) in order to use in Ga mass transfer studies and found as

$$
\begin{aligned}
& T=1250 \pm 10^{\circ} \mathrm{C} \\
& \Gamma_{G a}=1.8(1 \pm 0.22) \mathrm{g} / \mathrm{h}
\end{aligned}
$$




\section{APPENDIX E: SAFETY}

\section{E.1. GaN Growth System Operation}

\section{E.1.1. Inserting the substrate into the growth chamber}

- Set the butterfly valve to close on the pressure controller panel. Keep the butterfly valve closed during loading.

- Insert the Ga source holder, which is screwed onto the pedestal connected to the stainless steel support that is guided via four rods at the bottom part of the system.

- Place the substrate to the substrate holder which is attached to the water cooling rod, secure the end cap with four screws.

- O-rings between the end caps and the alumina reactor tube should be checked before each run.

\section{E.1.2. Pumping-down the Chamber after loading the source and substrate}

- Evacuate the reactor tube by opening the butterfly valve

- Wait until the pressure in the reactor tube reaches below 20 mTorr

- Purge the reactor with $\mathrm{N}_{2}$ several times.

- Fill the reactor tube with $\mathrm{N}_{2}$ prior to ramp-up

\section{E.1.3. Ramping-up}

- Make sure the cooling water valve is on.

- If the water flow rate is too low, a warning light is lit on the safety control panel. 
- Turn on both top and bottom power supplies.

- Make all the settings in Labview (i.e., top heater temperature, bottom heater temperature, ramp-up rate, ramp-down rate, and growth time.)

- Execute the LabView program.

- When the temperature reaches the set value, switch the gas from nitrogen to ammonia of the set flow rate.

- Growth is commenced at this point.

\section{E.1.4. Removing the Sample}

- Upon completion of the growth run the growth system is programmed to be

cooled down to room temperature. It takes about 3 hours for the system to reach room temperature from the heater temperature of $1650^{\circ} \mathrm{C}$.

- Terminate the LabView program by clicking on the 'Stop' icon on the screen.

- Turn off both top and bottom power supplies.

- Turn off the ammonia flow by setting the MFC to close.

- Evacuate the reactor tube as described previously.

- Fill the reactor tube with nitrogen to 760 Torr.

- Unscrew the end caps.

- Remove the source holder and the sample

\section{E.1.5. Idling of the Growth System}

- Keep the power supplies off.

- Make sure all gas valves are closed. 
- If the system is not running for a few days, it is advised to shut off the cooling water to avoid condensation of moisture on the chamber especially during summer.

- Keep the mechanical pumps running and make sure all valves between the pumps and the chambers are closed when not in use.

\section{E.2. Safety Features}

- If the temperature of either top or bottom heater exceeds the set value $\left(\sim 1800^{\circ} \mathrm{C}\right)$, the output of the power supplies is cut off. The set value can be adjusted on the Omega temperature controller located on the front panel. If the temperature increases above $1800^{\circ} \mathrm{C}$, the O-rings between the reactor tube and the outer chamber would degrade.

- If the pressure in the outer chamber exceeds 40 mTorr, a warning light is lit and the power output goes to zero.

- If the flow rate of the cooling water is too low, the warning light is on and the power supply returns to the manual mode.

- All of the above safety features were implemented to protect the graphite heaters. However, monthly check-up of these features is strongly advised in case of malfunction. 